NBER WORKING PAPER SERIES

\title{
THE ROLE OF TIME PREFERENCES AND EXPONENTIAL-GROWTH BIAS IN RETIREMENT SAVINGS
}

\author{
Gopi Shah Goda \\ Matthew R. Levy \\ Colleen Flaherty Manchester \\ Aaron Sojourner \\ Joshua Tasoff \\ Working Paper 21482 \\ http://www.nber.org/papers/w21482
}

\author{
NATIONAL BUREAU OF ECONOMIC RESEARCH \\ 1050 Massachusetts Avenue \\ Cambridge, MA 02138 \\ August 2015
}

We are grateful to Tania Gutsche and Bart Orriens as well as the staff at the American Life Panel for their assistance with fielding this study. The authors gratefully acknowledge financial support provided by the TIAA-CREF Institute and the Pension Research Council/Boettner Center of the Wharton School at the University of Pennsylvania. This research was also supported by the U.S. Social Security Administration through grant number RRC08098400-07 to the National Bureau of Economic Research as part of the SSA Retirement Research Consortium. Additional support was provided by the National Institute on Aging of the National Institutes of Health under grant number R01AG020717 and the Social Security Administration for the UAS data collection. Kirill Demtchouk, Dominika Jaworski, Garrett Thoelen, and Wenjie Zhang provided exceptional research assistance. The authors also thank John Beshears, Jeff Brown, Leandro Carvalho, David Laibson, Annamaria Lusardi, Olivia Mitchell, Changcheng Song, Wesley Yin and seminar participants at USC, RAND, and North Carolina State University for helpful comments. The findings and conclusions expressed are solely those of the authors and do not represent the views of NIH, SSA, any agency of the Federal Government, the NBER, or any other institution with which the authors are affiliated.

NBER working papers are circulated for discussion and comment purposes. They have not been peerreviewed or been subject to the review by the NBER Board of Directors that accompanies official NBER publications.

(C) 2015 by Gopi Shah Goda, Matthew R. Levy, Colleen Flaherty Manchester, Aaron Sojourner, and Joshua Tasoff. All rights reserved. Short sections of text, not to exceed two paragraphs, may be quoted without explicit permission provided that full credit, including (C) notice, is given to the source. 
The Role of Time Preferences and Exponential-Growth Bias in Retirement Savings

Gopi Shah Goda, Matthew R. Levy, Colleen Flaherty Manchester, Aaron Sojourner, and Joshua Tasoff

NBER Working Paper No. 21482

August 2015

JEL No. H0

\section{ABSTRACT}

There is considerable variation in retirement savings within income, age, and educational categories. Using a broad sample of the U.S. population, we elicit time preference parameters from a quasi-hyperbolic discounting model, and perceptions of exponential growth. We find that present bias (PB), the tendency to value utility in the present over the future in a dynamically inconsistent way, and exponential-growth bias (EGB), the tendency to neglect compounding, are prevalent and distinct latent variables. PB, EGB, and the long-run discount factor are all highly significant in predicting retirement savings, even while controlling for measures of IQ and general financial literacy as well as a rich set of demographic controls. We find that lack of self-awareness of these biases has an additional independent negative impact on retirement savings. We assess potential threats to a causal interpretation of our results with a hypothetical choice experiment and several robustness exercises. Finally, we explore potential mechanisms for our findings. If the relationship we estimate is causal, our estimates suggest that eliminating PB and EGB would be associated with an increase in retirement savings of $12 \%$, or as high as $70 \%$ using estimates that account for classical measurement error.

Gopi Shah Goda

Stanford University

SIEPR

366 Galvez St.

Stanford, CA 94305

and NBER

gopi@stanford.edu

Matthew R. Levy

Department of Economics

London School of Economics

and Political Science

Houghton Street

London WC2A 2AE

m.r.levy@1se.ac.uk

Colleen Flaherty Manchester

Work and Organizations

University of Minnesota

Room 3-300R

321 - 19th Avenue South

Minneapolis, MN 55455

cmanch@umn.edu

\author{
Aaron Sojourner \\ Carlson School of Management \\ 321 19th Ave S, 3-300 \\ Minneapolis, MN 55409 \\ asojourn@umn.edu \\ Joshua Tasoff \\ Claremont Graduate University \\ Department of Economics \\ 160 East Tenth Street \\ Claremont, CA 91711 \\ joshua.tasoff@cgu.edu
}




\section{Introduction}

As of 2015 there is an estimated $\$ 14.4$ trillion invested in employer-sponsored defined contribution plans and individual retirement accounts in the United States (Investment Company Institute, 2015). Individuals vary considerably in their retirement wealth levels even after conditioning on observables such as income, age, and education. The decline of traditional pension plans means employer-provided individual accounts such as $401(\mathrm{k}) \mathrm{s}$ will be a major source of retirement income for millions of Americans, and variation in individual abilities and attitudes toward saving will become an increasingly important driver of retirement wealth accumulation, decumulation, and Americans' ability to smooth consumption over the lifecycle. Understanding the forces that influence this tremendous quantity of wealth and its distribution is therefore of central importance for positive economics and policy analysis.

Standard intertemporal-choice models predict that time preferences, as measured by the discount rate, and features of the budget constraint, such as liquidity constraints, influence retirement savings. However, the complexity of the problem increases the likelihood that "behavioral" factors influence retirement wealth accumulation. Theoretically, at least two psychological biases predict that people may save insufficiently for retirement. Present bias (PB) is the tendency to underweight future consumption relative to present consumption in a dynamically inconsistent way (Strotz, 1956; Laibson, 1997; O'Donoghue and Rabin, 1999a). A theoretical literature shows that in lifecycle-consumption models, present bias can lead to lower savings relative to an unbiased person who shares the same long-run discount factor (Laibson, 1997, 1998; Laibson et al., 1998; Angeletos et al., 2001; Diamond and Köszegi, 2003). A person with present-biased preferences may intend to save more in the future but never do so. Furthermore, present-biased agents may procrastinate on the decision to enroll in a tax-deferred savings plan, also resulting in lower savings (O'Donoghue and Rabin, 1999a,b, 2001).

While $\mathrm{PB}$ is a preference parameter, exponential-growth bias (EGB) is a perceptual bias whereby people underestimate exponential growth due to neglecting compound interest. A person with EGB will underestimate the returns to savings and the costs of holding debt. Levy and Tasoff (2015a) show, in a lifecycle-consumption model, that EGB can lead to undersaving for retirement 
under certain conditions. A large body of evidence suggests that this bias is widespread and robust (Wagenaar and Sagaria, 1975; Wagenaar and Timmers, 1979; Keren, 1983; Benzion, Granot and Yagil, 1992; Eisenstein and Hoch, 2007; McKenzie and Liersch, 2011; Almenberg and Gerdes, 2012). In addition, a growing body of literature finds that EGB is negatively correlated with total savings (Stango and Zinman, 2009; Levy and Tasoff, 2015a).

In this paper, we examine the relationship between retirement savings, time preferences and EGB in a rich statistical model that includes these behavioral parameters simultaneously as well as a diverse set of controls to address potential confounds. Our study builds upon literature to date which has largely focused on retirement outcomes and a single behavioral characteristic, for instance the propensity to plan (Ameriks, Caplin and Leahy, 2003), financial literacy (Lusardi and Mitchell, 2007), or numeracy (Banks, O'Dea and Oldfield, 2010). PB and EGB have distinct influences on economic decisions, as they affect different aspects of the individual's intertemporal-choice problem (i.e., PB affects preferences, while EGB manifests in the budget constraint). Empirically, however, their relative importance in predicting retirement wealth is unknown.

This paper makes several contributions to the literature. First, we measure the joint distribution of time preferences, EGB, financial literacy, and IQ in a broad sample of U.S. households. We find that PB and EGB are unrelated: the biases are uncorrelated $(r=-0.036)$, suggesting that the biases are distinct and do not stem from the same deeper latent variable. We estimate the parameters of a quasi-hyperbolic discount function (Laibson, 1997) and find that while on average the population is time consistent, a large fraction are present biased. Replicating previous work (Levy and Tasoff, 2015a), we find that a large fraction of the population exhibits EGB.

We next establish an empirical link between retirement savings, time preferences, and EGB. While the theoretical relationship between standard time preference and retirement savings in discounted utility models is well-understood, and the relationship between retirement savings and PB specifically has been discussed in theoretical contexts for nearly two decades (Laibson, Repetto and Tobacman, 1998; O'Donoghue and Rabin, 1999b), there have been surprisingly few attempts to research the relationship empirically. ${ }^{1}$ Our analysis aims to fill this gap. We control for income,

\footnotetext{
${ }^{1}$ We discuss exceptions in Section 2.3.
} 
education, risk preferences, financial literacy, and a measure of IQ, as well as a host of other background characteristics, and find that time preferences and EGB are statistically significant and economically meaningful determinants of retirement savings. A one standard deviation reduction in the long-run discount factor is associated with approximately $\$ 20,400$ less retirement wealth relative to a mean of $\$ 132,926$; a one standard deviation increase in PB is associated with approximately $\$ 12,700$ less in retirement wealth. A one standard deviation increase in EGB is associated with $\$ 13,400$ less retirement savings.

We also establish a link between self-awareness of these biases and retirement savings. It has been suggested that self-awareness regarding one's biases may be as important or even more important in determining behavior than the direct effect of the bias itself (O'Donoghue and Rabin, 2001; Levy and Tasoff, 2015b). A sophisticated agent who is aware of his or her self-control problems may be able to implement commitment devices to counteract the bias, while a naif would not. Likewise, a person with EGB who is aware of his or her inability in solving such problems could seek help or use tools, whereas an overconfident person will exhibit insufficient demand for tools and advice. We directly measure sophistication regarding present bias and overconfidence regarding exponential estimation. We find that overconfidence regarding exponential estimation has an additional negative effect on retirement savings. Our results suggest that sophistication decreases the impact of present bias, though the measured interaction is not statistically significant. As far as we are aware, this is the first study to test for an association between a direct measure of self-awareness regarding these biases and economic outcomes.

While these findings together present a plausible case for a causal relationship between retirement savings, time preferences and EGB, they cannot establish air-tight evidence for causality. Indeed, establishing a causal relationship would seem to be a near-impossible task because behavioral parameters cannot be randomly assigned. We take two approaches to assessing the causal interpretation of our results. First, we field a hypothetical choice experiment where subjects are randomly assigned interventions designed to mitigate the effects of PB and EGB, and find evidence that those with higher levels of $\mathrm{PB}$ and EGB respond more to the interventions. Under the assumption that our treatments mitigate the targeted biases, evidence of heterogeneous effects 
establishes a causal pathway from EGB and PB to retirement wealth accumulation. Second, we use available data to assess the plausibility of additional potential threats to a causal interpretation. We find no evidence for an association between income and the biases, reducing the plausibility of a reverse causal interpretation. We investigate omitted variable bias by showing that our main results are robust to a wide variety of additional controls for one's access to employer saving plans, expected retirement age, subjective assessments of one's health and life expectancy, and alternative measures of IQ and financial literacy. In addition, we find that our results are robust to using retirement wealth recorded from other surveys, suggesting that they are not likely to be driven by non-classical measurement error stemming from our survey instrument. Together, these findings point to a causal relationship between time preferences, EGB and saving for retirement. Under this interpretation, eliminating both $\mathrm{PB}$ and EGB from the sample would lead to a 12 percent increase in overall retirement savings. The regression coefficients are likely to understate the true association between retirement savings, time preferences and EGB due to attenuation bias caused by measurement error. After employing an instrumental variables strategy to correct for classical measurement error, a causal interpretation of our estimates suggests retirement wealth could increase by as much as 70 percent if PB and EGB were eliminated.

Finally, we discuss the potential mechanisms for the effects of our behavioral parameters on retirement savings. We find evidence that overconfidence about exponential estimation and PB decrease saving flows into employer-sponsored retirement accounts. Conversely, we find no evidence that our behavioral parameters operate through the equity allocation in retirement accounts or enrollment in employer-sponsored retirement plans. We find no evidence that the biases affect the propensity to plan, but do find that financial literacy is positively associated with planning.

The next section lays out the conceptual framework and presents related literature. In Section 3 we present the research design. Section 4 contains the main results, while Section 5 reports the results of our hypothetical choice experiment. We explore additional evidence for a causal interpretation and potential mechanisms in Section 6. Section 7 concludes. 


\section{Conceptual Framework and Prior Literature}

In our empirical analysis we take a reduced-form approach, estimating relationships with limited structure between our behavioral parameters of interest and retirement savings. This section provides the theoretical basis for our statistical models and outlines theoretical predictions between these parameters and retirement savings established by previous research. We use the model below, not to generate novel implications of PB and EGB, which have been done elsewhere in the literature, but instead to motivate the empirical analysis. We conclude the section by summarizing existing theoretical predications and previous empirical findings.

\subsection{Conceptual Framework}

People are assumed to have quasi-hyperbolic utility functions (Phelps and Pollak, 1968; Laibson, 1997) over a vector of consumption $x \in \mathbb{R}^{T-t+1}$ of the form

$$
U_{i, t}(x) \equiv u_{i}\left(x_{t}\right)+\beta_{i} \sum_{\tau=t+1}^{T} \delta_{i}^{\tau-t} u_{i}\left(x_{\tau}\right)
$$

where $T$ is the final period, $t$ is the current period, $i$ is the individual, $1-\beta_{i}$ is the degree of present bias, and $\delta_{i}$ is the (exponential) long-run discount factor. The individual may overestimate the $\beta_{i}$ used by future selves, as in O'Donoghue and Rabin (1999a, 2001). The individual's current utility is given by (1) but she incorrectly believes her future utility in period $s>t$ is determined with $\hat{\beta}_{i} \geq \beta_{i}$ yielding

$$
\tilde{U}_{i, s}(x) \equiv u_{i}\left(x_{s}\right)+\hat{\beta}_{i} \sum_{\tau=s+1}^{T} \delta_{i}^{\tau-t} u_{i}\left(x_{\tau}\right)
$$

The individual uses backwards-induction given her beliefs to solve for her perception-perfect strategy (O’Donoghue and Rabin, 1999a).

In addition to the possibility of having biased time preferences, people may also be biased in their perceptions of exponential growth, which affects the budget constraint. While PB and EGB are both referred to as biases here and in the literature, there is an important conceptual distinction 
that deserves mention: PB may be considered a preference parameter, while EGB is a perceptual error. In most contexts the welfare implications of EGB are therefore less ambiguous than those from PB.

Using the parametric model of Levy and Tasoff (2015a), let $\alpha_{i}$ represent's individual $i$ 's accuracy in her exponential perceptions. Given an interest rate $\vec{r}$ and time horizon $T$, the person's perception function $p\left(\vec{r}, t ; \alpha_{i}\right)$ is the perception of the period- $T$ value of one dollar invested at time $t<T$ :

$$
p\left(\vec{r}, t ; \alpha_{i}\right)=\prod_{s=t}^{T-1}\left(1+\alpha_{i} r_{s}\right)+\sum_{s=t}^{T-1}\left(1-\alpha_{i}\right) r_{s}
$$

When $\alpha_{i}=0$, the individual does not compound interest and incorrectly perceives growth to be linear. When $\alpha_{i}=1$, the person correctly perceives growth to be exponential. Values of $\alpha_{i} \in[0,1]$ generate perceptions that are between linear and exponential growth.

When maximizing utility over the lifecycle given a vector of income $\hat{y}$ the person must choose a vector of consumption $\hat{c}$ that maximizes (2) subject to expected future behavior and the true budget constraint written in terms of the period- $T$ value of money,

$$
\sum_{s=0}^{T} \hat{c}_{s} \cdot p(\vec{r}, s ; 1) \leq \sum_{s=0}^{T} y_{s} \cdot p(\vec{r}, s ; 1)
$$

Since the person misperceives exponential growth, she perceives the budget constraint as:

$$
\sum_{s=0}^{T} \hat{c}_{s} \cdot p\left(\vec{r}, s ; \alpha_{i}\right) \leq \sum_{s=0}^{T} y_{s} \cdot p\left(\vec{r}, s ; \alpha_{i}\right)
$$

The individual is subject to the true budget constraint in (4), and thus she will revise her consumption plans in subsequent periods. Equation (5) reveals two errors. On the right-hand side of the inequality, the person misperceives the intertemporal prices of consumption. This is the price effect of EGB, and it can be further decomposed into a perceived income effect and a perceived substitution effect. On the left hand side, the person misperceives the value of her wealth. This is the wealth effect of EGB. ${ }^{2}$

\footnotetext{
${ }^{2}$ Endogenizing labor supply decisions would add a further substitution effect to lifetime earnings.
} 
The theory takes $\alpha_{i}$ as an exogenous primitive. A broader interpretation considers $\alpha_{i}$ as the output of a production process that inputs numeracy, the ability to use tools, available tools, effort, attention, and intrinsic ability. This broader interpretation allows $\alpha_{i}$ to vary for the same person based on education, the availability of tools, and incentives, and is a helpful way to think about the distributional results in Section 4.1 which presents the joint distribution of $\alpha_{i}$ with other observables.

Our interpretation of $\alpha_{i}$ also provides a useful way to think about the joint distribution with financial literacy. We think of compound-interest perceptions as a component of overall financial literacy, but in contrast to other financial literacy measures, EGB is formally modeled allowing for precise point and comparative static predictions of behavior. It is a portable model in the sense that it can be easily imported to arbitrary economic environments or married to other models of preferences and perceptions. One can estimate a person's parameter $\alpha_{i}$ and predict their behavior out of sample in completely different contexts. Thus, even though compound-interest perception may be considered a component of financial literacy, the model of EGB leads to theoretical predictions that more aggregate concepts of financial literacy may miss.

Self-awareness about these biases is predicted to dramatically change behavior in some environments. When $\hat{\beta}=\beta$, the person is fully aware of the inconsistency in her time preferences and is said to be sophisticated; when $\hat{\beta}>\beta$, she is not fully aware of her bias and is said to be naive. In some environments, sophisticated individuals could mitigate the behavioral effects of PB by relying on commitment devices; however, sophisticates do not always do better than naifs (O'Donoghue and Rabin, 1999a). We discuss this point more in Section 2.2.

People could also differ in their self-awareness about EGB. The law of iterated expectations makes it impossible for a person to know that their perceptions are biased in a particular direction, as this would immediately imply that they should revise their estimates in the opposite direction of the bias. However, one could be aware of an inability to solve exponential problems while at the same time not know the direction of the bias (Levy and Tasoff, 2015b). A self-aware person with EGB could seek out tools and help in order to make better financial decisions, while someone who is overconfident may not. Empirically, we can investigate how overconfidence relates to economic 
outcomes.

\subsection{Predictions}

Theory predicts an unambiguous positive relationship between $\delta$ and retirement savings. In contrast, the relationship between $\beta$ and $\alpha$ with retirement savings is less obvious. The relationship could be either positive or negative depending on ancillary conditions that are typically unobserved. Table 1 summarizes the theoretical predictions from the literature and demonstrates the considerable ambiguity in the theory literature. Resolution of this ambiguity requires empirical analysis, which this paper provides.

Most of the past research regarding present bias analyzes the intuitive relationship that retirement savings should increase in $\beta$. The mechanisms differ based on whether people are self-aware about their bias or not. O'Donoghue and Rabin (1999a) show that naive present-biased people may endlessly procrastinate a costly task that yields future benefit, for example 401(k) enrollment. O’Donoghue and Rabin (1999b, 2001) introduce a second mechanism in which a person with even small amounts of naivete can procrastinate when choice sets are large because, "the better is the enemy of the good." A slightly naive present-biased person may forgo choosing a good enough retirement portfolio immediately in order to to make a better decision in the future, but then procrastinate. The greater the optimal effort one should expend, the greater the procrastination. Laibson $(1997,1998)$ and Laibson, Repetto and Tobacman (1998) model sophisticated present-biased agents and show that consumption tracks income and therefore there will be a drop in consumption at retirement. Sophisticates hold most of their wealth in illiquid investments to prevent future selves from squandering resources. Diamond and Köszegi (2003) and Zhang (2013) endogenize the timing of retirement and show that sophisticated present-biased people may also save less to prevent their future selves from retiring too early.

It is also possible that PB can counterintuitively increase saving for both naifs and sophisticates. Findley and Caliendo (2015) show that when retirement is endogenous naifs may save too much expecting to retire early. Diamond and Kőszegi (2003) show that sophisticates with endogenous retirement timing may save more to accommodate an earlier retirement. Similarly, O'Donoghue 
Table 1: Review of Theoretical Predictions between Behavioral Parameters and Retirement Savings

\begin{tabular}{|c|c|c|c|c|}
\hline$\overline{\text { Prediction }}$ & $\begin{array}{l}\text { Role of Self- } \\
\text { Awareness }\end{array}$ & Citations & Explanation & $\overline{\text { Conditions }}$ \\
\hline \multicolumn{5}{|c|}{ Time Preferences: Long-run discount rate $(\delta)$ and Present Bias $(\beta)$} \\
\hline $\begin{array}{l}\delta \quad \text { increases } \\
\text { savings }\end{array}$ & $\mathrm{N} / \mathrm{A}$ & $\begin{array}{l}\text { Samuelson } \quad(1937) ; \\
\text { Modigliani and Brum- } \\
\text { berg (1954); Frederick et } \\
\text { al. (2002) }\end{array}$ & $\begin{array}{l}\text { Higher } \delta \text { implies lower discount- } \\
\text { ing of future consumption }\end{array}$ & \\
\hline \multirow[t]{4}{*}{$\begin{array}{l}\beta \quad \text { increases } \\
\text { savings }\end{array}$} & Naive & $\begin{array}{l}\text { O'Donoghue and Rabin } \\
\text { (1999a) }\end{array}$ & Procrastination & $\begin{array}{l}\text { Immediate cost, one- } \\
\text { time retirement decision }\end{array}$ \\
\hline & & $\begin{array}{l}\text { O'Donoghue and Rabin } \\
(1999 \mathrm{~b}, 2001)\end{array}$ & $\begin{array}{l}\text { Large costs of good decisions } \\
\text { lead to procrastination }\end{array}$ & $\begin{array}{l}\text { Partial naivete, immedi- } \\
\text { ate cost }\end{array}$ \\
\hline & Sophisticated & $\begin{array}{l}\text { Laibson (1997); Laibson } \\
\text { et al. (1998) }\end{array}$ & $\begin{array}{l}\text { Use illiquid asset as a commit- } \\
\text { ment technology. }\end{array}$ & $\begin{array}{l}\text { Access to a liquid and an } \\
\text { illiquid asset. }\end{array}$ \\
\hline & & $\begin{array}{l}\text { Diamond and Köszegi } \\
\text { (2003); Zhang (2013) }\end{array}$ & $\begin{array}{l}\text { Those with lower } \beta \text { save less to } \\
\text { prevent early retirement. }\end{array}$ & $\begin{array}{l}\text { Choice for retirement } \\
\text { timing and for savings. }\end{array}$ \\
\hline \multirow[t]{2}{*}{$\begin{array}{l}\beta \quad \text { decreases } \\
\text { savings }\end{array}$} & Naive & $\begin{array}{l}\text { Findley and Caliendo } \\
(2015)\end{array}$ & $\begin{array}{l}\text { Naifs save too much expecting } \\
\text { to retire young }\end{array}$ & $\begin{array}{l}\text { Choice for retirement } \\
\text { timing and for savings. }\end{array}$ \\
\hline & Sophisticated & $\begin{array}{l}\text { Diamond and Köszegi } \\
\text { (2003); Zhang (2013) } \\
\text { O'Donoghue and Rabin } \\
\text { (1999a) }\end{array}$ & $\begin{array}{l}\text { Those with lower } \beta \text { save more to } \\
\text { accommodate early retirement } \\
\text { Preproperation }\end{array}$ & $\begin{array}{l}\text { Choice for retirement } \\
\text { timing and for savings } \\
\text { Immediate cost, one- } \\
\text { time retirement decision }\end{array}$ \\
\hline \multicolumn{5}{|c|}{ Exponential-Growth Bias $(\alpha)$} \\
\hline \multirow[t]{3}{*}{$\begin{array}{l}\alpha \quad \text { increases } \\
\text { savings }\end{array}$} & Overconfident & $\begin{array}{l}\text { Stango and Zinman } \\
(2009)\end{array}$ & $\begin{array}{l}\text { Underestimate future value of } \\
\text { savings; more severe for longer } \\
\text { time horizons }\end{array}$ & \\
\hline & & Goda et al. (2012) & $\begin{array}{l}\text { Price effect of EGB: decom- } \\
\text { posed into a perceived income } \\
\text { effect and perceived substitu- } \\
\text { tion effect }\end{array}$ & EIS $>1$ \\
\hline & & Levy and Tasoff (2015a) & $\begin{array}{l}\text { Price effect of EGB; Wealth ef- } \\
\text { fect of EGB: overestimate the } \\
\text { present value of future income }\end{array}$ & EIS $>1$ \\
\hline \multirow[t]{3}{*}{$\begin{array}{l}\alpha \quad \text { decreases } \\
\text { savings }\end{array}$} & Overconfident & Goda et al. (2012) & Price effect of EGB & EIS $<1$ \\
\hline & & Levy and Tasoff (2015a) & $\begin{array}{l}\text { Price effect of EGB; Wealth ef- } \\
\text { fect of EGB }\end{array}$ & $\begin{array}{l}\text { EIS }<1 \text { and income re- } \\
\text { ceived sufficiently early. }\end{array}$ \\
\hline & & Levy and Tasoff (2015d) & $\begin{array}{l}\text { EGB can cause overestimation } \\
\text { of returns, reversing wealth ef- } \\
\text { fect }\end{array}$ & $\begin{array}{l}\text { Interest rates vary suffi- } \\
\text { ciently over time. }\end{array}$ \\
\hline $\begin{array}{l}\alpha \text { does not af- } \\
\text { fect savings }\end{array}$ & $\begin{array}{l}\text { Aware of error, } \\
\text { but unaware of } \\
\text { bias }\end{array}$ & Levy and Tasoff (2015b) & $\begin{array}{l}\text { People who misestimate expo- } \\
\text { nential growth can outsource fi- } \\
\text { nancial decisions }\end{array}$ & $\begin{array}{l}\text { Existence of well- } \\
\text { functioning market for } \\
\text { financial services. }\end{array}$ \\
\hline
\end{tabular}


and Rabin (1999a) show that sophisticates may exhibit preproperation, locking themselves into savings commitments immediately due to pessimism about their future behavior.

Similar theoretical ambiguity surrounds $\alpha$. Stango and Zinman (2009) explain how underestimating the future value of savings could result in lower savings and this effect is magnified for longer time horizons. Goda et al. (2012) and Levy and Tasoff (2015a) explain that the price effect of EGB depends on the elasticity of intertemporal substitution (EIS). When the EIS > 1, EGB leads to lower savings. In addition, the wealth effect of EGB will also lead to lower savings. But the opposite relationship is also possible. When the EIS $<1$ and income is mostly received early in the lifecycle (i.e. the wealth effect of EGB is small), EGB can increase savings. ${ }^{3}$ To further complicate the issue, when returns are time-varying, a person with EGB can overestimate the return since the person perceives the mean return to be closer to the arithmetic mean than the correct geometric mean. Thus with time-varying returns the predictions can potentially be reversed (Levy and Tasoff, 2015d). Finally, it is also possible for there to be no association between $\alpha$ and saving. If a biased person is aware that she cannot do the computations (while remaining unaware of the direction of her bias), she can hire someone or purchase tools to help her make better financial decisions. Ultimately, the effect of these biases on retirement savings is an empirical question for which theory, with limited information about context, cannot give unambiguous answers.

\subsection{Previous Empirical Findings}

There is surprisingly little research that has measured these behavioral parameters in broad crosssections of the population. To our knowledge, the only other paper to have directly elicited time preferences in a broad cross-section of the U.S. is Heutel et al. (2014). Eisenhauer and Ventura (2006), Dohmen et al. (2012), and Enzler et al. (2014) measure time preferences in representative Italian, German, and Swiss samples. The only papers to have measured the marginal distribution of EGB are Stango and Zinman (2009) and Levy and Tasoff (2015a). No papers have measured their joint distribution, nor the joint distributions with IQ or financial literacy.

The extant literature on time preferences and retirement savings has measured the relationship

\footnotetext{
${ }^{3}$ For a typical earnings profile, however, the wealth effect will dominate.
} 
in indirect ways. Early studies fit models of consumption and wealth accumulation to panel data to infer time preferences (Bernheim, Skinner and Weinberg, 2001; Angeletos, Laibson, Repetto, Tobacman and Weinberg, 2001). More recent studies have used proxy measures of time preferences. van Rooij, Lusardi and Alessie (2012) used smoking and heavy drinking as a proxy for time preference and found no association with net worth. Ameriks, Caplin and Leahy (2003) use a time preference elicitation measure that potentially identifies the long-run discount factor but does not identify PB. ${ }^{4}$ More recently, Brown and Previtero (2014) take an ecological approach to measuring procrastination. They use administrative data to show that those who sign up on the last day of their health care open enrollment period contribute less to their retirement savings plans, and are more likely to stick to default allocations. Our study is most similar to recent work by Eisenhauer and Ventura (2006) and Heutel et al. (2014) who measure time preferences in a similar way to us, with broad samples in Italy and the U.S. Eisenhauer and Ventura (2006) find that PB preferences and a dichotomous variable of whether or not the person has contributed to a pension are significantly related; however the only control in the regression is income. Heutel et al. (2014) correlate their measures of time preference with the dichotomous variable of having any retirement savings. They do not find a relationship between retirement savings and PB, although they do find a significant correlation with the long-run discount factor $\delta$.

There are no other studies that directly associate EGB with retirement savings. Stango and Zinman (2009) use the responses to a series of questions in the Survey of Consumer Finances in which participants estimate APR from a repayment schedule. They find a significant correlation between this payment bias and short-term debt, share of savings in equity, savings rate, net worth, and use of financial advice. Levy and Tasoff (2015a) directly measure EGB and find that it is significantly associated with total savings, but do not have data on retirement saving or time preferences. Goda et al. (2014) and Song (2012) conduct field experiments designed to counteract EGB and find that informational interventions are effective at increasing retirement saving. Levy and Tasoff (2015c) conduct a theoretically motivated lab experiment in which subjects have a

\footnotetext{
${ }^{4}$ Their elicitation involves a hypothetical scenario in which a person is presumed to be 50 and then lives to 80 , there is no inflation and all medical expenses are covered. The person must choose how to allocate their entire wealth between ages 50-64, 65-79, and a bequest.
} 
consumption-savings task, and validate the lifecycle predictions of the model of EGB. None of these experiments establish a link between the bias and savings behavior.

There is a sizable literature that has measured the association of other related observables with retirement savings. Ameriks, Caplin and Leahy (2003) find that the propensity to plan is predictive of retirement savings. Ameriks, Caplin, Leahy and Tyler (2007) construct a measure of self-control and find that it predicts net worth but not retirement assets. The literature on the relationship between financial literacy and retirement savings finds significant associations between financial literacy and retirement planning (Lusardi and Mitchell, 2007; van Rooij, Lusardi and Alessie, 2012). Using four different measures of financial literacy in the American Life Panel (with one of the measures including 70 items), Hung, Parker and Yoong (2009) replicate this association. They also find that these measures correlate with having ever saved for retirement but not with one's 401(k) balance. ${ }^{5}$ van Rooij et al. (2012) additionally find that financial literacy is correlated with net worth and Banks et al. (2010) find that numeracy is highly predictive of net worth while controlling for other cognitive measures.

To summarize, there remains a large gap in the literature connecting direct measures of time preferences and EGB with retirement savings. Relating direct measures to retirement savings is important for building evidence regarding a causal relationship and is important for measuring the impact of these biases.

\section{Study Design and Data}

Data collection took place online and comprised two surveys that were administered several weeks apart. The two-wave design allowed us to separate measurement of retirement and other financial outcomes from the treatments in our hypothetical choice experiment as well as to mitigate concerns of single-source bias in measuring the relationship between our key parameters of interest and retirement wealth. A complete list of content covered in each survey is provided in Table A.1.

We administered our survey to two distinct samples: 1) the RAND American Life Panel (ALP), and 2) the Understanding America Study (UAS) administered by University of Southern California.

\footnotetext{
${ }^{5}$ Only one of the four measures is found to be significant at the $p<0.1$ level.
} 
The ALP is a sample of approximately 5,000 adults, while UAS consists of approximately 2,000 adults. To achieve representativeness, both ALP and UAS invite subjects to join the sample through random sampling techniques and provide a laptop or tablet as well as internet services to individuals invited to join who do not have such access. In both samples, subjects are regularly invited to take online surveys and are typically paid a fixed amount based on the length of the survey. ${ }^{6}$

We collected our data in multiple cohorts between August 2014 and June 2015. ${ }^{7}$ Overall, we invited 4,700 individuals to participate; 2,601 completed Survey 1, and 2,393 completed Survey 2 (response rate of $51 \%$ based on Survey 2). Among the respondents, we restrict our main analysis sample to the 2,317 individuals with usable responses for our variables of interest. We use this sample to evaluate the distribution of EGB and time preferences as well as the relationship with retirement savings and other financial outcomes. Appendix Table B.1 shows select demographic and economic variables obtained for non-respondents and our estimation sample. Respondents were on average older than non-respondents, but not richer after controlling for age.

\subsection{Parameter Elicitations}

\subsubsection{Exponential-Growth Bias Elicitation}

To elicit the $\alpha$ described in Section 2, we asked participants five real-stakes questions about the value of different assets that involve compound interest calculations. The full text of the questions can be found in Figures A.1-A.5 in Appendix A. In contrast to past survey measures of financial literacy our participants earned payments based on the accuracy of their responses to these five questions. Most respondents could earn up to $\$ 3$ per question, for a maximum of $\$ 15 .^{8}$ One out of 20 participants were randomly assigned to a high-stakes group where the earnings were multiplied by 5 and provided up to $\$ 15$ for each question answered, for a maximum total of $\$ 75$.

Subjects were neither encouraged nor prohibited from getting help or using calculators. The instructions stated, "You may use whatever approaches you would like to answer these questions."

\footnotetext{
${ }^{6}$ The rate is approximately $\$ 20$ per 30 minutes.

${ }^{7}$ This was done for budgeting purposes due to uncertainty on response rates and performance of subjects on real-stakes questions. See Table A.2 for information on the timing and response rate of each cohort.

${ }^{8}$ Participants earned $\$ 3$ if their response was within $10 \%$ of the correct answer, $\$ 2$ within $25 \%$, and $\$ 1$ within $50 \%$.
} 
This way we identify subjects' perceptions of exponential growth in the same unrestricted environment in which most people make their important financial decisions. Furthermore, by providing financial stakes, these questions may be more likely to induce individuals to rely on the resources they would typically use to make economic decisions. ${ }^{9}$

We use the method in Levy and Tasoff (2015a) to identify $\alpha_{i}$. Let subject $i$ 's responses on question $j \in\{1, \ldots, 5\}$ be denoted by $y_{i j}$, and the correct response be given by $c_{j}$. Let $\vec{a}(\alpha)$ : $\mathbb{R} \rightarrow \mathbb{R}_{+}^{|\mathcal{J}|}$ be a function that generates the answers consistent with a given level of $\alpha$ on the five questions. Thus $\vec{a}(1)$ is a vector containing the five correct answers. To measure subject- $i$ 's degree of EGB, we calculate the value of $\alpha_{i}$ which minimizes the mean squared error of the model against their actual answers, with each question normalized by the correct answer:

$$
\text { Alpha }=\arg \min _{\alpha} \frac{1}{5} \sum_{j=1}^{5}\left(\frac{y_{i j}-a_{j}(\alpha)}{a_{j}(1)}\right)^{2}
$$

We also measure subjects' self-awareness of their EGB. After completing the five compoundinterest questions, we asked subjects to choose between their performance earnings or an automatic specified payment using a multiple-price list. We define overconfidence as the difference between a subjects' minimum acceptable payment and their performance earnings, as a fraction of possible earnings: (certain payment - performance earnings)/(max earnings). This measure takes on the value of 0 when a person's evaluation of their performance earnings is equal to their true performance earnings. The measure takes on the value of 1 when a person values her performance earnings maximally but true performance earnings are zero, and -1 when a person values her performance earnings at 0 when the true performance earnings are maximal. ${ }^{10}$

Table 2 displays summary statistics for the key variables of interest in the study, including Alpha. Recall that a value of 1 indicates accurate perception of exponential growth, while a value of 0 indicates individuals perceive the growth to be linear. The sample mean of Alpha is 0.57, with a standard deviation of 0.49. Self-awareness of one's misunderstanding of exponential growth

\footnotetext{
${ }^{9}$ We use reports of tool use and help from others as well as the amount of financial incentives as part of our instrumental variables strategy to address measurement error in $\alpha$; see Table 9.

${ }^{10}$ Risk aversion will cause a person to value the certain money over the risky performance earnings. This will bias down a person's elicited overconfidence; thus our measure is a lower bound. In our empirical analysis of retirement savings, we control for risk preferences.
} 
Table 2: Behavioral Parameters and Survey Constructs

\begin{tabular}{lcccc}
\hline \hline & mean & sd & $\min$ & $\max$ \\
\hline Alpha & 0.571 & 0.489 & 0.000 & 3.000 \\
Beta & 1.028 & 0.208 & 0.468 & 2.135 \\
Delta & 0.708 & 0.172 & 0.461 & 0.985 \\
Imputed Beta & 0.140 & 0.347 & 0.000 & 1.000 \\
Imputed Delta & 0.097 & 0.296 & 0.000 & 1.000 \\
Fin Lit & 2.570 & 0.699 & 0.000 & 3.000 \\
IQ Measure & 2.412 & 1.521 & 0.000 & 5.000 \\
Missing Fin Lit & 0.001 & 0.029 & 0.000 & 1.000 \\
Missing IQ Measure & 0.003 & 0.055 & 0.000 & 1.000 \\
Sophisticated & 0.486 & 0.500 & 0.000 & 1.000 \\
Overconfidence & 0.308 & 0.380 & -1.000 & 1.000 \\
\hline Observations & 2317 & & \\
\hline Nos: Imputed Beta and Delta refer to observations reaching a \\
corner in the staircase elicitation task. Fin Lit refers to number of \\
questions correct (out of 3). IQ Measure refers to number of questions \\
correct (out of 5).
\end{tabular}

is low: the mean value of overconfidence is 0.31 , indicating that individuals are overconfident on average. This evidence is consistent with laboratory findings (Levy and Tasoff, 2015b).

\subsubsection{Time Preference Elicitation}

We adapt the time-staircase procedure from Falk, Becker, Dohmen, Huffman and Sunde (2014) to identify three time preference parameters $(\beta, \delta, \hat{\beta})$ as described in Section 2. The staircases have the form:

Present-Future Staircase: Would you rather receive $\$ 100$ today or $\$[\mathrm{X}]$ in 12 months?

Future-Future Staircase: Would you rather receive $\$ 120$ in 12 months or $\$[\mathrm{Y}]$ in 24 months?

Prediction Staircase: Suppose that 12 months from now, you are going to be given the choice between the following: receiving a payment on that day (that is, 12 months from today) or a payment 12 months later (that is, 24 months from today) ... Do you think you would rather choose to receive $\$ 110$ on that day or $\$[\mathrm{Z}] 12$ months later?

In our survey instrument, the future value $\mathrm{X}$ was always greater than 100 , $\mathrm{Y}$ was always greater than 120 , and $\mathrm{Z}$ was always greater than 110 . If the subject indicated they prefer the money sooner (later), the second dollar amount increases (decreases) on the next question. For each staircase, 
subjects answer five questions, gradually narrowing the interval that contains the indifference point. Since the questions are binary and have parallel structure, they are easily understood and can be answered very quickly. In order to remove potential bias from individuals mechanically repeating answers, we randomize the order of the Present-Future, Future-Future, and Prediction Staircases and utilize different base values for the different sets of questions (i.e., the Present-Future Staircase always begins with $\$ 100$ today, the Future-Future Staircase with $\$ 120$ in 12 months, and the Prediction Staircase with $\$ 110$ on the day 12 months from now). While this staircase method did not involve real stakes, Falk et al. (2014) show that behavior between a no-stakes and real-stakes version is highly correlated. ${ }^{1112}$

We identify $\beta_{i}, \delta_{i}$, and $\hat{\beta}_{i}$ because each staircase identifies an indifference point within a fairly small interval. ${ }^{13}$ From the Future-Future Staircase, Delta $=120 / Y_{\text {cutoff. }}$ We impute the cutoff as the midpoint of the interval. ${ }^{14}$ Likewise we do the same midpoint imputation for the other staircases. From the Present-Future Staircase Beta ${ }_{i}=100 /\left(\right.$ Delta $_{i} X_{\text {cutoff })}$, and from the Prediction Staircase $\widehat{\operatorname{Beta}}_{i}=110 /\left(\right.$ Delta $\left._{i} Z_{\text {cutoff }}\right)$. We use $\widehat{\operatorname{Beta}}_{i}$ to construct a measure of self-awareness of one's time-inconsistent tendencies. We construct a binary measure of sophistication that equals 1 if an individual's $\widehat{\operatorname{Beta}}_{i} \leq$ Beta $_{i}$ and 0 otherwise. ${ }^{15}$

The summary statistics for the time preference parameters are displayed in Table 2. The average value of Beta is 1.03, which corresponds to approximately time-consistent preferences on average; however, there is substantial variation (standard deviation of 0.21 ). In terms of self-

\footnotetext{
${ }^{11}$ The authors find a correlation between the staircase measures and incentivized experimental measures of 0.5241 . This is impressively high given that the correlation is close to the test-retest correlation of 0.6637 for the incentivized experiment.

${ }^{12}$ Recently real-effort tasks have been used to measure time preference (Augenblick, Niederle and Sprenger, 2015), however there is yet no evidence that these measures correlate with other economic behaviors, while there is quite a large literature that suggests that the monetary elicitations do (see Section 2.3 for a summary). Augenblick, Niederle and Sprenger (2015) find that real-effort and monetary elicitations do not correlate with each other. We also conducted a real-effort time-preference elicitation as well but use the monetary elicitation in our main analysis given some likely confounds to our effort elicitation. See Appendix A for a brief description.

${ }^{13}$ We cannot identify the indifference point for those who select the upper bound of the time staircase. In this case, we use the upper bound value plus the difference between that value and the second-to-last value to determine the indifference point. We include a dummy variable for those with these imputed values in the analysis. Beta is imputed for $14 \%$ of our sample, while Delta is imputed for $9.7 \%$ of our sample.

${ }^{14}$ Inputting the midpoint bounds the magnitude of the error to be quite small. The magnitude of the error on $\delta$, for example, is bounded to be below about 0.015 .

${ }^{15}$ We use an indicator variable instead of including $\widehat{\operatorname{Beta}}_{i}$ directly in the regression because $\widehat{\text { Beta }}_{i}$ is near collinear with Beta $_{i}$ with a correlation of $r=0.61$.
} 
awareness of present-biased preferences, $49 \%$ of the sample is sophisticated. The average value of our annual Delta is 0.71; again, there is substantial variation (standard deviation of 0.17). By way of comparison, Heutel et al. (2014) calculate an average monthly value of Delta as 0.846 and an average value of Beta as 0.936 using a slightly different elicitation procedure.

\subsection{Financial Literacy and Cognitive Ability Measures}

Recent research has devoted much attention to measuring and describing the relationship between financial literacy, numeracy, and financial decisions (e.g. van Rooij et al., 2012; Banks et al., 2010; Lusardi and Mitchell, 2014). While we consider $\alpha$ as a component of financial literacy, we depart from past research by focusing on this behavioral parameter that is specific, yet portable to many economic decisions. Notwithstanding, it is useful to determine to what extent our measure of EGB is related to existing measures of financial literacy as well as cognitive ability.

For financial literacy, we include the 3-item battery of financial literacy questions developed by Lusardi and Mitchell (2011) and widely-used since then (Lusardi and Mitchell, 2014). Because this 3-item financial literacy assessment does not include a question that isolates understanding of compound interest, it is useful to determine to what extent Alpha is related to this highly-used metric as well as whether EGB uniquely predicts financial decisions over and above general financial literacy.

Similarly, we evaluate whether EGB is distinct from general cognitive ability by using a measure developed by selecting a subset of items from the public-domain assessment tool International Cognitive Ability Resource (ICAR) (Condon and Revelle, 2014). ${ }^{16}$ The original ICAR test includes a total of 60 items grouped into four dimensions: verbal reasoning, letter and number series, matrix reasoning, and three-dimensional rotation. From the validated 16-item subset of ICAR, we selected 5 questions to measure cognitive reasoning that represent the four dimensions and that also vary in the percent of respondents who answered correctly in past research (ranging from $17 \%$ to $73 \%$

\footnotetext{
${ }^{16}$ This tool is designed to increase the measurement of cognitive ability by being a free and flexible tool for researchers. Privately owned tools, such as the Raven's Standard Progression Matrix (RSPM) test, are cost-prohibitive and cumbersome to incorporate into large-scale data collection. RSPM is currently owned by Pearson and use requires subjects to enter a private-domain portal; items cannot be directly incorporated into existing surveys.
} 
correct). ${ }^{17}$

Table 2 reports summary statistics for these financial literacy and cognitive ability proxies. The average number correct on the 3 -item financial literacy battery is 2.57 out of $3 ; 68 \%$ answered all 3 questions correctly, a rate much higher than the $34 \%$ found by Lusardi and Mitchell (2014). ${ }^{18}$ The average number correct on the cognitive ability test was 2.41 out of 5 ; only $8.9 \%$ answered all 5 questions correctly.

\subsection{Household Financial and Background Information}

Our main wealth accumulation measure of interest is retirement savings. We also collect data on several other financial outcomes for the household, including non-retirement savings, housing (equity and mortgages), asset allocation (retirement and non-retirement assets), debts (secured and unsecured), net worth, payday loan utilization, bankruptcy filings, and current access to employerprovided retirement plans (offering, enrollment and contributions). We evaluate the relationship between these outcomes and our EGB and time preference measures.

Table 3 reports the summary statistics for these financial outcomes. ${ }^{19}$ Average retirement savings is $\$ 132,926$ with a standard deviation of $\$ 276,052 ; 31 \%$ of the sample has no retirement savings. The mean and median retirement savings in our sample conditional on having any retirement savings is $\$ 191,298$ and $\$ 59,500$, respectively. These moments match well with recent data from the Survey of Consumer Finances, which reports 49.2\% of Americans having any retirement savings, and a conditional mean and median of $\$ 201,300$ and $\$ 59,000$ in 2013 (Bricker et al., 2014).

Average non-retirement savings is much lower with a mean of $\$ 51,665$ and standard deviation of $\$ 155,025$. For measures of debt, the largest debt holding is mortgage debt, followed by secured and unsecured debt . ${ }^{20}$ Average net worth is $\$ 330,771$, with substantial variation $(\mathrm{sd}=\$ 941,044)$.

\footnotetext{
${ }^{17}$ We used the same number of ICAR questions as as we did to elicit our estimate of EGB in order to keep the measurement error to a similar magnitude.

${ }^{18}$ This higher percentage correct could be due to the fact that many individuals in the ALP sample have been asked this same battery of questions in previous surveys. In robustness checks, we also use individuals' scores from the first time they faced these questions in the ALP, which lowers the average score to 2.39.

${ }^{19}$ We winsorize retirement savings, non-retirement savings, and outstanding mortgage for the top $1 \%$, and net worth for the bottom and top $0.5 \%$.

${ }^{20}$ Our measures of both secured and unsecured debt come from categorical responses, and we use the midpoints of each category in order to impute a continuous value. The categories are: less than 1,000; between 1,000 and 10,000; between 10,000 and 50,000; between 50,000 and 100,000; between 100,000 and 250,000; and 250,000 or more.
} 
About $7.7 \%$ of the sample used short-term loans (such as payday loans) in the last five years and $5.6 \%$ declared bankruptcy in the past 5 years.

Table 3: Retirement Savings, Non-Retirement Savings, Debt and Financial Outcomes

\begin{tabular}{lcccc}
\hline \hline & mean & sd & min & max \\
\hline Retirement Savings & 132,926 & 276,052 & 0 & 1700000 \\
Has Any Retirement Savings & .695 & .461 & 0 & 1 \\
Non-Retirement Savings & 51,665 & 155,025 & 0 & 1100000 \\
Outstanding Mortgage & 56,160 & 94,624 & 0 & 460,000 \\
Other Secured Debt & 16,478 & 37,347 & 500 & 250,000 \\
Unsecured Debt & 13,334 & 28,425 & 500 & 250,000 \\
Net Worth & 330,771 & 941,044 & $-245,500$ & 9639000 \\
Short-Term Loan (last 5 years) & .0768 & .266 & 0 & 1 \\
Declared Bankruptcy (last 5 years) & .0561 & .23 & 0 & 1 \\
\hline Observations & 2317 & & & \\
\hline \hline
\end{tabular}

Notes: Retirement Savings, Non-Retirement Savings, Outstanding Mortgages Winsorized for top 1\%. Net Worth Winsorized for top 0.5\%. Other Secured Debt and Unsecured Debt represent midpoints from categorical responses.

Because variation in the aforementioned financial outcomes may be due to variation in household attributes other than time preference and EGB, we use a rich set of controls in the analysis. Table 4 reports the summary statistics for many of these measures. We conduct a real-stakes elicitation of risk preferences using individuals' choice over lotteries. Individuals could earn payments based on whether a coin flip ends in heads or tails. They choose from 6 options, from equal payments for heads or tails (Category 1 ) up to $\$ 15$ for heads and $\$ 0$ for tails (Category 6 ). The proportion of the sample in each risk category is included in Table 4. We also collect information through our survey on annual income (own and spouse's) and financial decision making (expected age for claiming retirement benefits, and whether the respondent is the financial decision maker in the household). Finally, the ALP and UAS also include a rich set of background information on each respondent, including gender, age, marital status, number of household members, state of residence, ethnicity, work status, highest education, and occupation category. The average age is 51.5 years, $60 \%$ of the sample is married, and $55 \%$ of the sample is female. We include the variables listed in Table 4 as controls in our regression analysis. 
Table 4: Demographic Controls

\begin{tabular}{lcccc}
\hline \hline & mean & sd & min & max \\
\hline Age & 51.474 & 15.156 & 18.000 & 96.000 \\
Female & 0.551 & 0.498 & 0.000 & 1.000 \\
Family Income & 66600.279 & 55841.256 & 0.000 & $2.00 \mathrm{e}+05$ \\
Education & & & & \\
$\quad$ HS or Less & 0.189 & 0.391 & 0.000 & 1.000 \\
Some College & 0.239 & 0.427 & 0.000 & 1.000 \\
Assoc Degree & 0.122 & 0.328 & 0.000 & 1.000 \\
BA/BS Degree & 0.267 & 0.443 & 0.000 & 1.000 \\
Post BA/BS & 0.183 & 0.387 & 0.000 & 1.000 \\
Marital Status & & & & \\
Married/Partnered & 0.600 & 0.490 & 0.000 & 1.000 \\
Separated & 0.023 & 0.150 & 0.000 & 1.000 \\
Divorced & 0.144 & 0.351 & 0.000 & 1.000 \\
Widowed & 0.049 & 0.216 & 0.000 & 1.000 \\
Never Married & 0.184 & 0.387 & 0.000 & 1.000 \\
Missing & 0.000 & 0.000 & 0.000 & 0.000 \\
Add' HH Members & 0.997 & 1.098 & 0.000 & 3.000 \\
Num of Children & 0.725 & 1.179 & 0.000 & 9.000 \\
Hispanic/Latino & 0.130 & 0.337 & 0.000 & 1.000 \\
Race & & & & \\
White/Caucasian & 0.791 & 0.407 & 0.000 & 1.000 \\
Black/African American & 0.112 & 0.316 & 0.000 & 1.000 \\
American Indian & 0.011 & 0.103 & 0.000 & 1.000 \\
Asian & 0.031 & 0.174 & 0.000 & 1.000 \\
Other & 0.054 & 0.227 & 0.000 & 1.000 \\
Missing & 0.000 & 0.021 & 0.000 & 1.000 \\
Risk Aversion & & & & \\
Category 1 & 0.339 & 0.474 & 0.000 & 1.000 \\
Category 2 & 0.166 & 0.372 & 0.000 & 1.000 \\
Category 3 & 0.164 & 0.371 & 0.000 & 1.000 \\
Category 4 & 0.077 & 0.267 & 0.000 & 1.000 \\
Category 5 & 0.042 & 0.201 & 0.000 & 1.000 \\
Category 6 & 0.208 & 0.406 & 0.000 & 1.000 \\
Missing & 0.003 & 0.055 & 0.000 & 1.000 \\
\hline Observations & 2317 & & & \\
\hline \hline
\end{tabular}

Notes: Family Income shown Winsorized for top 5\%. Higher risk aversion categories represent decreasing risk aversion. 


\section{Results}

\subsection{Relationship between EGB, PB, and other individual characteristics}

In this section, to facilitate description, we categorize individuals into four EGB types: Linear, Below Exponential, Accurate, and Above Exponential. The types partition the range of Alpha, based on the incentive ranges used in our elicitation task. Accurate types perform well on the five $\alpha$-elicitation items, earn full incentive payments, have values of Alpha in $[0.9523,1.045)$ and comprise $22 \%$ of the sample. Linear types severely underestimate exponential growth. They have values of Alpha in [0,0.01), which would earn them $\$ 0$ in the $\alpha$-elicitation. Twenty-nine percent of the sample falls in this category. Below Exponential types have values of Alpha between Linear and Accurate, and earn intermediate payments. They underestimate exponential growth to an intermediate degree and make up $41 \%$ of the sample. Above Exponential types overestimate exponential growth with values of Alpha $\geq 1.045$ and comprise $8 \%$ of the sample. ${ }^{21}$ We also divide individuals into either present biased $($ Beta $<1)$ or not present biased (Beta $\geq 1)$. Fifty-five percent of our sample falls into the present bias category.

Measurement of both EGB and PB in the same sample permits estimation of the joint distribution of both biases. Just $10 \%$ of individuals are both accurate with respect to exponential growth and not present biased. The other $90 \%$ display one or both types of bias. Figure 1 presents the share of people falling into each of the $8 \mathrm{EGB} \times \mathrm{PB}$ categories. The correlation between Alpha and Beta is $-0.036(p=0.08)$ suggesting that the biases are independent and not strongly correlated (Appendix Table B.2).

We explore how Alpha, Beta, Delta, overconfidence and sophistication relate to conventional demographic characteristics and our measures of financial literacy and IQ by regressing our survey constructs on these items. Table 5 displays the results for selected demographic characteristics. We also present evidence on correlates of our measure of financial literacy (excluding the financial literacy measure itself from the list of regressors) in the last column of Table 5 .

Overall, we find little explanatory power from standard demographics for our survey constructs,

\footnotetext{
${ }^{21}$ The distribution of Alpha is quite similar to the only other representative sample measure found in Levy and Tasoff (2015a) who find a mean of 0.53 and a median of 0.60.
} 


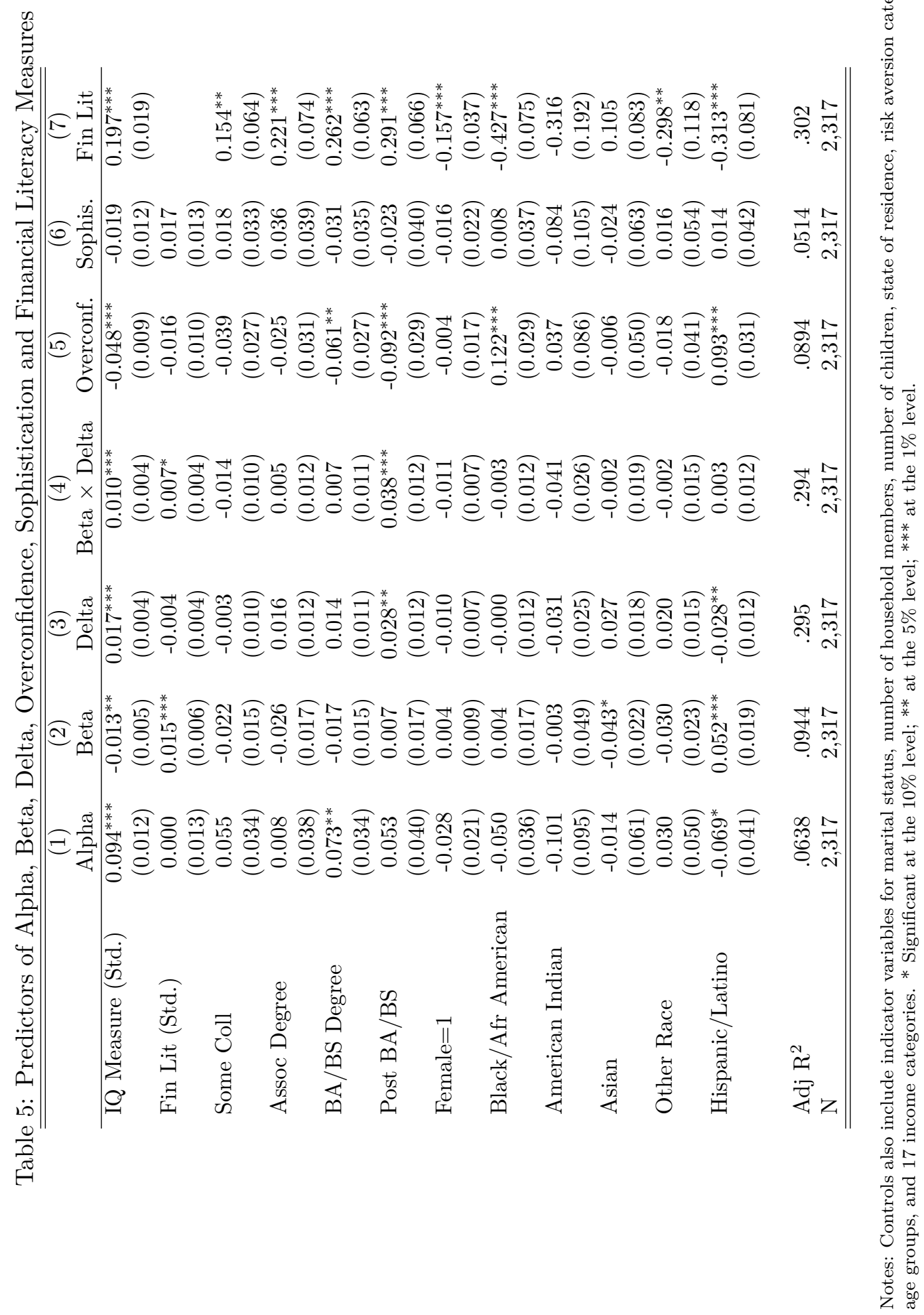


Figure 1: Joint Distribution of Present Bias and EG Bias

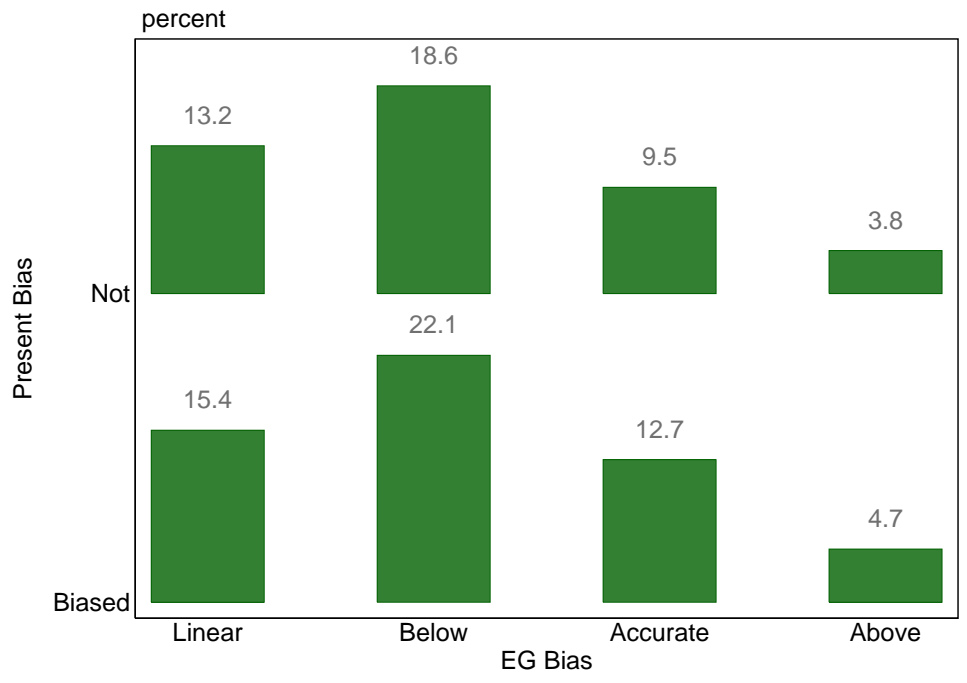

though there are some exceptions. For instance, we find statistically significant relationships between Hispanic/Latino and Alpha, overconfidence, and time preferences. We also find a significant relationship between higher levels of education and Alpha, Delta, and overconfidence. By contrast, our measure of financial literacy is strongly correlated with our IQ measure as well as education, gender, race, and ethnicity.

The results in Column (1) suggest that a one standard deviation increase in our measure of IQ is associated with a $0.094(p<0.01)$ increase in Alpha. While Alpha is not significantly correlated with a standard measure of financial literacy, the linear specification misses the nonlinearity in the relationship between the two. In the appendix, Figure B.1 presents predicted IQ scores by EGB category from a regression of our IQ measure on EGB category indicators and all other controls. After conditioning on the controls, individuals in the Accurate EGB category have the highest average predicted IQ scores, those with Linear EGB have the lowest, and those with moderate levels of EGB (either above or below exponential growth) have average levels. While our measure of financial literacy appears unrelated to Alpha in Table 5, in Figure B.2 the relationship has a nonlinearity similar to that shown with IQ but with magnitudes about one-fourth the size. These weak and non-monotonic associations warrant analysis of EGB independent of other observables such as financial literacy or cognitive ability. 
In conclusion, this first look at the joint distribution of EGB and time preferences, along with measures of self-awareness and conventional characteristics reveals new insights. First, Alpha and Beta appear to be largely independent rather than correlated. Second, with some exceptions, we measure weak or small relationships with conventional characteristics. This finding suggests that these measures identify latent behavioral parameters that cannot be explained using demographic and conventional measures.

\subsection{Retirement savings}

Consistent with much of the theoretical literature, we hypothesize that retirement savings are increasing in Alpha, Beta, and Delta. We would like to estimate the causal effects of these parameters. Ideally, we would randomly shock individuals' values of these characteristics before they enter the labor market, wait while they make consumption and saving decisions over the lifecycle, and measure retirement saving levels. Of course, this is not feasible. Instead, to isolate the associations of interest, we condition on a rich set of control variables. We assess causal interpretations in more detail in Section 6.

Our main specification regresses outcomes on Alpha, $\ln ($ Beta $), \ln ($ Delta $)$, and a rich set of demographic and economic controls. ${ }^{22}$ In Table 6, Column (1), we begin with a set of controls that are plausibly exogenous to the behavioral parameters: indicator variables for age in 10-year bins, gender, marital status, size of household, number of children, racial group, Hispanic ethnicity, riskaversion categories, state of residence, and missing values. The coefficient on Alpha, $\$ 54,782$, can be interpreted as an estimate of how much more retirement savings those with accurate perceptions of exponential growth $($ Alpha=1) have over those who misperceive exponential growth as linear $($ Alpha $=0)$. The results imply that a one standard deviation difference in Alpha (0.489) is associated with an $\$ 26,800$ difference in retirement savings. The $\$ 130,336$ estimated coefficient on $\ln ($ Beta) implies that a difference of one standard deviation of $\ln ($ Beta) (0.181) is associated with a $\$ 23,600$ difference in retirement savings. Finally, the coefficient of $\$ 184,766$ on $\ln$ (Delta) implies that a one standard deviation increase in long-run patience (0.252) is associated with a $\$ 46,600$ difference in

\footnotetext{
${ }^{22}$ We use log-transformed values of Beta and Delta because our survey questions directly identify Delta and Beta $\times$ Delta, rather than each separately. Using $\ln ($ Beta $)$ and $\ln ($ Delta $)$ in the regression analysis nests $\ln ($ Beta $\times$ Delta $)$.
} 
Table 6: Relationship between Alpha, Beta, Delta and Retirement Wealth

\begin{tabular}{lcccc|c}
\hline \hline & $(1)$ & $(2)$ & $(3)$ & $(4)$ & $(5)$ \\
\hline Alpha & $54,782^{* * *}$ & $30,320^{* * *}$ & & $27,325^{* * *}$ & $18,216^{* *}$ \\
& $(11,823)$ & $(10,514)$ & & $(10,561)$ & $(8,717)$ \\
$\ln$ (Beta) & $130,336^{* * *}$ & $68,653^{* * *}$ & & $69,908^{* * *}$ & $45,966^{*}$ \\
& $(28,579)$ & $(25,752)$ & & $(26,089)$ & $(24,737)$ \\
$\ln$ (Delta) & $184,766^{* * *}$ & $83,198^{* * *}$ & $64,511^{* *}$ & $80,923^{* * *}$ & $49,408^{*}$ \\
& $(30,945)$ & $(28,241)$ & $(25,071)$ & $(27,981)$ & $(26,113)$ \\
Fin Lit (Std.) & & & 2,903 & 1,822 & -822 \\
& & & $(4,443)$ & $(4,509)$ & $(6,310)$ \\
IQ Measure (Std.) & & & $11,394^{* *}$ & $8,995^{*}$ & 5,571 \\
& & & $(5,082)$ & $(5,086)$ & $(4,690)$ \\
Demog Controls & Yes & Yes & Yes & Yes & Yes \\
Add'l Controls & No & Yes & Yes & Yes & Yes \\
& & & & & \\
Mean of Dep Var & 132,926 & 132,926 & 132,926 & 132,926 & 97,313 \\
Adj R & 0.177 & 0.367 & 0.365 & 0.367 & 0.375 \\
N & 2,317 & 2,317 & 2,317 & 2,317 & 2,317 \\
\hline \hline
\end{tabular}

Notes: Dependent variable is Winsorized retirement wealth. Demographic controls include indicator variables for female, marital status, number of household members, number of children, race, ethnicity, state of residence, risk aversion category, and 10-year age groups. Additional controls include indicator variables for highest level of education, 17 income categories, and 10-year age groups $\times$ income category interactions. * Significant at the $10 \%$ level; ** at the $5 \%$ level; *** at the $1 \%$ level.

retirement savings. All coefficients are statistically significant at levels $p<0.01$.

Next, to help address large sources of omitted-variable bias in Column (1), Column (2) reports the results after adding control variables that strongly determine the level of retirement savings and which we expect, in part, are driven by EGB or time preferences: education level, retirement status, indicators for household income in 17 bins and all age-income interactions. Unsurprisingly, the adjusted- $R^{2}$ rises considerably when we add these controls, to 0.367. The coefficients on Alpha, $\ln ($ Beta $)$, and $\ln$ (Delta) each fall by around half and all remain highly significant statistically and economically. Given the sample's mean outcome of $\$ 132,926$ in retirement savings, the estimated $\$ 30,320$ coefficient on Alpha implies that the difference between those with accurate perceptions of exponential growth and those with linear perceptions is about $23 \%$ of the outcome mean. A standard deviation difference in Alpha, $\ln ($ Beta), and $\ln ($ Delta) is associated with differences of $11 \%, 9 \%$, and $16 \%$ of retirement savings, respectively.

In Column (3), we include standardized financial literacy and our standardized IQ measure, 
but for comparability with past studies exclude Alpha and $\ln$ (Beta). The estimated coefficient on financial literacy is $\$ 2,903$ and represents the average difference in retirement wealth for those with a one standard deviation difference in financial literacy. The coefficient is small and not statistically significant. The coefficient on our standardized IQ measure, $\$ 11,394$, is statistically significant $(p=0.025)$ and suggests a one standard deviation increase in IQ is associated with $\$ 11,394$ in additional retirement savings.

Specification (4) produces our main result by including Alpha, $\ln ($ Beta $), \ln ($ Delta) along with our standardized financial literacy and IQ measures and the full set of controls. The estimated coefficients on our behavioral parameters change little from the specification in Columns (2) which exclude financial literacy and IQ. These coefficients imply that a one standard deviation difference in Alpha, $\ln ($ Beta), and $\ln ($ Delta) are associated with $\$ 13,400, \$ 12,700$, and $\$ 20,400$ differences in retirement savings, repsectively. All coefficients are statistically significant at the $1 \%$ level. A one standard deviation difference in the IQ measure is associated with an $\$ 8,995(p<0.10)$ difference in retirement saving, and financial literacy is statistically insignificant. In sum, direct measures of time preference and EGB have independent power to empirically explain retirement savings conditional on measures of general cognitive skill, financial literacy, and a rich set of controls.

We show robustness to alternative specifications of our behavioral parameters and dependent variable in Appendix Table C.1. Our results are robust to including Beta and Delta linearly and including higher-order terms. We find no evidence that there is an interaction effect between Alpha and $\ln$ (Beta). When we use our baseline specification to predict having any retirement savings, we find that $\ln ($ Delta $)$ is statistically significant but no evidence that Alpha or $\ln ($ Beta) predict this outcome. All three behavioral parameters predict retirement savings conditional on having wealth, and $\ln ($ Beta $)$ and $\ln ($ Delta $)$ are both statistically significant predictors of $\ln$ (Retirement Wealth).

Our baseline specification assumes that the effect of Alpha, $\ln$ (Beta) and $\ln$ (Delta) on retirement wealth is homogenous after controlling for demographics and economic covariates. We examine heterogeneity across several margins in Section 4.5. Here, however, we focus on heterogeneity across age. Because accumulated retirement wealth is a stock variable which reflects the entire history of past saving decisions, it is reasonable to expect that the behavioral factors will have a 
greater effect on the savings of those approaching retirement. We therefore run a variant of the specification in Column (4) of Table 6, but interact Alpha, $\ln$ (Beta), $\ln ($ Delta), Fin Lit, and IQ with a quadratic in age.

The average marginal effects of each of these factors for ages 30-65 is shown, along with $95 \%$ confidence intervals, in Figure 2. All five factors display an upward-sloping trajectory. That is, the cumulative effect of impatience or EGB is increasing with age. None of the factors are significant for 30-40 year-olds, but we estimate very large and highly significant effects for people over 50 . Thus specification (4) may understate the effects for people nearing retirement. In contrast, we do not find a significant relationship at any age between financial literacy or IQ and retirement wealth after controlling for EGB and PB, although a similar increasing pattern exists for these variables..

Figure 2: Heterogeneous Effects of Alpha, $\ln ($ Beta $), \ln ($ Delta $)$, Financial Literacy and IQ Measure on Retirement Wealth By Age
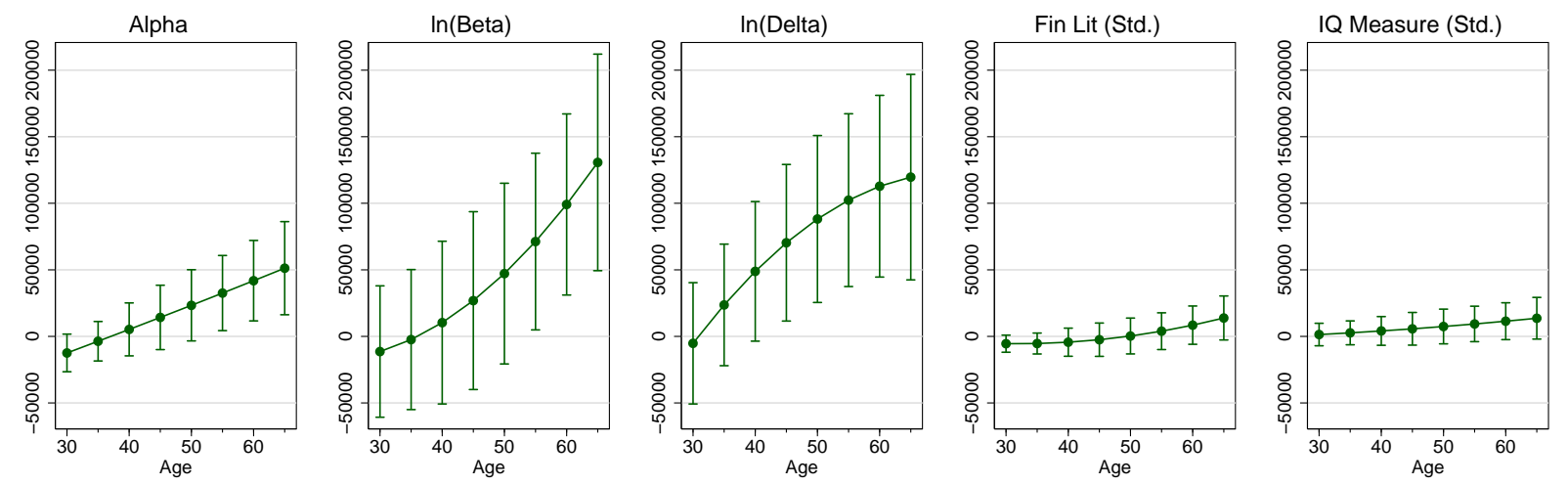

Notes: Average marginal effects on Winsorized retirement wealth. All parameters are interacted with a quadratic in age in a common regression equation. Demographic controls include indicator variables for female, marital status, number of household members, number of children, race, ethnicity, state of residence, risk aversion category, and 10-year age groups. Additional controls include indicator variables for highest level of education, 17 income categories, and 10-year age groups $\times$ income category interactions. $95 \%$ confidence intervals shown.

Some selection into the ALP and UAS samples, and response to our survey, means our analytic sample differs slightly from a nationally-representative population. Specification (5) uses weighted least-squares (WLS) to attempt to adjust for demographic differences between our analytic sample and the national population, applying weights provided by the ALP and UAS for this purpose. The weighted sample appears younger, 46.8 instead of 51.5 average years of age. The estimated rela- 
tionships between time preferences and EGB with retirement savings using WLS are all somewhat smaller, though only a little smaller as a proportion of average wealth, which makes sense given the evidence in Figure 2 as this analysis gives less weight to individuals in or close to retirement and more weight to those who have had less time to accumulate retirement savings. We focus our analysis on the unweighted sample and provide analogous results using weighted least-squares in Appendix D.

\subsection{Other Financial Outcomes}

Next, we look beyond retirement savings to study the relationship between Alpha, $\ln ($ Beta), and $\ln ($ Delta $)$ and other items on the household balance sheet. We regress non-retirement savings, outstanding mortgage, measures of secured and unsecured debt, net worth, and recent use of payday loans or bankruptcy filings on Alpha, $\ln ($ Beta), and $\ln$ (Delta) and our other baseline controls using the specification in Column (4) in Table 6 and report the results in Table 7.

Column (1) presents the relationship between our parameters and non-retirement savings. As predicted by theory, time preferences matter in savings accumulation more generally. A one standard deviation difference in $\ln ($ Beta) $(\ln ($ Delta $))$ is associated with $\$ 12,600(\$ 14,200)$ in additional non-retirement saving. We do not find evidence of a significant relationship between EGB and nonretirement saving. This lack of evidence is not surprising, as wealth held in non-retirement accounts tends to be for more immediate needs and EGB is less important for shorter savings horizons. IQ has a statistically significant but quantitatively small relationship. We do not find evidence that financial literacy is associated with differences in non-retirement savings when controlling for other factors.

Time-preference parameters have strong relationships with outstanding mortgage debt levels in the expected direction as seen in Column (2). Those who are more time-consistent borrow less $(p<0.10)$. A one standard deviation higher level of $\ln$ (Beta) is associated with $-\$ 3,600$ less mortgage debt, corresponding to $6 \%$ of the mean level. We do not find evidence of a significant relationship between mortgage levels and $\ln ($ Delta), EGB or our IQ measure. Our model indicates that a person with a standard deviation higher financial literacy has $\$ 5,062$ more in mortgage 


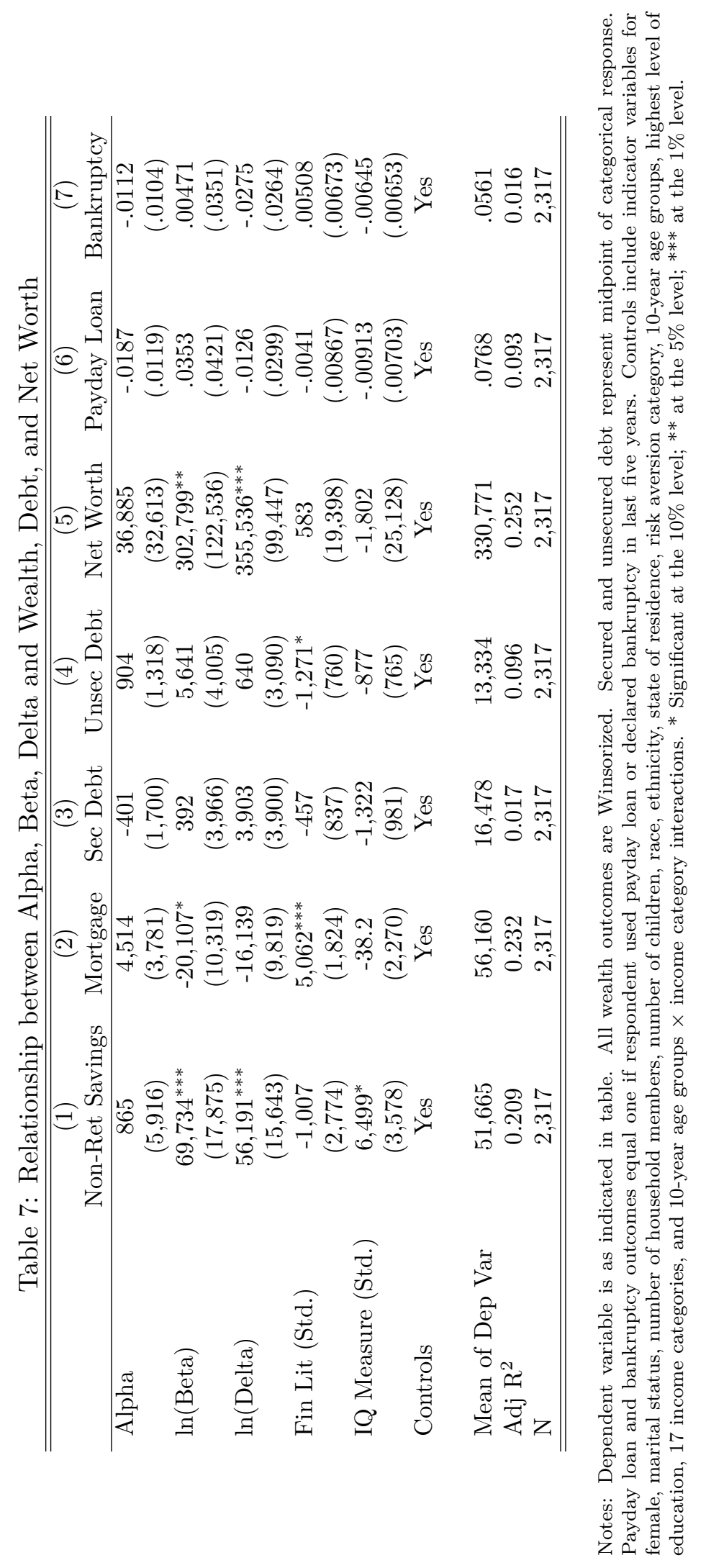


debt $(p<0.01)$, a somewhat counterintuitive finding. ${ }^{23}$ We do not find evidence that any of the parameters have a significant relationship with measures of other secured debt (Column (3)). We find that those with one standard deviation higher financial literacy report $\$ 1,271$ less unsecured debt $(p<0.10)$ but do not find significant relationships with other parameters (Column $(4)){ }^{24}$

Net worth is the sum of retirement savings, non-retirement saving and housing equity, less secured and unsecured debt. Consistent with the previous results, Column (5) shows that time preferences have a strong relationship with net worth. A one standard deviation difference in $\ln$ (Beta) and $\ln ($ Delta $)$ is associated with $\$ 54,800(p<0.05)$ and $\$ 89,600(p<0.01)$ higher net worth. The association with Alpha is present mainly for retirement savings, which is only one component of net worth, and it is not significant here. The estimated coefficients on both IQ and financial literacy are both small and statistically insignificant.

Finally, we test for relationships with indicators of whether the individual used a payday loan or declared bankruptcy in the last five years and report the results in Columns (6) and (7). Despite our long time window, these are reportedly rare events, with base rates of 7.7 and 5.6 percent. Given the low power, we find no evidence that our parameters are associated with these outcomes.

In sum, the model of time preference explains variation in multiple components of the household balance sheet and is reinforced in net worth. Present bias and long-run patience each have explanatory power. In contrast, EGB appears to matter for retirement savings but not for other financial outcomes. General cognitive ability conditional on education, income, time preferences, EGB and other controls displays some explanatory force for retirement and non-retirement savings. Conditional on all the other predictors, higher financial literacy is associated with somewhat higher levels of mortgage debt and lower levels of unsecured debt.

\footnotetext{
${ }^{23}$ Given the tax advantages of mortgage debt, and historically low interest rates at the time, it may be reasonable for financially sophisticated people to hold larger mortgages.

${ }^{24}$ Because our measures of secured and unsecured debt represent the midpoints of categorical responses, we have considerably less power to detect associations. However, the relationships we report are robust to representing these measures with categorical variables using ordered probit/logit regressions or using the intervals to perform interval regressions.
} 
Table 8: Relationship between Overconfidence, Sophistication and Retirement Wealth

\begin{tabular}{lcccc}
\hline \hline & $(1)$ & $(2)$ & $(3)$ & $(4)$ \\
\hline Alpha & $21,509^{*}$ & $27,270^{* *}$ & $27,273^{* *}$ & $21,407^{*}$ \\
& $(11,051)$ & $(10,603)$ & $(10,601)$ & $(11,060)$ \\
Overconfidence & $-23,655^{*}$ & & & $-24,059^{* *}$ \\
& $(12,143)$ & & & $(12,151)$ \\
$\ln$ (Beta) & $69,248^{* * *}$ & $75,420^{* * *}$ & $112,653^{* * *}$ & $110,894^{* * *}$ \\
& $(26,427)$ & $(27,393)$ & $(42,619)$ & $(42,633)$ \\
Sophisticated & & $-4,748$ & $-4,193$ & $-4,642$ \\
& & $(10,798)$ & $(10,727)$ & $(10,739)$ \\
Sophisticated $\times \ln ($ Beta $)$ & & & $-65,964$ & $-67,204$ \\
& & & $(50,731)$ & $(50,822)$ \\
$\ln ($ Delta $)$ & $78,158^{* * *}$ & $80,640^{* * *}$ & $79,861^{* * *}$ & $77,316^{* * *}$ \\
& $(28,035)$ & $(28,015)$ & $(28,001)$ & $(28,026)$ \\
Fin Lit (Std.) & 1,398 & 1,764 & 1,668 & 1,336 \\
& $(4,550)$ & $(4,577)$ & $(4,574)$ & $(4,548)$ \\
IQ Measure (Std.) & $8,752^{*}$ & $9,248^{*}$ & $9,352^{*}$ & $8,759^{*}$ \\
& $(5,132)$ & $(5,144)$ & $(5,151)$ & $(5,151)$ \\
Controls & Yes & Yes & Yes & Yes \\
Mean of Dep Var & 132,926 & 132,926 & 132,926 & 132,926 \\
Adj R & 0.368 & 0.367 & 0.367 & 0.368 \\
N & 2,317 & 2,317 & 2,317 & 2,317 \\
\hline \hline
\end{tabular}

Notes: Dependent variable is Winsorized retirement wealth. Controls include indicator variables for female, marital status, number of household members, number of children, race, ethnicity, state of residence, risk aversion category, 10-year age groups, highest level of education, 17 income categories, and 10-year age groups $\times$ income category interactions. * Significant at the $10 \%$ level; ** at the $5 \%$ level; *** at the $1 \%$ level.

\subsection{Self-awareness}

We next turn to the effect of self-awareness about one's biases on retirement savings. Self-awareness has the potential to mitigate the impact of the biases. For instance, a person who is aware of her EGB could rely on the market to acquire tools or seek advice, and a sophisticated present-biased person could use commitment devices to control the impulses of her future selves. Sophistication or partial sophistication also has the potential to backfire through preproperation (O'Donoghue and Rabin, 1999a) and engaging in futile attempts at self control (Heidhues and Köszegi, 2009). Theory therefore predicts that overconfidence in exponential estimation should go in the opposite direction to the direct effect of Alpha, but the effect of sophistication regarding $\mathrm{PB}$ on savings is ambiguous. 
Table 8 shows the relationship between these variables and retirement savings. Column (1) adds overconfidence as an independent variable to our baseline specification from Column (4) in Table 6. Recall that the variable can take on values between $[-1,1]$ with 0 indicating neither over- nor underconfidence, negative values indicating underconfidence and positive values indicating overconfidence. The estimated coefficient on overconfidence is $-\$ 23,655(p<0.10)$. Those with one standard deviation higher overconfidence have about $\$ 9,000$ lower retirement savings, about $7 \%$ of the mean level. Including overconfidence in the specification leads the coefficient on Alpha to decrease by about a fifth, to $\$ 21,509$, and to become marginally significant $(p<0.10)$. In contrast, estimated coefficients on other factors barely change. These results suggest that people with Alpha=0 may have quite different levels of savings: one who is fully self-aware of making an error will save $\$ 23,655$ more than one who believes there is no error. Some caution is warranted in interpreting this result, however, as EGB and overconfidence are strongly — though not mechanically - positively correlated. We reject the null hypothesis that the coefficients on Alpha and overconfidence are jointly zero $(p=0.005)$.

Columns (2) and (3) show the effect of self-awareness of PB on retirement savings. Recall that sophistication is an indicator variable that takes on the value of 1 if $\widehat{\operatorname{Beta}}_{i} \leq \operatorname{Beta}_{i}$. Column (2) shows that the inclusion of sophistication directly into the model has no meaningful effect directly on retirement savings nor on the coefficient on $\ln ($ Beta). In Column (3) we interact sophistication with $\ln$ (Beta). The coefficient on $\ln$ (Beta) increases to $\$ 112,653$ and the interaction term is negative but insignificant at $-\$ 65,964$. That is, the interaction represents a $58 \%$ reduction in the effect of $\ln ($ Beta $)$, and is marginally significant when expressed as this ratio $(p=0.061)$. This evidence is consistent with the notion that sophistication mitigates the self-control problems caused by high present bias. The regression is the first to our knowledge that uses an elicited measure of sophistication to predict savings outcomes. In Column (4), we include the full set of self-awareness variables - overconfidence, sophistication, and the interaction between sophistication and $\ln ($ Beta) — and find results quantitatively similar to those when each was added independently. 


\subsection{Heterogeneity in the effects of EGB and time preferences on retirement savings}

The effects of the behavioral parameters may vary as a function of observable characteristics. Appendix Table C.2 shows the baseline regression among split samples of the population. We examine how our estimates differ by income, whether the respondent is the financial head, marital status, age, gender, education, among those offered employer retirement plans, and among those enrolled in employer retirement plans. We also report the $p$-values of tests for equality on the coefficients for Alpha, $\ln ($ Beta $), \ln ($ Delta $)$, and all three jointly at the bottom of the table.

We find evidence that the effects of Alpha, $\ln ($ Beta), and $\ln ($ Delta) differ among those with income above and below the median. In particular, the effects are large in magnitude and statistically significant for those with above-median income, and indistinguishable from zero for those with below-median income. These differences are likely to be driven by the large differences in retirement wealth across the two groups. While the coefficients on $\ln$ (Beta) and $\ln$ (Delta) for financial heads are larger in magnitude than those for non-financial heads, the coefficient on Alpha is smaller and none are statistically distinguishable across the two groups.

We next examine differences by marital status, age, gender, and education. While both average retirement savings and the coefficients on our parameters of interest are larger for married respondents, we cannot reject the null hypothesis that the effects of Alpha, $\ln ($ Beta), and $\ln ($ Delta) differ by marital status. The differences we document by age are consistent with those shown in Figure 2, which showed effects that are increasing in age. Only the effects of $\ln$ (Beta) differ across gender, with higher coefficients for men, and the coefficients on Alpha and $\ln ($ Delta) are higher for more highly educated respondents than for those with lower levels of education.

Finally, we explore the role of institutions in the relationship between our parameters of interest and retirement savings. In particular, we look for differences in the effects of Alpha, $\ln ($ Beta), and $\ln ($ Delta $)$ across those offered and not offered an employer savings plan, and across those enrolled and not enrolled in their employer savings plan. We do not find evidence that our behavioral parameters effect people across these groups differently. 


\subsection{Classical measurement error}

While the preceding analysis has taken our measures of the behavioral parameters as given, they are of course only estimates of the true underlying parameters. The measure of EGB is estimated from a five-item incentivized task, while the time preference parameters are calculated from responses to three sets of unincentivized questions. Our methodology enables us to compute exact parameter values, but it is quite likely that they contain a substantial amount of measurement error. To the extent that it is classical, the subsequent attenuation bias will reduce our estimated effects. We therefore seek to address potential measurement error with both an instrumental variables and an errors-in-variables approach.

We have several potential instruments for both EGB and time preference parameters. Following the incentivized EGB questions, we asked subjects to report what tools they used and what help they received in completing the task. ${ }^{25}$ People with a greater tendency to use tools or seek out help may have a higher expressed Alpha. We also use whether respondents were randomized to receive higher stakes on the incentivized questions. Under the assumption that the use of help and tools and the stakes on these particular questions only affects retirement savings through EGB after controlling for economic and demographic observables, using these as instruments for Alpha will allow us to quantify the bias on our estimate of Alpha stemming from classical measurement error.

To address the measurement error in time preferences, we use simple psychological questions (SPQs) that are designed to ask people about their time preferences using plain language. We have subjects rank the following statements on a 5-point Likert scale: "I do things when I originally planned to do them," "I am willing to give up something that is beneficial today in order to receive a greater benefit in the future," and "I tend to postpone tasks even if I know it would be better to do them right away." 26 By using SPQs one can obtain correlates of the underlying preference parameters in a frugal and simple manner. Alone, the SPQs cannot be used to give point estimates of the preference parameters, but when paired with parameter elicitations, as done in

\footnotetext{
${ }^{25}$ Specifically, we asked whether they used any of the following tools: pencil-and-paper, a calculator, a spreadsheet, or other. We also asked if they received help from: a spouse, another family member, a friend, or other.

${ }^{26}$ The first question was developed for this study. The latter two questions were designed and found to be significant predictors by Falk et al. (2014).
} 
Table 9: Adjustments for Classical Measurement Error

\begin{tabular}{lccccc}
\hline \hline & $(1)$ & $(2)$ & $(3)$ & $(4)$ & $(5)$ \\
\hline Alpha & $27,446^{* * *}$ & $179,132^{* *}$ & $21,366^{* *}$ & $144,707^{* *}$ & $157,973^{* *}$ \\
& $(10,592)$ & $(75,138)$ & $(10,648)$ & $(67,003)$ & $(72,580)$ \\
$\ln ($ Beta $\times$ Delta $)$ & $77,632^{* * *}$ & $62,270^{* *}$ & $403,794^{* * *}$ & $396,392^{* * *}$ & $302,696^{* *}$ \\
& $(23,164)$ & $(24,760)$ & $(89,175)$ & $(93,307)$ & $(119,140)$ \\
Controls & Yes & Yes & Yes & Yes & Yes \\
& & & & & \\
Mean of Dep Var & 132,926 & 132,926 & 132,926 & 132,926 & 132,926 \\
F-Stat (Alpha) & & 12.189 & & 4.640 & \\
F-Stat (ln(Beta $\times$ Delta) $)$ & & & 10.855 & 7.578 & \\
Over ID p-value & & 0.896 & 0.960 & 0.992 & \\
Adj R & & & & \\
N & 0.368 & 0.300 & 0.310 & 0.267 & \\
\hline \hline
\end{tabular}

Notes: Dependent variable is Winsorized retirement wealth. Instruments for Alpha include high stakes and tool use. Instruments for $\ln ($ Beta $\times$ Delta $)$ include SPQs as described in text. Controls include indicator variables for female, marital status, number of household members, number of children, race, ethnicity, state of residence, risk aversion category, 10-year age groups, highest level of education, 17 income categories, and 10-year age groups $\times$ income category interactions. Column (5) shows estimates from errors-in-variables regression. * Significant at the $10 \%$ level; $* *$ at the $5 \%$ level; $* * *$ at the $1 \%$ level.

this analysis, a statistical relationship between the SPQs and the underlying behavioral parameters can be estimated. The SPQs can then be used as instruments to control for classical measurement error in the elicited parameter. This method is a straightforward application of the standard IV approach to address measurement error but, to our knowledge, has not previously been used to address measurement error in elicited behavioral parameters. ${ }^{27}$

In principle, our three SPQs would be sufficient to instrument separately for short-run and long-run time preferences (i.e., both $\ln ($ Beta) and $\ln ($ Delta)). In practice, however, these SPQs were a weak instrument for $\ln$ (Beta) separately and so we use the SPQs as instruments for total discounting $(\ln ($ Beta $\times$ Delta $))$ in this section. ${ }^{28}$

Table 9 presents the results of our approach to addressing measurement error in our independent variables. We first report the results of our baseline OLS regression, using the aggregate time preference measure $\ln ($ Beta $\times$ Delta $)$ rather than $\ln ($ Beta $)$ and $\ln ($ Delta $)$ separately. The results are very similar to the baseline regression for both EGB and time preferences. In Column (2), we use only the help and tools indicator variables to instrument for Alpha. We have a strong

\footnotetext{
${ }^{27}$ We report summary statistics of our instruments in Appendix Table B.4.

${ }^{28}$ We report the results of our first stage regressions in Appendix Table C.6.
} 
first stage $(\mathrm{F}=12.19)$, and the coefficient on Alpha increases roughly ten-fold to $\$ 179,100$. This amounts to roughly doubling the average retirement savings in our sample when moving from the linear $($ Alpha $=0)$ to the unbiased $($ Alpha=1) type. While considerably larger than our baseline regression, this coefficient is in fact not significantly different from the finding in Levy and Tasoff (2015a) which used a 10-item EGB measure and found a coefficient of $\$ 93,500$ on total savings (without controlling for time preferences).

Column (3) of Table 9 instruments for $\ln ($ Beta $\times$ Delta $)$ with our three simple psychological questions, but does not instrument for Alpha. Again we have a strong first stage $(\mathrm{F}=10.86)$, and the coefficient on $\ln ($ Beta $\times$ Delta $)$ is considerably increased to $\$ 403,794$. For comparability, this coefficient implies that a one standard deviation increase in our time preference measure is associated with a $\$ 101,000$ increase in retirement wealth.

We find a similar result when we simultaneously instrument for both Alpha and $\ln ($ Beta $\times$ Delta) in Column (4). The coefficients are slightly reduced, to $\$ 144,707$ and $\$ 396,392$ respectively, but remain strongly significant and considerably larger than the OLS estimates. While we urge caution in using these coefficients rather than the more conservative OLS coefficients, we note that there is great value in using SPQs to control for classical measurement error of elicited behavioral parameters.

Finally, we attempt to address measurement error in our parameters with an alternative approach. We re-contacted a random subsample of 50 subjects, and re-elicited our parameters. This allows us to estimate the reliability of our measures, and use this estimate to run an errors-invariables regression in Column (5) of Table 9. The full table of correlations and reliabilities for this sample appear in Appendix Table B.3. The results are remarkably similar to the instrumental variables approach. The coefficient on Alpha increases to $\$ 157,973$, and is significant at $p=0.0296$. The coefficient on $\ln ($ Beta $\times$ Delta $)$ is also similar to the IV coefficient at $\$ 302,696$, and remains significant at $p=0.011$. 


\section{Hypothetical Choice Experiment}

The central challenge in identifying a causal effect of our behavioral parameters on retirement wealth is that they are not randomly assigned. Fundamental to the data-generating process is the possibility that parameters may be endogenous to the outcome or correlated with some omitted variable. In this section, we describe methods and results from an experiment designed to generate further evidence on whether the observed conditional association between our behavioral parameters and retirement savings is causal.

We design an intervention specifically targeted at counteracting EGB and another specifically targeted at counteracting PB on an individual's choice of retirement contributions. We randomly assign the interventions and measure their effects on hypothetical-savings choices. As in prior studies that look at effects on real economic outcomes (Madrian and Shea, 2001; Thaler and Benartzi, 2004; Chetty et al., 2014; Goda et al., 2014), our interventions affect average behavior in the predicted direction. Unlike most prior studies, we have individual-level measures of biases and can test whether the interventions have larger effects among those with more bias than among those with less bias. ${ }^{29}$ A bias-counteracting treatment should affect behavior more among those with bias than it does among those without bias.

That is, we run a regression of the form:

$$
y_{i}=\gamma_{0}+\gamma_{1} X_{i}+\gamma_{2} T_{i}+\gamma_{3} T_{i} X_{i}+u_{i}
$$

where $T_{i}$ is a treatment which may have a direct effect on the outcome $y_{i}$, and an interaction with the bias $X_{i}$. The concern is that $E[u \mid X] \neq E[u]$, in which case regressing outcomes on $X_{i}$ among un-treated subjects will lead to a biased estimate of $\gamma_{1}$. Despite this, (7) in fact does lead to a consistent estimate of $\gamma_{3}$ if $E[u \mid X, T]=E[u \mid X]$. This condition states that the relationship between any omitted variables and the observed measure of bias does not differ between the treatment and control groups. ${ }^{30}$ Thus we require that the treatments narrowly target the biases, and do not

\footnotetext{
${ }^{29}$ A notable exception is Ashraf, Karlan and Yin (2006) who measure time preferences and interact them with a commitment-savings treatment.

${ }^{30}$ Nizalova and Murtazashvili (2014) derive general conditions on the consistency of OLS estimation of such interaction terms. We extend their approach by noting that, as the treatment may at most fully compensate for the bias,
} 
operate through interaction with an omitted variable. The fact that we designed the treatments exactly for this purpose and randomly assigned them gives the condition credibility here.

For this method to provide evidence on the causal relationship between the behavioral parameters and retirement savings it must also be the case that behavior in the hypothetical scenario is correlated with real retirement-saving decisions. The control condition is therefore designed as an ecologically "naturalÕÕ environment. Consistent with this claim, hypothetical contributions in the control condition are strongly positively correlated with actual contributions in employersponsored retirement plans (correlation $r=.46, p<0.001$ ). Furthermore, the effect of the EGB treatments on hypothetical contributions are similar to those documented in Goda et al. (2014), where similar treatments were fielded and changes in real contributions were tracked.

Our outcomes are retirement-savings choices in a hypothetical scenario involving the introduction of a match in an employer-provided retirement plan. The treatments involved varying how the value of the new, hypothetical employer match was displayed (EGB Treatments) and the provision of incentives for completing paperwork necessary for making a contribution change (PB Treatments).

\subsection{Design}

Similar to Goda, Manchester and Sojourner (2014), we delivered the EGB Treatments through an embedded online calculator that displayed the value of the employer match. ${ }^{31}$ The first treatment condition (Balance) showed a projected account balance at retirement based on a hypothetical contribution amount, investment return, and retirement age entered by the respondent, while the second treatment condition (Income) displayed a projected annual income in retirement based on the same assumptions as the first treatment. ${ }^{32}$ The control condition only displayed the annual value

the consistently-estimated $\gamma_{3}$ may also serve as a lower bound on the magnitude of the direct effect of the bias, $\gamma_{1}$. That is, because the interventions may not fully shift behavior of biased types to the behavior of unbiased types $\gamma_{3}$ is a lower bound on the main effect of the behavioral parameter.

${ }^{31}$ The value of the employer match was randomized to be $\$ 0.50$ or $\$ 1.00$ per dollar contributed by the employee. Respondents were required to use the calculator tool at least once before continuing with the survey and they could use it as many times as they liked.

${ }^{32}$ Calculations were based on the annualized value of hypothetical contribution amounts and were assumed to be made annually at the end of each year with no inflation and no intermediate withdrawals from the account. The starting value for the investment return and retirement age was randomized across individuals. Individuals were provided with default investment returns of either $3 \%, 5 \%$, or $7 \%$ with equal probability. Individuals were 
of the employer match based on the hypothetical contribution amount entered by the respondent; this was also displayed in each treatment condition. Survey 1 also included a hypothetical choice scenario involving the introduction of a matching component, but all respondents viewed the same information (i.e., the control condition). Data from Survey 1 serve as part of the control sample.

Images of the calculator survey page are shown in Figures A.6 through A.8 in Appendix A. In the framework of Ambuehl et al. (2014), the EGB Treatments may be considered as simply-framed choice sets relative to the complexly-framed choice set in the control. Goda et al. (2014) reports results from a field experiment among employees at the University of Minnesota where projections like these were delivered via mail along with retirement-planning forms and access to an online calculator was offered via email. There, Income projections increased average individual retirement contributions to employer-sponsored accounts.

The PB Treatment dimension provided incentives to complete the stated 60 minutes of paperwork required for making a contribution change to the hypothetical savings plan as a result of the new match. The first treatment condition (Incentive) informed respondents that they would receive a hypothetical $\$ 50$ payment if they completed the paperwork, while the second treatment condition (Incentives + Deadline) included this same payment, but imposed a deadline that the respondent needed to complete the paperwork within one week in order to earn the payment. ${ }^{33}$ The control condition provided no additional information on the page. The treatments were administered in a fully-crossed design over these two dimensions, resulting in a total of 9 experimental groups (8 treatment groups and 1 pure control group).

We examine the effects of our EGB treatment on the amount that subjects would contribute in response to the hypothetical employer match and our PB treatment on the timing of completing the paperwork required to make any change. Our measure of contributions includes all changes without the burden of completing paperwork. ${ }^{34}$ Our analysis of the effects of our treatment on post-

also provided with default retirement ages of either 65 or 67 with equal probability. The projected annual income in retirement was calculated based on applying an age- and gender-specific annuity factor to the aforementioned projected account balance at retirement (Goda, Manchester and Sojourner, 2014).

${ }^{33}$ Due to ERISA guidelines that prevent direct incentives for changing contribution amounts, we inform respondents that on the paperwork they may elect to make no change in their contributions. Images of the PB Treatments are shown in Figures A.9 through A.11.

${ }^{34}$ If respondents did not choose to make a change, they were offered another opportunity to make a change, where the change was "as simple as clicking a button." 
match contributions control for the respondents' pre-match contributions (before any experimental manipulation was delivered) and its square. We examine the effects of our PB Treatments on the timing of completing the necessary paperwork (i.e., today, later this week, after one week, or never). We use responses from both Survey 1 and Survey 2, which includes a total of 4,081 observations. ${ }^{35}$

\subsection{Results}

We investigate both the overall average treatment effect for each intervention, and heterogeneity in the treatment effect based on underlying behavioral parameters. Magnitudes should be interpreted with caution given that outcomes are hypothetical. ${ }^{36}$ In what follows, we focus on the signs of the key coefficients.

We first examine the effects of the EGB Treatments and heterogeneous effects by Alpha in Table 10. The outcome variable that we examine is post-match hypothetical contributions, controlling for one's pre-match hypothetical contributions. ${ }^{37}$ Column (1) reports the effects of the EGB Treatments on post-match hypothetical contributions. We find that the Income treatment, which presented the value of the employer match as an annual income stream in retirement, had the largest estimated effect on ideal contributions: individuals in the income treatment increased their post-match contributions by $\$ 685$ a year more than the control group. The Balance treatment also had a positive effect on post-match contributions ( $\$ 467$ relative to the control group), but the effect is only marginally significant $(p=0.075) .{ }^{38}$

The next two columns investigate whether there is evidence that the treatments had a heterogeneous effect on those with and without EGB. Column (2) of Table 10 represents Alpha linearly, and Column (3) uses a quadratic functional form for Alpha. Our hypothesis is that the interaction between the treatment effects and Alpha is negative, implying that the treatments have a stronger effect on those with higher levels of EGB. Given the directional prediction of our model, we per-

\footnotetext{
${ }^{35}$ Summary statistics for these outcomes are reported in Appendix Table B.5.

${ }^{36}$ However, behavior in the experiment is highly correlated with actual savings choices. Individuals' pre-match hypothetical contributions are strongly positively correlated with their reported actual level of contributions to employer-sponsored retirement plans (correlation $r=.46, p<0.001$ ).

${ }^{37}$ We also control for $\ln ($ Beta $), \ln ($ Delta $)$, the PB Treatments, the randomized match, and our baseline set of demographic controls.

${ }^{38}$ The direction of these results is consistent with Goda, Manchester and Sojourner (2014). We also cannot reject the null that the treatment effect for the Balance and Income treatments are equivalent.
} 
Table 10: Hypothetical Choice Experiment: Effects of EGB Treatments and Heterogeneity in Alpha on Post-Match Contributions

\begin{tabular}{|c|c|c|c|}
\hline & $(1)$ & $(2)$ & $(3)$ \\
\hline Alpha & $\begin{array}{c}119 \\
(175)\end{array}$ & $\begin{array}{c}174 \\
(213)\end{array}$ & $\begin{array}{c}1,125^{* *} \\
(489)\end{array}$ \\
\hline Alpha $\times$ Alpha & & & $\begin{array}{c}-688^{* *} \\
(347)\end{array}$ \\
\hline Balance Projection & $\begin{array}{l}467^{*} \\
(265)\end{array}$ & $\begin{array}{c}406 \\
(348)\end{array}$ & $\begin{array}{c}510 \\
(367)\end{array}$ \\
\hline Income Projection & $\begin{array}{l}685^{* *} \\
(292)\end{array}$ & $\begin{array}{c}946^{* * *} \\
(361)\end{array}$ & $\begin{array}{c}1,154^{* * *} \\
(380)\end{array}$ \\
\hline Balance Projection $\times$ Alpha & & $\begin{array}{c}107 \\
(358)\end{array}$ & $\begin{array}{l}-487 \\
(714)\end{array}$ \\
\hline Income Projection $\times$ Alpha & & $\begin{array}{l}-455 \\
(336)\end{array}$ & $\begin{array}{c}-1,651^{* *} \\
(733)\end{array}$ \\
\hline Balance Projection $\times$ Alpha $\times$ Alpha & & & $\begin{array}{c}439 \\
(463)\end{array}$ \\
\hline Income Projection $\times$ Alpha $\times$ Alpha & & & $\begin{array}{l}856^{*} \\
(437)\end{array}$ \\
\hline $\ln ($ Beta $)$ & $\begin{array}{c}777 \\
(520)\end{array}$ & $\begin{array}{c}787 \\
(519)\end{array}$ & $\begin{array}{c}823 \\
(523)\end{array}$ \\
\hline $\ln ($ Delta $)$ & $\begin{array}{c}966 \\
(680)\end{array}$ & $\begin{array}{c}968 \\
(679)\end{array}$ & $\begin{array}{c}955 \\
(679)\end{array}$ \\
\hline Controls & Yes & Yes & Yes \\
\hline $\begin{array}{l}\text { Mean of Dep Var } \\
p \text {-value for Heterogeneous }\end{array}$ & 6,040 & 6,040 & 6,040 \\
\hline Treatment Effects & & & \\
\hline Balance & & 0.383 & 0.450 \\
\hline Income & & 0.088 & 0.024 \\
\hline $\operatorname{Adj} R^{2}$ & 0.994 & 0.994 & 0.994 \\
\hline $\mathrm{N}$ & 4,081 & 4,081 & 4,081 \\
\hline
\end{tabular}

Notes: Dependent variable is post-match hypothetical contribution. Controls include indicator variables for survey number, PB Treatment indicator variables, randomized match and quadratic in pre-match hypothetical contribution. Additional controls include indicator variables for female, marital status, number of household members, number of children, race, ethnicity, state of residence, risk aversion category, 10-year age groups, highest level of education, 17 income categories, and 10-year age groups $\times$ income category interactions. ${ }^{*}$ Significant at the $10 \%$ level; $* *$ at the $5 \%$ level; $* * *$ at the $1 \%$ level. 
form a one-sided test of the hypothesis that individuals with accurate understanding of EGB (i.e, Alpha=1) respond less than those with the most EGB (i.e., Alpha=0) for each of the EGB Treatments and report the corresponding $p$-values at the bottom of these columns for each of the EGB Treatments. The interaction reveals an effect of EGB on contributions. In both specifications, we reject the null hypothesis that the Income treatment had the same effect on biased and unbiased types. However, we find no evidence that the Balance treatment had heterogeneous treatment effects by Alpha.

Table 11 reports the effects of the PB Treatments on both the timing and post-match contribution amounts. Overall treatment effects are reported in Column (1), while Columns (2)-(3) report interactions between our treatments and $\ln ($ Beta), and $p$-values analogous to those provided in Table 10. Here, we implement the test by evaluating the effects of each treatment at Beta=1, which represents time-consistent preferences, and Beta $=0.7$, which is commonly used in the literature to represent time-inconsistent preferences.

We find that the Incentive + Deadline treatment had a large, statistically significant effect on timing, increasing the likelihood of making a change this week by 8.3 percentage points $(p<0.01)$. However, the treatment that only involved incentives had a more modest effect of 4.3 percentage points $(p=0.05)$.

The results in Columns (2) and (3) provide only weak evidence that the effects of the PB Treatments are operating through differences in PB. While the point estimates are generally higher for present-biased individuals than for those who are not present biased, the differences are only statistically significant at conventional levels for the Incentive treatment for the quadratic specification. The fact that the stronger treatment did not produce heterogeneous treatment effects is surprising; however, it is consistent with the Deadline providing a focal completion time for time-consistent individuals (Loewenstein and Prelec, 1991).

To summarize, in order to find evidence for a causal association between a behavioral trait and an economic outcome, we test theoretically motivated heterogeneous treatment effects in a naturalistic environment related to the economic outcome under consideration. To our knowledge, this approach used for this purpose is novel. 
Table 11: Hypothetical Choice Experiment: Effects of PB Treatments and Heterogeneity in Beta on Paperwork Timing

\begin{tabular}{|c|c|c|c|}
\hline & $(1)$ & $(2)$ & $(3)$ \\
\hline \multirow[t]{2}{*}{$\ln ($ Beta $)$} & $.115^{* *}$ & $.12^{* *}$ & $.124^{* *}$ \\
\hline & $(.0458)$ & $(.0523)$ & $(.0604)$ \\
\hline \multirow[t]{2}{*}{$\ln ($ Beta $) \times \ln ($ Beta $)$} & & & -.0433 \\
\hline & & & $(.122)$ \\
\hline \multirow[t]{2}{*}{ Incentive } & $.0428^{*}$ & $.0437^{*}$ & .0182 \\
\hline & $(.023)$ & $(.023)$ & $(.0242)$ \\
\hline \multirow[t]{2}{*}{ Inc + Deadline } & $.0829^{* * *}$ & $.0822^{* * *}$ & $.0833^{* * *}$ \\
\hline & $(.022)$ & $(.0221)$ & $(.0227)$ \\
\hline \multirow[t]{2}{*}{ Incentive $\times \ln ($ Beta $)$} & & -.0875 & $-.262^{* * *}$ \\
\hline & & $(.0886)$ & $(.1)$ \\
\hline \multirow[t]{2}{*}{ Inc + Deadline $\times \ln ($ Beta $)$} & & .0489 & .0621 \\
\hline & & $(.0931)$ & $(.11)$ \\
\hline \multirow[t]{2}{*}{ Incentive $\times \ln ($ Beta $) \times \ln ($ Beta $)$} & & & $.859^{* * *}$ \\
\hline & & & $(.212)$ \\
\hline \multirow[t]{2}{*}{ Inc + Deadline $\times \ln ($ Beta $) \times \ln ($ Beta $)$} & & & -.0595 \\
\hline & & & $(.247)$ \\
\hline \multirow[t]{2}{*}{ Alpha } & -.0202 & -.0206 & -.0204 \\
\hline & $(.0153)$ & $(.0153)$ & $(.0153)$ \\
\hline \multirow[t]{2}{*}{$\ln ($ Delta $)$} & $.0687^{*}$ & $.0688^{*}$ & $.0688^{*}$ \\
\hline & $(.0389)$ & $(.0389)$ & $(.0388)$ \\
\hline Controls & Yes & Yes & Yes \\
\hline Mean of Dep Var & .79 & .79 & .79 \\
\hline \multicolumn{4}{|l|}{$p$-value for Heterogeneous } \\
\hline \multicolumn{4}{|l|}{ Treatment Effects } \\
\hline Incentive & & 0.162 & 0.000 \\
\hline Inc+Deadline & & 0.300 & 0.317 \\
\hline Adj $R^{2}$ & 0.077 & 0.077 & 0.079 \\
\hline $\mathrm{N}$ & 4,081 & 4,081 & 4,081 \\
\hline
\end{tabular}

Notes: Dependent variable is indicator variable for making a change within one week. Controls include indicator variables for survey number, EGB Treatment indicator variables, randomized match and quadratic in pre-match hypothetical contribution. Additional controls include indicator variables for female, marital status, number of household members, number of children, race, ethnicity, state of residence, risk aversion category, 10-year age groups, highest level of education, 17 income categories, and 10 -year age groups $\times$ income category interactions. ${ }^{*}$ Significant at the $10 \%$ level; $* *$ at the $5 \%$ level; $* * *$ at the $1 \%$ level. 


\section{Causality and Alternative Explanations}

In this section, we explore some of the remaining threats to causal identification, to the extent possible given data limitations. In particular, we: show the robustness of our results to alternative sets of controls to understand the role of omitted-variable bias; discuss the possibility that our results are driven by reverse causality between wealth and our parameters of interest; and investigate bias from non-classical measurement error in the elicitation of our key behavioral parameters and our main retirement wealth outcome.

\subsection{Omitted-variable bias}

Our main regression specifications already include a rich and flexible set of demographic and behavioral controls. However, there are additional factors which could conceivably affect retirement savings and which could be correlated with our parameters. In addition, alternative ways to measure financial literacy and IQ could impact the measured relationship between our behavioral parameters and retirement savings. We use both other survey items we collected and draw upon

linked responses to prior surveys fielded by other researchers and answered by some of the same respondents.

We first explore the robustness of our results to additional control variables that may explain variation in retirement savings and may be correlated with our parameters of interest in Appendix Table C.3. In Columns (1)-(4), we add additional controls for occupation, employer-provided retirement plan characteristics (match, non-matching contributions), and expected retirement age. The coefficients on our main parameters are not significantly affected by the inclusion of these additional variables and remain strongly significant. A particular concern is that our time-preference elicitation uses preferences over the timing of receipt of money, and so may be confounded by liquidity constraints. In Column (5) we add several controls for liquidity constraints (secured and unsecured debt, home ownership, and housing equity) that were collected in our survey and find no significant effect on the coefficients of our main parameters. We were additionally able to match roughly half of our subjects to FICO scores and subjective health measures asked previously in the online panel, and include these along with the other variables in Columns (6)-(7). Once again 
the coefficients are largely unaffected, but the standard errors increase given the sharply reduced sample. It is thus unlikely that liquidity constraints, variation in health, or job characteristics are driving our results.

We also explore the robustness of our results to alternative measures of financial literacy and IQ in Appendix Table C.4. ${ }^{39}$ We use two alternative measures of financial literacy: a standardized score on the same three questions in our financial literacy inventory the first time the subject answered it in the online panel, and a broader 5-item financial literacy measure from other surveys in the online panel. ${ }^{40}$ While we do not lose sample size with the first alternative, our sample size reduces considerably when we use the broader measure. We also replace our measure of IQ by using IQ measures from previous specialized surveys. Our coefficient estimates are very consistent across specifications, though we lose a great deal of power with the reductions in sample size in Columns (3) and (4).

\subsection{Reverse causality}

While Section 5 yields consistent estimation internally, it is possible that there remains a problem of reverse causality outside the experiment.

If high wealth accumulation led to better understanding of exponential growth or higher levels of Alpha, we would expect to see a strong association between Alpha and income given the high correlation between income and wealth. However, we do not find such evidence. Appendix Figure B.3 shows the predicted effects of each of 17 income categories on Alpha in a regression that includes our other baseline controls and shows a flat relationship between Alpha and these income categories. Moreover, replacing the income categories with a continuous income measure results in a small and statistically insignificant association between income and Alpha $(\mathrm{p}=0.39)$. Finally, when we stratify our sample by income in Table C.2, we continue to find that Alpha has a strong and important effect on retirement wealth among those with more similar levels of income.

Moreover, while we find a significant effect of Alpha on retirement wealth, it is notable that in

\footnotetext{
${ }^{39}$ Summary statistics of the variables used in this section are reported in Appendix Table B.7.

${ }^{40}$ This broader measure includes questions on mortgages and the relationship between interest rates and bond prices.
} 
Table 7 we did not find a significant effect of Alpha on net worth (unlike the time preferences). This is what we would expect, given that EGB requires a long planning horizon to have any substantial impact, and retirement savings are likely to be more long-term than other savings goals. If high Alpha were caused by wealth, however, then one would expect the same relationship with net worth as with retirement savings.

While reverse causality between retirement wealth and Alpha is a plausible source of bias in our findings, most economic research takes preferences such as $\beta$ and $\delta$ as exogenous primitives. However, if retirement wealth were a determinant of long- or short-run discount factors, we would expect to see a strong relationship between $\ln$ (Beta) and $\ln$ (Delta) with income as discussed above. However, Appendix Figures B.4 and B.5 show a flat relationship between income and $\ln ($ Beta) and $\ln ($ Delta). Moreover, the measured correlations between $\ln$ (Beta) and $\ln ($ Delta) and income are close to zero and statistically insignificant $(r=0.02, p=0.31$ for $\ln$ (Beta) and $r=0.03, p=0.16$ for $\ln ($ Delta $))$.

\subsection{Non-classical measurement error}

While we address the issue of classical measurement error in Section 4.6, it is also possible that there is non-classical measurement error which could affect our identification. In particular, if our measured parameters are correlated with measurement error in retirement wealth, then we would have a biased estimate of the relationship. For example, it is conceivable that subjects reporting higher wealth levels would then be "primed" to perform better on our elicitation tasks.

There are several reasons why non-classical measurement error is unlikely to be explaining our results. First, our study design already segregates EGB and time preference elicitations into different surveys, reducing the possibility that one set of questions contaminates responses to another. Second, we repeat the analysis using alternative measures of retirement wealth collected from separate surveys that have no preference elicitations. In particular, we use a separate retirement wealth measure collected for a subsample of our subjects in the ALP Financial Crisis Surveys between 2014-2015. We report this alternative regression in Appendix Table C.5. While our estimation sample is halved, the coefficients on Alpha, $\ln$ (Beta) and $\ln$ (Delta) remain statistically significant 
and in fact increase in magnitude. This evidence suggests that spillovers due to our study design are unlikely to explain our findings.

\subsection{Potential mechanisms}

In this section, we explore potential channels through which EGB and PB may influence retirement wealth accumulation. As described in Section 2, there are many possible channels. For instance, differences in retirement savings for present-biased versus time-inconsistent individuals could be the result of lack of adequate retirement planning, which has been shown to influence retirement wealth (Ameriks, Caplin and Leahy, 2003), or delayed enrollment in retirement savings plans. Differences in retirement savings between those with accurate and biased perceptions of exponential growth could be due to lower levels of contributions or differences in asset allocation.

Table 12 reports the results of regressing various potential outcomes on our bias parameters. ${ }^{41}$ We also include measures of self-awareness (i.e., overconfidence regarding EGB, sophistication, and its interaction with $\ln ($ Beta) ) as they are likely to affect consumers' planning decisions and demand for commitment devices and advice. All columns include our common set of controls, including IQ and financial literacy. We also report the mean levels of the dependent variables in the table.

The first column of Table 12 is a linear regression of the extent to which subjects agree with the statement "I have thought about planning financially for retirement" ( 1 = Hardly at all, $4=$ A lot). Our parameters do not appear to predict this outcome, although it is likely that the tests are underpowered. ${ }^{42}$ In contrast, financial literacy is strongly positively associated with retirement planning attitudes, consistent with past research.

Columns (2) and (3) examine respondents' use of employer-sponsored retirement accounts. We restrict the sample in these columns to those subjects whose employer offers such a plan. In Column (2), we estimate a linear probability model of whether subjects are enrolled in their employer's plan or not. We find no evidence that our measures, including financial literacy and IQ, predict enrollment. One reason this may be the case is if employers implement automatic enrollments and defaults that result in very little association between one's own biases and enrollment decisions.

\footnotetext{
${ }^{41}$ We report the summary statistics of these outcomes in Appendix Table B.6.

${ }^{42}$ The outcome comes from a previous wave of the ALP, and we were only able to match 693 subjects.
} 


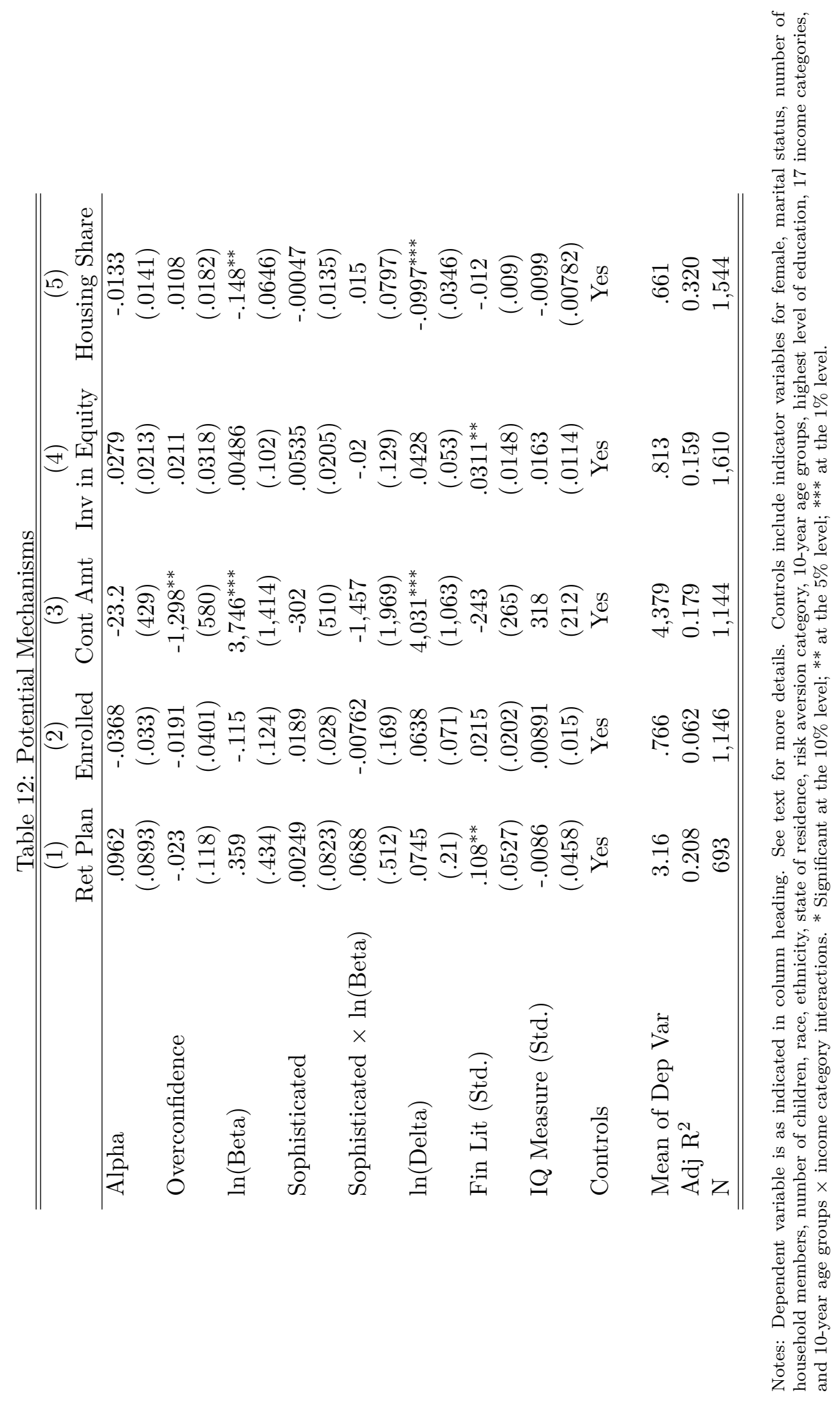


Indeed, a large percentage of those offered plans are enrolled (77 percent).

Column (3) displays the results when current annual contributions to employer-sponsored retirement accounts is the outcome. We find that time preferences significantly predict current contributions: a one standard deviation increase in $\ln$ (Beta) increases current contributions by $\$ 667$, while a one standard deviation increase in $\ln ($ Delta) increases current contributions by $\$ 975$. While Alpha does not predict contributions, overconfidence (which is negatively correlated with Alpha) is a strong predictor: a one standard deviation increase in overconfidence decreases contributions by $\$ 570$.

Finally, we explore whether biased and unbiased individuals invest their assets differently. In Column (4), we regress an indicator for whether the subject has any retirement savings invested in equities. We find no evidence that our behavioral parameters affect this outcome, although financial literacy is significantly positive. ${ }^{43}$ Column (5) restricts the sample to homeowners, and uses housing equity as a share of net assets as the outcome. Present-biased agents are predicted to have more of their savings in illiquid assets such as housing, either because they are sophisticated and demand a greater share of illiquid assets as in Angeletos et al. (2001) or because they are naive and simply spend down their liquid savings. We indeed find that both $\ln$ (Beta) and $\ln$ (Delta) have a negative and statistically significant relationship with the share of assets in housing $(p=0.022$ for $\ln ($ Beta $)$ and $p=0.004$ for $\ln ($ Delta $))$. These results imply that more impatient consumers are indeed using illiquid housing wealth as a vehicle for saving more than patient consumers, which could result in lower levels of retirement wealth accumulation.

Overall, we find evidence that Alpha operates primarily through reduced contributions among those who are overconfident in their ability to understand exponential growth. High short- and long-term discount rates reduce contributions into retirement accounts, and increase the amount invested in illiquid assets, thus resulting in lower levels of retirement wealth accumulation.

\footnotetext{
${ }^{43}$ This finding is consistent with van Rooij et al. (2012), who find that consumers with better financial literacy achieve higher market returns.
} 


\section{Conclusion}

The analysis in this paper reveals a robust association between retirement savings, time preferences, and EGB. We measure the joint distributions of these behavioral parameters, along with selfawareness of these parameters, financial literacy, and an IQ measure in a broad sample and find that these measures are largely distinct from each other. The behavioral parameters each have independent significant and economically meaningful effects on retirement savings after controlling for a rich set of observable characteristics.

We bolster this analysis with two additional strategies to provide rigorous indirect evidence: first, we design a hypothetical choice experiment that delivers treatments designed to mitigate the biases, and, second, we use available data to assess potential threats to a causal interpreta-

tion, including omitted variable bias, non-classical measurement error, and reverse causality. The hypothetical-choice experiment shows that randomly-assigned treatments designed to counteract EGB affected those with greater EGB more strongly than those with less EGB, providing evidence consistent with a causal relationship. Evidence for heterogeneous treatment effects for the PB Treatments were weaker. Our analysis of potential threats to causal interpretation reveals consistent support for the behavioral parameters affecting retirement savings. Evaluation of potential mechanisms points to contribution decisions, rather than asset allocation, as the primary pathway through which the influence occurs.

To give a sense of the economic magnitude of the estimated relationships and to assess the overall implications for retirement savings, we can make a back-of-the-envelope prediction of retirement savings if EGB and PB were entirely counteracted, under the assumption that both are causally related to retirement savings. Using our OLS baseline model as a lower bound and our IV model (that corrects for potential measurement error in bias parameters) as an upper bound, shifting all those who underestimate exponential growth to accurate understanding, and all those we measure as present biased to be time consistent, would increase retirement savings by approximately $12-$ $70 \%$. While the upper bound may seem large, there is substantial room for growth given that over 30 percent of our sample has no retirement savings.

This research has several implications for the behavioral parameters of interest and financial 
outcomes. First, it refines our understanding of the importance of financial literacy in determining such outcomes. We show that EGB, which is a well-defined component of financial literacy, is highly influential for part of the household balance sheet, namely saving decisions with a long time horizon, such as retirement savings. Alternatively, other aspects of financial literacy captured by standard survey measures do not appear related to retirement savings, but are instead related to mortgage size, debt, planning behavior and investment in equities.

Second, we clarify theoretical predictions surrounding EGB and PB. Namely, our empirical findings suggest that, on average, the income and wealth effects of EGB dominate the substitution effect in determining retirement saving decisions. Furthermore, our findings highlight the importance of overconfidence about EGB in explaining why retirement savings contributions are low for many Americans. By finding that long-run and short-run time preferences similarly influence economic decisions, our results are inconsistent with theoretical predictions that PB can lead to higher savings. Additionally, we find support for impatient individuals investing a greater fraction of their wealth in illiquid assets, specifically housing equity, as a vehicle for saving.

Finally, our study shows that the measured behavioral parameters are distinct and unlikely to stem from the same underlying factor. While this has important implications for theory, it also is potentially important for policy and suggests that a single policy tool is unlikely to address any misallocations these biases may cause. While defaults and other alternatives have successfully increased average contributions in many contexts, and retirement income projections may move people toward better decisions when well-implemented, there is no evidence that these fully counteract the effects of EGB and PB on retirement-saving decisions. Furthermore, interventions aimed at increasing self-awareness have not been tested in this context. More evidence regarding the ability of interventions to target biases related to retirement-saving decisions is needed and remains an important direction for future research. 


\section{References}

Almenberg, Johan and Christer Gerdes, "Exponential Growth Bias and Financial Literacy," Applied Economics Letters, 2012, 19, 1693-1696.

Ambuehl, Sandro, B. Douglas Bernheim, and Annamaria Lusardi, "Financial Education, Financial Competence, and Consumer Welfare," NBER Working Paper 20618, National Bureau of Economic Research 2014.

Ameriks, John, Andrew Caplin, and John Leahy, "Wealth Accumulation and the Propensity to Plan," Quarterly Journal of Economics, August 2003, 118 (3), 1007-1047.

_ , _ , , and Tom Tyler, "Measuring Self-Control Problems," American Economic Review, June 2007, $97(3), 966-972$.

Angeletos, George-Marios, David Laibson, Andrea Repetto, Jeremy Tobacman, and Stephen Weinberg, "The Hyperbolic Consumption Model: Calibration, Simulation, and Empirical Evaluation," Journal of Economic Perspectives, 2001, 15 (3), 47-68.

Ashraf, Nava, Dean Karlan, and Wesley Yin, "Tying Odysseus to the Mast: Evidence From a Commitment Savings Product in the Philippines," Quarterly Journal of Economics, 2006, 121 (2), 635-672.

Augenblick, Ned, Muriel Niederle, and Charles Sprenger, "Working Over Time: Dynamic Inconsistency in Real Effort Tasks," Quarterly Journal of Economics, 2015, Forthcoming.

Banks, James, Cormac O'Dea, and Zoë Oldfield, "Cognitive Function, Numeracy, and Retirement Saving Trajectories," Economic Journal, November 2010, 120, F381-F410.

Benzion, Uri, Alon Granot, and Joseph Yagil, "The Valuation of the Exponential Function and Implications for Derived Interest Rates," Economic Letters, 1992, 38, 299-303.

Bernheim, B. Douglas, Jonathan Skinner, and Steven Weinberg, "What Accounts for the Variation in Retirement Wealth among U.S. Households?," American Economic Review, 2001, 91 (4).

Bricker, Jesse, Lisa J. Dettling, Alice Henriques, Joanne W. Hsu, Kevin B. Moore, John Sabelhaus, Jeffrey Thompson, and Richard A. Windle, "Changes in U.S. Family Finances from 2010 to 2013: Evidence from the Survey of Consumer Finances," Federal Reserve Bulletin 4, Board of Governors of the Federal Reserve System 2014.

Brown, Jeffrey and Alessandro Previtero, "Procrastination, Present-Biased Preferences, and Financial Behaviors," August 2014. Working Paper.

Chetty, Raj, John Friedman, Soren Leth-Petersen, Torben Nielsen, and Tore Olsen, "Active vs. Passive Decisions and Crowd-Out in Retirement Savings Accounts: Evidence from Denmark," Quarterly Journal of Economics, 2014, 129 (3), 1141-1219.

Condon, David M. and William Revelle, "The international cognitive ability resource: Development and initial validation of a public-domain measure," Intelligence, 2014, 43, $52-64$.

Diamond, Peter and Botond Köszegi, "Quasi-hyperbolic Discounting and Retirement," Journal of Public Economics, 2003, 87 (9), 1839-1872.

Dohmen, Thomas, Armin Falk, David Huffman, and Uwe Sunde, "Interpreting Time Horizon Effects in Inter-Temporal Choice," February 2012. CESifo Working Paper No. 3750.

Eisenhauer, Joseph G. and Luigi Ventura, "The prevalence of hyperbolic discounting: some European evidence," Applied Economics, 2006, 38, 1223-1234.

Eisenstein, Eric M. and Stephen J. Hoch, "Intuitive Compounding: Framing, Temporal Perspective, and Expertise," Working Paper, Cornell University 2007.

Enzler, Heidi Bruderer, Andreas Diekmann, and Reto Meyer, "Subjective Discount Rates in the General Population and Their Predictive Power for Energy Saving Behavior," Energy Policy, 2014, 65, $524-540$.

Falk, Armin, Anke Becker, Thomas Dohmen, David Huffman, and Uwe Sunde, "An Experimentally-Validated Survey Module of Economic Preferences," February 2014. Working Paper.

Findley, T. Scott and Frank N. Caliendo, "Time Inconsistency and Retirement Choice," February 2015. CESifo Working Paper No. 5208. 
Frederick, Shane, George Loewenstein, and Ted O'Donoghue, "Time Discounting and Time Preference: A Critical Review," Journal of Economic Literature, 2002, 40 (2), 351-401.

Goda, Gopi Shah, Colleen Flaherty Manchester, and Aaron Sojourner, "What Will My Account Really Be Worth? An Experiment on Exponential Growth Bias and Retirement Saving," NBER Working Paper 17927, National Bureau of Economic Research 2012.

_ , _, and _, "What Will My Account Really Be Worth? Experimental Evidence on How Retirement Income Projections Affect Saving," Journal of Public Economics, 2014, 119, 80-92.

Heidhues, Paul and Botond Köszegi, "Futile Attempts at Self-Control," Journal of the European Economic Association, April-May 2009, 7 (2-3), 423-434.

Heutel, Garth, David Bradford, Charles Courtemanche, Patrick McAlvanah, and Christopher Ruhm, "Time Preferences and Consumer Behavior," July 2014. NBER Working Paper 20320.

Hung, Angela A., Andrew M. Parker, and Joanne K. Yoong, "Defining and Measuring Financial Literacy," September 2009. RAND Labor and Population Working Paper Series.

Investment Company Institute, "The U.S. Retirement Market, Fourth Quarter 2014," http://www. ici.org/info/ret_14_q4_data.xls March 2015.

Keren, Gideon, "Cultural Differences in the Misperception of Exponential Growth," Perception and Psychophysics, 1983, 34 (3), 289-293.

Laibson, David, "Golden Eggs and Hyperbolic Discounting," Quarterly Journal of Economics, 1997, 62 (2), 443-477.

_ , "Life-cycle Consumption and Hyperbolic Discount Functions," European Economic Review, 1998, 42 (3), 861-871.

_, Adrea Repetto, and Jeremy Tobacman, "Self-Control and Saving for Retirement," Brookings Papers on Economic Activity, 1998, 1, 91-196.

Levy, Matthew R. and Joshua Tasoff, "Exponential Growth Bias and Lifecycle Consumption," Journal of the European Economic Association, 2015, Forthcoming.

_ and _ , "Exponential-Growth Bias and Overconfidence," March 2015. Working Paper.

_ and _, "Framing Interest: Misperceptions of Consumption and Savings," May 2015. Working Paper.

_ and _ , "Misunderestimation: Exponential-Growth Bias and Time-Varying Returns," July 2015. Working Paper.

Loewenstein, George and Drazen Prelec, "Negative Time Preference," American Economic Review, 1991, 81 (2), 347-352.

Lusardi, Annamaria and Olivia Mitchell, "Financial Literacy and Retirement Preparedness: Evidence and Implications for Financial Education," Business Economics, 2007, 42 (1), 35-44.

- and Olivia S. Mitchell, "Planning and Financial Literacy: How Do Women Fare?," American Economic Review, 2011, 98 (2), 413-417.

_ and _, "The Economic Importance of Financial Literacy: Theory and Evidence," Journal of Economic Literature, March 2014, 52 (1), 5-44.

Madrian, Brigitte C. and Dennis F. Shea, "The Power of Suggestion: Inertia in 401(k) Participation and Savings Behavior," Quarterly Journal of Economics, 2001, 116 (4), 1149-1525.

McKenzie, Craig R.M. and Michael J. Liersch, "Misunderstanding Savings Growth: Implications for Retirement Savings Behavior," Journal of Marketing Research, 2011, 48, S1-S13.

Modigliani, Franco and Richard Brumberg, "Utility Analysis and the Consumption Function: An Interpretation of Cross Section Data," in K.K. Kurihara, ed., Post Keynesian Economics, New Brunswick, NJ: Rutgers University Press, 1954.

Nizalova, Olena Y. and Irina Murtazashvili, "Exogenous Treatment and Endogenous Factors: Vanishing of Omitted Variable Bias on the Interaction Term," Journal of Econometric Methods, September 2014.

O'Donoghue, Ted and Matthew Rabin, "Doing It Now or Later," American Economic Review, March 1999, 89 (1), 103-124. 
_ and _, "Procrastination in Preparing for Retirement," in Henry Aaron, ed., Behavioral Dimensions of Retirement Economics, Brookings Institution Press \& Russell Sage Foundation, 1999, pp. 125-156.

_ and _, "Choice and Procrastination," Quarterly Journal of Economics, 2001, 116 (1), 121-160.

Phelps, Edmund S and Robert A Pollak, "On Second-Best National Saving and Game-Equilibrium Growth," Review of Economic Studies, 1968, 35 (2), 185-199.

Samuelson, Paul, "A Note on Measurement of Utility," Review of Economic Studies, 1937, 116 (40), $155-61$.

Solon, Gary, Steven Haider, and Jeffrey Wooldridge, "What Are We Weighting For?," Journal of Human Resources, 2015, 50 (2), 301-316.

Song, Changcheng, "Financial Illiteracy and Pension Contributions: A Field Experiment on Compound Interest in China," January 2012. Working Paper.

Stango, Victor and Jonathan Zinman, "Exponential Growth Bias and Household Finance," Journal of Finance, December 2009, 64 (6), 2807-2849.

Strotz, Robert H., "Myopia and Inconsistency in Dynamic Utility Maximization," Review of Economic Studies, 1956, 23, 165-180.

Thaler, Richard and Shlomo Benartzi, "Save More Tomorrow: Using Behavioral Economics to Increase Employee Saving," Journal of Political Economy, 2004, 112 (1), S164-S187.

van Rooij, Maarten C.J., Annamaria Lusardi, and Rob J.M. Alessie, "Financial Literacy, Retirement Planning and Household Wealth," Economic Journal, May 2012, 122, 449-478.

Wagenaar, Willem A. and Han Timmers, "The Pond-and-Duckweed Problem: Three Experiments on the Misperception of Exponential Growth," Acta Psychologica, 1979, 43, 239-251.

- and Sabato D. Sagaria, "Misperception of Exponential Growth," Perception and Psychophysics, 1975, $18(6), 416-422$.

Westat, "Data Set Aggregation," Appendix B, U.S. Department of Health and Human Services December 2006.

Zhang, Lin, "Saving and retirement behavior under quasi-hyperbolic discounting," Journal of Economics, 2013, 109 (57-71). 


\section{Appendix A Survey Design}

Table A.1 describes the content of each module contained in the two surveys, which were administered several weeks apart. ${ }^{44}$ We collected data from four cohorts (cohort 1, 2, and 3 from the RAND ALP sample, and 4 from the UAS sample) based on date invited to complete Survey 1. Each cohort subsample was selected at random from the respective survey sample. The number of invitations, completions, and usable responses are described in Table A.2. We extended the sample beyond the ALP because we were able to secure additional funding that was conditional on use of the UAS sample.

We attempted a real-effort time-preference elicitation in addition to our monetary time-preference elicitation. However, the fundamental assumption necessary for identification - that people would be available to do real-effort tasks over the course of three consecutive weeks - largely failed despite requiring this for participation. The free responses indicate that people's choices for engaging in tasks over time was primarily influenced by how busy they were over the subsequent three weeks. We iterated a total of six combination lab and Amazon MTurk pilot experiments to achieve an implementable survey design, but despite this serious attempt "calendar effects" still confounded our final elicitation. In contrast, Augenblick, Niederle and Sprenger (2015) had several design differences that reduced this issue. Since it was a lab experiment they could make it clear to subjects that they needed to participate on multiple occasions. The physical presence of professor-experimenters with student subjects makes this requirement more emphatic relative to our text-based requirement of participating in multiple scheduled surveys, which was highly unusual for ALP participants. Augenblick, Niederle and Sprenger (2015) were also able to pay contingent on full participation but we were not. Even still in Augenblick, Niederle and Sprenger (2015) 12\% of subjects may have exhibited some calendar effects as they dropped over the course of the multiple-week experiment. Our calendar effects were much more severe.

\footnotetext{
${ }^{44}$ We used two different elicitation procedures to identify the time-preference parameters: asking for preferences regarding real-effort tasks for real stakes (Survey 1), and asking for preferences for different sums of money over time in a hypothetical choice paradigm (Survey 2). Despite careful design and piloting, the former appear to have measured calendar effects rather than a behavioral time-preference parameter.
} 
Table A.1: Survey Design

\begin{tabular}{|c|c|c|}
\hline Survey & Module & Description \\
\hline \multirow[t]{5}{*}{1} & Hypothetical Retirement Savings 1 & $\begin{array}{l}\text { Elicits a baseline hypothetical } 401(\mathrm{k}) \text { contribution with and } \\
\text { without a matching contribution from an employer. }\end{array}$ \\
\hline & Background Characteristics 1 & $\begin{array}{l}\text { Includes measures of income, marital status, retirement sav- } \\
\text { ings, non-retirement savings, asset allocation, primary res- } \\
\text { idence value, mortgage, secured debts, unsecured debts, 3- } \\
\text { question financial literacy, unincentivized compounding in- } \\
\text { terest question, self-reported financial knowledge. }\end{array}$ \\
\hline & EG Bias Elicitation & $\begin{array}{l}\text { Elicits subjects' } \alpha \text { and subjects' overconfidence regarding } \\
\text { their ability to accurately compute solutions to questions } \\
\text { that involve compounding interest (incentivized). }\end{array}$ \\
\hline & Real-Effort PB Elicitation & $\begin{array}{l}\text { Elicits subjects' } \beta_{R}, \hat{\beta_{R}}, \delta_{R} \text {. Subjects choose how to allocate } \\
\text { effort over time periods: today, next week, two weeks. Sub- } \\
\text { jects must also predict their future WTA for more effortful } \\
\text { tasks (incentivized). }\end{array}$ \\
\hline & Risk Elicitation & $\begin{array}{l}\text { Elicits subjects' coefficient of absolute risk aversion } r_{A} \text {. Sub- } \\
\text { jects choose one binary lottery from a menu of binary lot- } \\
\text { teries that have a risk-return tradeoff (incentivized). }\end{array}$ \\
\hline \multirow[t]{4}{*}{2} & Hypothetical Retirement Savings 2 & $\begin{array}{l}\text { Subjects are randomized into EGB and PB Treatment } \\
\text { groups, each with two treatment conditions and one control, } \\
\text { for a total of } 3 \mathrm{X} 3 \text { experimental groups. The pure control } \\
\text { condition is identical to Hypothetical Retirement Savings } 1 .\end{array}$ \\
\hline & $\begin{array}{l}\text { Hypothetical Monetary PB Elicita- } \\
\text { tion }\end{array}$ & $\begin{array}{l}\text { Elicits subjects' } \beta_{M}, \hat{\beta_{M}}, \delta_{M} \text {. Subjects choose between two } \\
\text { hypothetical sums of money to be received at two different } \\
\text { points in time. }\end{array}$ \\
\hline & Background Characteristics 2 & $\begin{array}{l}\text { Includes number of children, household wellbeing, self- } \\
\text { reported procrastination tendencies, financial decision } \\
\text { maker, income tax behavior, beliefs about active vs. passive } \\
\text { investment strategies, when they plan to collect retirement } \\
\text { benefits, use of payday loans and bankruptcy }\end{array}$ \\
\hline & Intelligence Test & $\begin{array}{l}\text { Five-question cognitive and reasoning test: three ques- } \\
\text { tions are alpha-numeric/mathematical, one question is on } \\
\text { pattern-matching, and one question is on mental rotation. }\end{array}$ \\
\hline
\end{tabular}


Table A.2: Survey Invitations and Responses

\begin{tabular}{c|cccccc}
\hline Cohort & Survey & Launch Date & Source & Invites & Completions & Usable \\
\hline \multirow{2}{*}{1} & 1 & $8 / 29 / 14$ & & 1500 & 1,008 & 911 \\
& 2 & $10 / 17 / 14$ & & & & \\
2 & 1 & $10 / 24 / 14$ & ALP Panel & 1500 & 692 & 625 \\
& 2 & $11 / 21 / 14$ & & & & \\
3 & 1 & $12 / 1 / 14$ & & 500 & 201 & 178 \\
& 2 & $12 / 29 / 14$ & & & & \\
4 & 1 & $4 / 29 / 15$ & UAS Panel & 1200 & 700 & 603 \\
\hline
\end{tabular}




\section{A.1 Survey Screenshots}

Figure A.1: $\alpha$ Elicitation: Question 1

\section{Hypothetical Investment Questions}

The closer your response is to the correct answer, the more you will earn. You may use whatever approaches you would like to answer these questions.

Each time your response is within $10 \%$ of the correct answer, you will receive $\$ 3$; responses within $25 \%$ will receive \$2; and responses within $50 \%$ will receive $\$ 1$. Responses more than $50 \%$ away from the correct answer will not receive a payment for that question.

Example: An asset has an initial value of $\$ 0$ but its value increases by $\$ 10$ every period. What is the value of the asset after 6 periods?

The correct answer is $\$ 60$. Earnings for different responses are shown below:

\begin{tabular}{|c|c|c|c|c|c|c|c|}
\hline Response & Below $\$ \mathbf{3 0}$ & $\mathbf{\$ 3 0 - \$ 4 4}$ & $\mathbf{\$ 4 5 - \$ 5 3}$ & $\$ 54-\$ 66$ & $\$ 67-\$ 75$ & $\$ 76-\$ 90$ & Above $\$ 90$ \\
\hline \hline Earnings & $\$ 0$ & $\$ 1$ & $\$ 2$ & $\$ 3$ & $\$ 2$ & $\$ 1$ & $\$ 0$ \\
\hline
\end{tabular}

\section{Question 1}

An asset has an initial value of $\$ 100$ and grows at an interest rate of $10 \%$ each period. What is the value of the asset after 20 periods?

\section{$\$$}
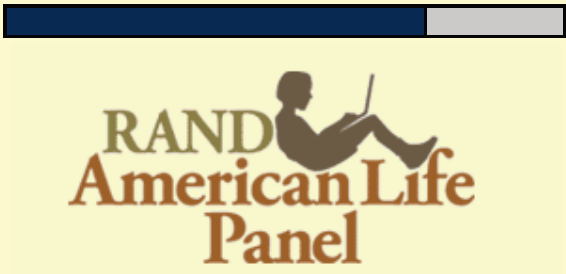
Figure A.2: $\alpha$ Elicitation: Question 2

\section{Hypothetical Investment Questions}

The closer your response is to the correct answer, the more you will earn. You may use whatever approaches you would like to answer these questions.

Each time your response is within $10 \%$ of the correct answer, you will receive $\$ 3$; responses within $25 \%$ will receive \$2; and responses within $50 \%$ will receive $\$ 1$. Responses more than $50 \%$ away from the correct answer will not receive a payment for that question.

Example: An asset has an initial value of $\$ 0$ but its value increases by $\$ 10$ every period. What is the value of the asset after 6 periods?

The correct answer is $\$ 60$. Earnings for different responses are shown below:

\begin{tabular}{|c|c|c|c|c|c|c|c|}
\hline Response & Below \$30 & $\$ 30-\$ 44$ & $\$ 45-\$ 53$ & $\$ 54-\$ 66$ & $\$ 67-\$ 75$ & $\$ 76-\$ 90$ & Above \$90 \\
\hline \hline Earnings & $\$ 0$ & $\$ 1$ & $\$ 2$ & $\$ 3$ & $\$ 2$ & $\$ 1$ & $\$ 0$ \\
\hline
\end{tabular}

\section{Question 2}

An asset has an initial value of $\$ 100$ and grows at an interest rate of $\mathbf{5 \%}$ each period. What is the value of the asset after $\mathbf{5 0}$ periods?

\section{$\$$}
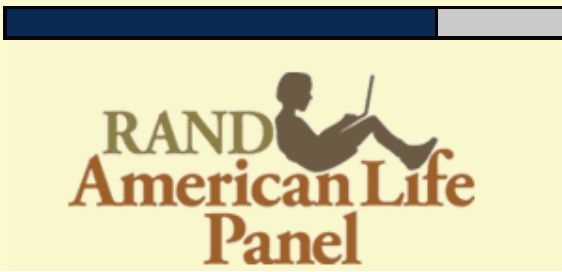
Figure A.3: $\alpha$ Elicitation: Question 3

\section{Hypothetical Investment Questions}

The closer your response is to the correct answer, the more you will earn. You may use whatever approaches you would like to answer these questions.

Each time your response is within $10 \%$ of the correct answer, you will receive \$3; responses within $25 \%$ will receive \$2; and responses within $50 \%$ will receive $\$ 1$. Responses more than $50 \%$ away from the correct answer will not receive a payment for that question.

Example: An asset has an initial value of $\$ 0$ but its value increases by $\$ 10$ every period. What is the value of the asset after 6 periods?

The correct answer is \$60. Earnings for different responses are shown below:

\begin{tabular}{|c|c||c|c|c||c||c||c|}
\hline Response & Below $\$ 30$ & $\$ 30-\$ 44$ & $\$ 45-\$ 53$ & $\$ 54-\$ 66$ & $\$ 67-\$ 75$ & $\$ 76-\$ 90$ & Above $\$ 90$ \\
\hline \hline Earnings & $\$ 0$ & $\$ 1$ & $\$ 2$ & $\$ 3$ & $\$ 2$ & $\$ 1$ & $\$ 0$ \\
\hline
\end{tabular}

\section{Question 3}

An asset has an initial value of $\$ 100$ and grows at an interest rate of $\mathbf{- 2 0 \%}$ in odd periods (starting with the first), and at $\mathbf{2 5 \%}$ in even periods. What is the value of the asset after 24 periods?

$\$$
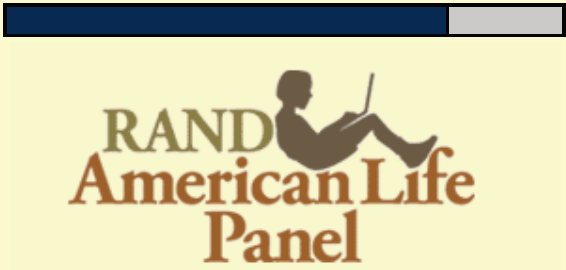
Figure A.4: $\alpha$ Elicitation: Question 4

\section{Hypothetical Investment Questions}

The closer your response is to the correct answer, the more you will earn. You may use whatever approaches you would like to answer these questions.

Each time your response is within $10 \%$ of the correct answer, you will receive $\$ 3$; responses within $25 \%$ will receive \$2; and responses within $50 \%$ will receive $\$ 1$. Responses more than $50 \%$ away from the correct answer will not receive a payment for that question.

Example: An asset has an initial value of $\$ 0$ but its value increases by $\$ 10$ every period. What is the value of the asset after 6 periods?

The correct answer is $\$ 60$. Earnings for different responses are shown below:

\begin{tabular}{|c|c||c|c|c|c||c|c||}
\hline Response & Below $\$ 30$ & $\$ 30-\$ 44$ & $\$ 45-\$ 53$ & $\$ 54-\$ 66$ & $\$ 67-\$ 75$ & $\$ 76-\$ 90$ & Above \$90 \\
\hline \hline Earnings & $\$ 0$ & $\$ 1$ & $\$ 2$ & $\$ 3$ & $\$ 2$ & $\$ 1$ & $\$ 0$ \\
\hline
\end{tabular}

\section{Question 4}

An asset has an initial value of $\$ 100$ and grows at an interest rate of $-\mathbf{4 0} \%$ in odd periods (starting with the first), and at $\mathbf{8 0} \%$ in even periods. What is the value of the asset after 14 periods?

\section{$\$$}
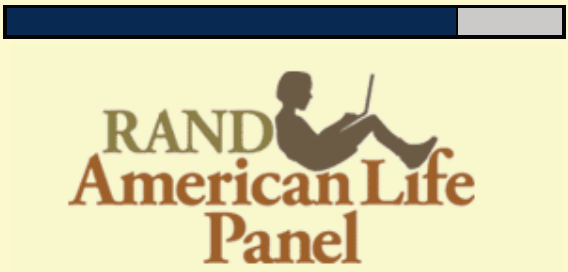
Figure A.5: $\alpha$ Elicitation: Question 5

\section{Hypothetical Investment Questions}

The closer your response is to the correct answer, the more you will earn. You may use whatever approaches you would like to answer these questions.

Each time your response is within $10 \%$ of the correct answer, you will receive \$3; responses within $25 \%$ will receive \$2; and responses within $50 \%$ will receive $\$ 1$. Responses more than $50 \%$ away from the correct answer will not receive a payment for that question.

Example: An asset has an initial value of $\$ 0$ but its value increases by $\$ 10$ every period. What is the value of the asset after 6 periods?

The correct answer is $\$ \mathbf{6 0}$. Earnings for different responses are shown below:

\begin{tabular}{|c|c|c|c|c|c|c|c|}
\hline Response & Below \$30 & $\$ 30-\$ 44$ & $\$ 45-\$ 53$ & $\$ 54-\$ 66$ & $\$ 67-\$ 75$ & $\$ 76-\$ 90$ & Above \$90 \\
\hline \hline Earnings & $\$ 0$ & $\$ 1$ & $\$ 2$ & $\$ 3$ & $\$ 2$ & $\$ 1$ & $\$ 0$ \\
\hline
\end{tabular}

\section{Question 5}

Asset $A$ has an initial value of $\$ 100$, and grows at an interest rate of $\mathbf{8 \%}$ each period. Asset $B$ has an initial value of $\$ X$, and grows at an interest rate of $\mathbf{8 \%}$ each period. Asset A grows for $\mathbf{1 0}$ periods, and Asset B grows for 24 periods. What value of $\mathbf{X}$ will cause the two assets to be of equal value?

$\$$ 
Figure A.6: EGB Treatment Calculator: Control

\section{New Retirement Savings Plan with Matching}

Now suppose your employer just changed the policy and is offering to match your regular contributions. For each $\$ 1.00$ you contribute, your employer will contribute an additional $\$ \mathbf{0 . 5 0}$ to your retirement account. This money will be invested along with your regular contributions.

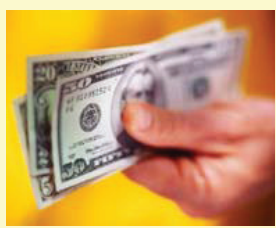

What is the value of this employer match?

Below you can see how much your regular contribution plus the employer match would be worth for the year. Enter a regular contribution amount, frequency of contribution, and click Calculate. Try as many times as you like!

\begin{tabular}{|l|c|c|c|c|}
\hline Contribution Amount & Every year & Every month & $\begin{array}{c}\text { Every two } \\
\text { weeks }\end{array}$ & Every week \\
\hline$\$$ & 0 & 0 & 0 & \\
\hline
\end{tabular}

Calculate

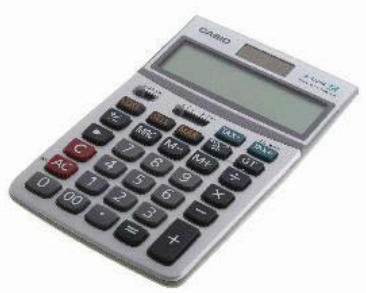

Contribution Calculator Output

\begin{tabular}{|l|l|}
\hline \multicolumn{1}{|l|}{} & \multicolumn{1}{c|}{ Annual Value } \\
\hline Your regular contribution & $\$$ \\
\hline Employer match contribution & $\$$ \\
\hline Total contribution & $\$$ \\
\hline
\end{tabular}


Figure A.7: EGB Treatment Calculator: Balance Treatment

\section{New Retirement Savings Plan with Matching}

Now suppose your employer just changed the policy and is offering to match your regular contributions. For each $\$ 1.00$ you contribute, your employer will contribute an additional $\$ \mathbf{0 . 5 0}$ to your retirement account. This money will be invested along with your regular contributions.

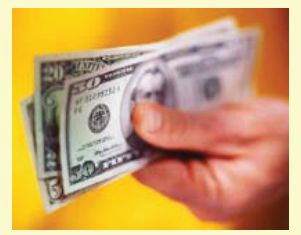

What is the value of this employer match?

Below you can see how much your regular contribution plus the employer match would be worth for the year and the projected balance at retirement. Enter a regular contribution amount, frequency of contribution, projected retirement age, and projected rate of investment return and click Calculate. Try as many times as you like!

\begin{tabular}{|l|c|c|c|c|}
\hline Contribution Amount & Every year & Every month & $\begin{array}{c}\text { Every two } \\
\text { weeks }\end{array}$ & Every week \\
\hline$\$$ & 0 & 0 & 0 & \\
\hline
\end{tabular}

Please choose a projected retirement age between 50 and 80 .

65

Please choose a projected rate of investment return.

7

$\%$

\section{Calculate}

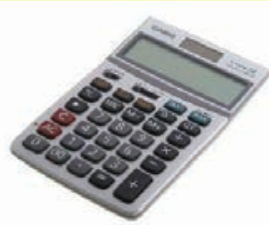

Contribution Calculator Output

\begin{tabular}{|l|l|l|}
\hline & \multicolumn{1}{|c|}{ Annual Value } & $\begin{array}{c}\text { Projected Balance } \\
\text { at Retirement }\end{array}$ \\
\hline $\begin{array}{l}\text { Your regular } \\
\text { contribution }\end{array}$ & $\$$ & $\$$ \\
\hline $\begin{array}{l}\text { Employer match } \\
\text { contribution }\end{array}$ & $\$$ & $\$$ \\
\hline Total contribution & $\$$ & $\$$ \\
\hline
\end{tabular}

The projections are calculated using the contribution amount, projected rate of investment return, projected retirement age you select, and your current age. The values assume contributions are made annually at the end of each year and grow at a constant rate with no inflation and no withdrawals from the account prior to the assumed retirement age. All values are rounded to the nearest dollar. 
Figure A.8: EGB Treatment Calculator: Income Treatment

\section{New Retirement Savings Plan with Matching}

Now suppose your employer just changed the policy and is offering to match your regular contributions. For each $\$ 1.00$ you contribute, your employer will contribute an additional $\$ \mathbf{0 . 5 0}$ to your retirement account. This money will be invested along with your regular contributions.

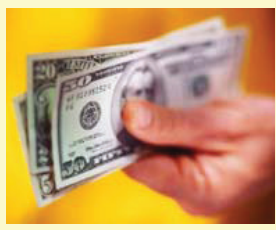

What is the value of this employer match?

Below you can see how much your regular contribution plus the employer match would be worth for the year and the projected annual income in retirement. Enter a regular contribution amount, frequency of contribution, projected retirement age, and projected rate of investment return and click Calculate. Try as many times as you like!

\begin{tabular}{|l|c|c|c|c|}
\hline Contribution Amount & Every year & Every month & $\begin{array}{c}\text { Every two } \\
\text { weeks }\end{array}$ & Every week \\
\hline$\$$ & 0 & 0 & 0 & \\
\hline
\end{tabular}

Please choose a projected retirement age between 50 and 80 .

65

Please choose a projected rate of investment return.

7

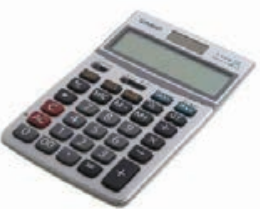

Contribution Calculator Output

\begin{tabular}{|c|c|c|}
\hline & Annual Value & $\begin{array}{c}\text { Projected Annual } \\
\text { Income in Retirement }\end{array}$ \\
\hline $\begin{array}{l}\text { Your regular } \\
\text { contribution }\end{array}$ & $\$$ & $\$$ \\
\hline $\begin{array}{l}\text { Employer match } \\
\text { contribution }\end{array}$ & $\$$ & $\$$ \\
\hline Total contribution & $\$$ & $\$$ \\
\hline
\end{tabular}

The projections are calculated using the contribution amount, projected rate of investment return, projected retirement age you select, and your current age. The values assume contributions are made annually at the end of each year and grow at a constant rate with no inflation and no withdrawals from the account prior to the assumed retirement age, and that the projected balance at retirement is used to purchase a single life annuity based on current annuity rates, your gender, and your projected retirement age. All values are rounded to the nearest dollar. 
Figure A.9: PB Treatment: Control

\section{New Retirement Savings Plan with Matching}

Under your employer's prior plan (i.e. no match), you stated you would contribute $\$ 1000$ every year.

You may wish to respond to the new matching contribution from your employer by changing your contributions. In order to enroll or change your contribution, you must contact an HR administrator and fill out several forms. You will specify an amount to contribute each year and designate how your contributions will be divided among investment options, including lifecycle funds that target a specific retirement date, index funds that track major asset classes, or mutual funds that pursue various investment strategies.

This entire paperwork process will take approximately 60 minutes of your time. At the end of completing the paperwork, you can elect to make a change in your contributions, or elect to continue with your prior contribution amount by selecting, "no change."

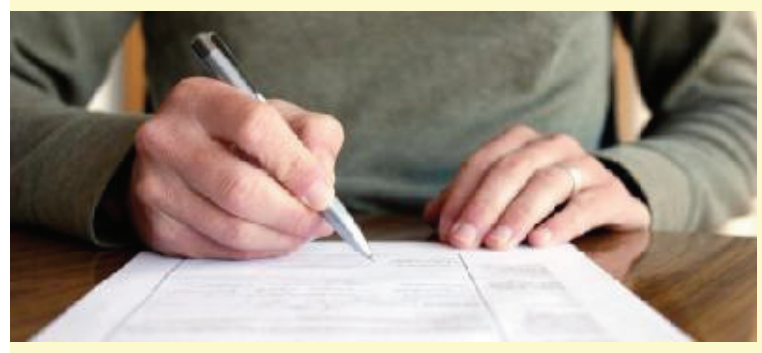

When answering the following questions, please consider the actual constraints you face in your life, including financial (i.e. income, savings, debt obligations) and time (i.e. all the things you have to do at work that take time).

Based on the change to your employer's match policy, would you choose to go through the paperwork process? If so, when would you do so?

No

Yes. I'd do it today.

Yes. Not today, but within a week.

Yes. Not within a week, but some time in the future. 
Figure A.10: PB Treatment: Incentive Treatment

\section{New Retirement Savings Plan with Matching}

Under your employer's prior plan (i.e. no match), you stated you would contribute $\$ 1000$ every year.

You may wish to respond to the new matching contribution from your employer by changing your contributions. In order to enroll or change your contribution, you must contact an HR administrator and fill out several forms. You will specify an amount to contribute each year and designate how your contributions will be divided among investment options, including lifecycle funds that target a specific retirement date, index funds that track major asset classes, or mutual funds that pursue various investment strategies.

This entire paperwork process will take approximately 60 minutes of your time. At the end of completing the paperwork, you can elect to make a change in your contributions, or elect to continue with your prior contribution amount by selecting, "no change."

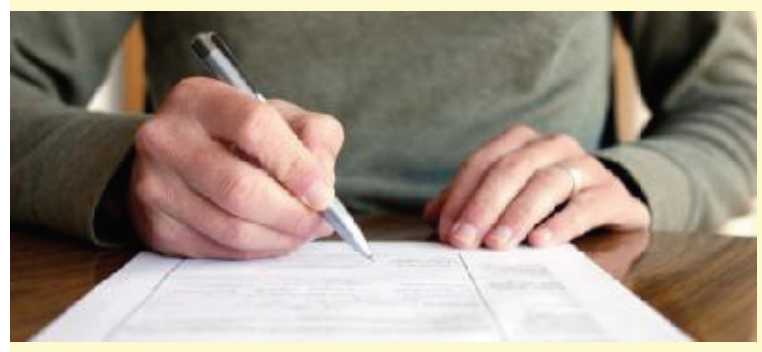

Your employer's new policy includes an additional bonus: if you complete the paperwork, you will get an immediate $\$ \mathbf{5 0}$ in cash to help compensate you for the hassle of completing the paperwork.

When answering the following questions, please consider the actual constraints you face in your life, including financial (i.e. income, savings, debt obligations) and time (i.e. all the things you have to do at work that take time).

Based on the change to your employer's match policy, would you choose to go through the paperwork process? If so, when would you do so?

No

Yes. I'd do it today.

Yes. Not today, but within a week.

Yes. Not within a week, but some time in the future. 
Figure A.11: PB Treatment: Deadline + Incentive Treatment

\section{New Retirement Savings Plan with Matching}

Under your employer's prior plan (i.e. no match), you stated you would contribute $\$ 1000$ every year.

You may wish to respond to the new matching contribution from your employer by changing your contributions. In order to enroll or change your contribution, you must contact an HR administrator and fill out several forms. You will specify an amount to contribute each year and designate how your contributions will be divided among investment options, including lifecycle funds that target a specific retirement date, index funds that track major asset classes, or mutual funds that pursue various investment strategies.

This entire paperwork process will take approximately 60 minutes of your time. At the end of completing the paperwork, you can elect to make a change in your contributions, or elect to continue with your prior contribution amount by selecting, "no change."

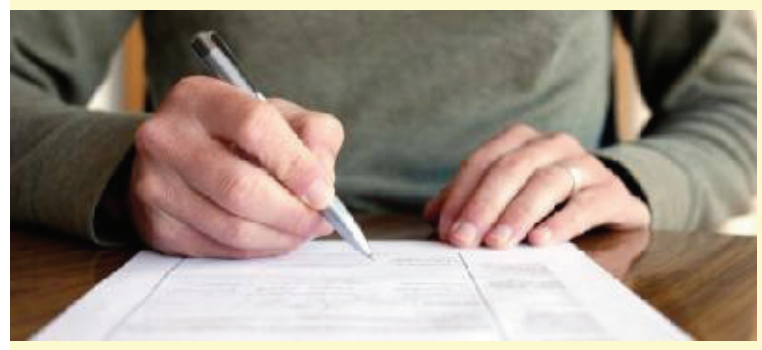

Your employer's new policy includes an additional bonus: if you complete the paperwork within a week, you will get an immediate $\$ \mathbf{5 0}$ in cash to help compensate you for the hassle of completing the paperwork. If you complete the paperwork after a week, you will not get the $\$ 50$ payment.

When answering the following questions, please consider the actual constraints you face in your life, including financial (i.e. income, savings, debt obligations) and time (i.e. all the things you have to do at work that take time).

Based on the change to your employer's match policy, would you choose to go through the paperwork process? If so, when would you do so?

\section{No}

Yes. I'd do it today.

Yes. Not today, but within a week.

Yes. Not within a week, but some time in the future. 
Appendix B Sample Selection, Additional Descriptive Statistics 
Table B.1: Demographic Controls, All Invitees

\begin{tabular}{|c|c|c|}
\hline & Non-Responder/Incomplete & Estimation Sample \\
\hline \multirow[t]{2}{*}{ Age } & 48.60 & 51.47 \\
\hline & $(15.78)$ & $(15.16)$ \\
\hline \multirow[t]{2}{*}{ Female } & 0.550 & 0.551 \\
\hline & $(0.487)$ & $(0.498)$ \\
\hline \multirow[t]{2}{*}{ Family Income } & 60589.9 & 65688.5 \\
\hline & $(46764.8)$ & $(47368.2)$ \\
\hline \multicolumn{3}{|l|}{ Education } \\
\hline \multirow[t]{2}{*}{ HS or Less } & 0.235 & 0.189 \\
\hline & $(0.424)$ & $(0.391)$ \\
\hline \multirow[t]{2}{*}{ Some College } & 0.247 & 0.239 \\
\hline & $(0.432)$ & $(0.427)$ \\
\hline \multirow[t]{2}{*}{ Assoc Degree } & 0.121 & 0.122 \\
\hline & $(0.326)$ & $(0.328)$ \\
\hline \multirow[t]{2}{*}{ BA/BS Degree } & 0.201 & 0.267 \\
\hline & $(0.401)$ & $(0.443)$ \\
\hline \multirow[t]{2}{*}{ Post BA/BS } & 0.140 & 0.183 \\
\hline & $(0.347)$ & $(0.387)$ \\
\hline \multicolumn{3}{|l|}{ Marital Status } \\
\hline \multirow[t]{2}{*}{ Married/Partnered } & 0.532 & 0.600 \\
\hline & $(0.499)$ & $(0.490)$ \\
\hline \multirow[t]{2}{*}{ Separated } & 0.0378 & 0.0229 \\
\hline & $(0.191)$ & $(0.150)$ \\
\hline \multirow[t]{2}{*}{ Divorced } & 0.135 & 0.144 \\
\hline & $(0.342)$ & $(0.351)$ \\
\hline \multirow[t]{2}{*}{ Widowed } & 0.0472 & 0.0492 \\
\hline & $(0.212)$ & $(0.216)$ \\
\hline \multirow[t]{2}{*}{ Never Married } & 0.203 & 0.184 \\
\hline & $(0.402)$ & $(0.387)$ \\
\hline \multirow[t]{2}{*}{ Add'l HH Members } & 1.230 & 0.997 \\
\hline & $(1.145)$ & $(1.098)$ \\
\hline \multirow[t]{2}{*}{ Hispanic/Latino } & 550.7 & 0.130 \\
\hline & $(2281.0)$ & $(0.337)$ \\
\hline \multicolumn{3}{|l|}{ Race } \\
\hline \multirow[t]{2}{*}{ White/Caucasian } & 0.682 & 0.791 \\
\hline & $(0.466)$ & $(0.407)$ \\
\hline \multirow[t]{2}{*}{ Black/African American } & 0.135 & 0.112 \\
\hline & $(0.342)$ & $(0.316)$ \\
\hline \multirow[t]{2}{*}{ American Indian } & 0.0115 & 0.0108 \\
\hline & $(0.107)$ & $(0.103)$ \\
\hline \multirow[t]{2}{*}{ Asian } & 0.0288 & 0.0311 \\
\hline & $(0.167)$ & $(0.174)$ \\
\hline \multirow[t]{2}{*}{ Other } & 0.0863 & 0.0544 \\
\hline & $(0.281)$ & $(0.227)$ \\
\hline \multirow[t]{2}{*}{ Missing } & 0.0559 & 0.000432 \\
\hline & $(0.230)$ & $(0.0208)$ \\
\hline $\mathrm{N}$ & 2434 & 2317 \\
\hline
\end{tabular}

Note: Family income is midpoint of 17 income categories. Non-responder/incomplete include 1850 invitees who did not begin the survey, 300 who began but did not complete, and 284 who completed but are missing data. 


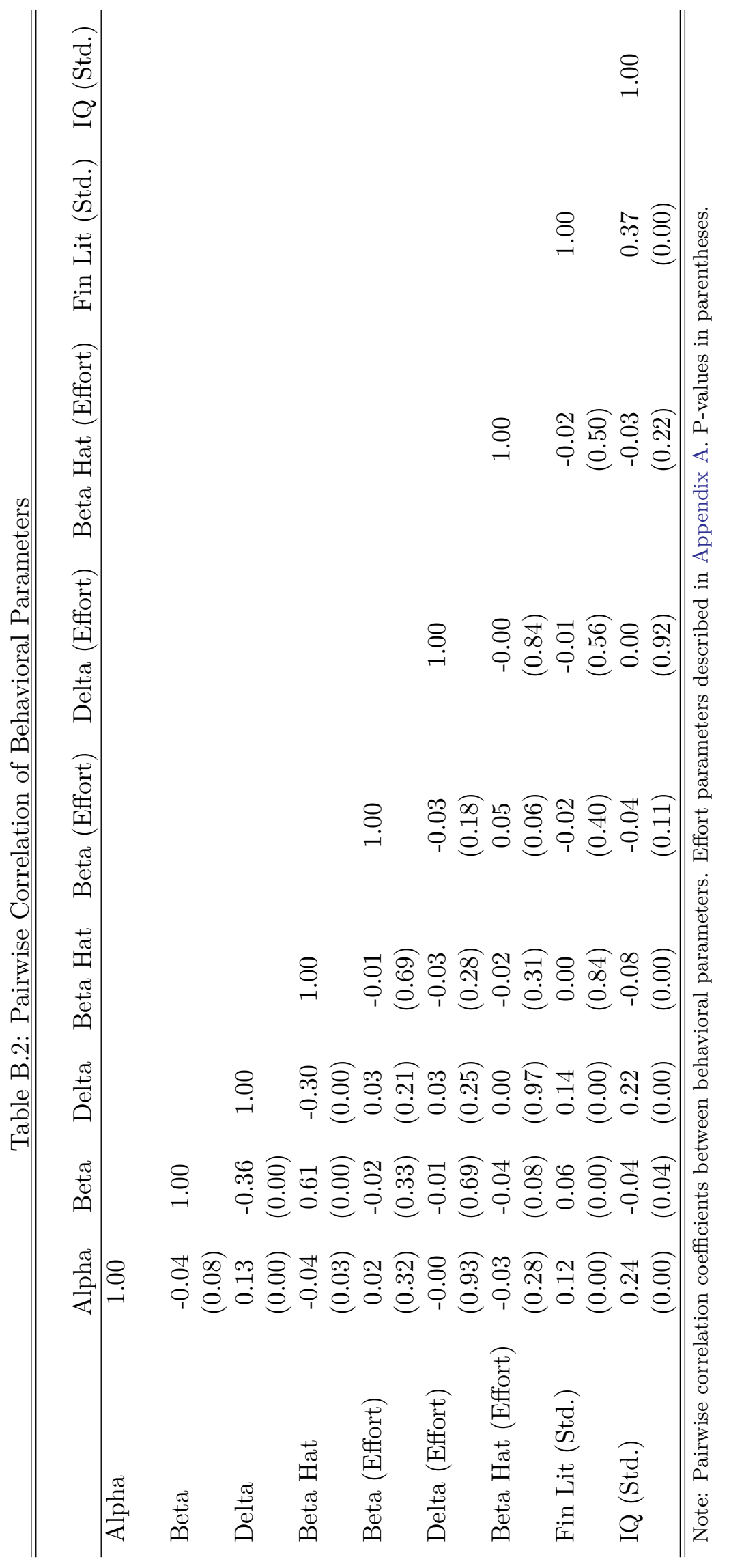




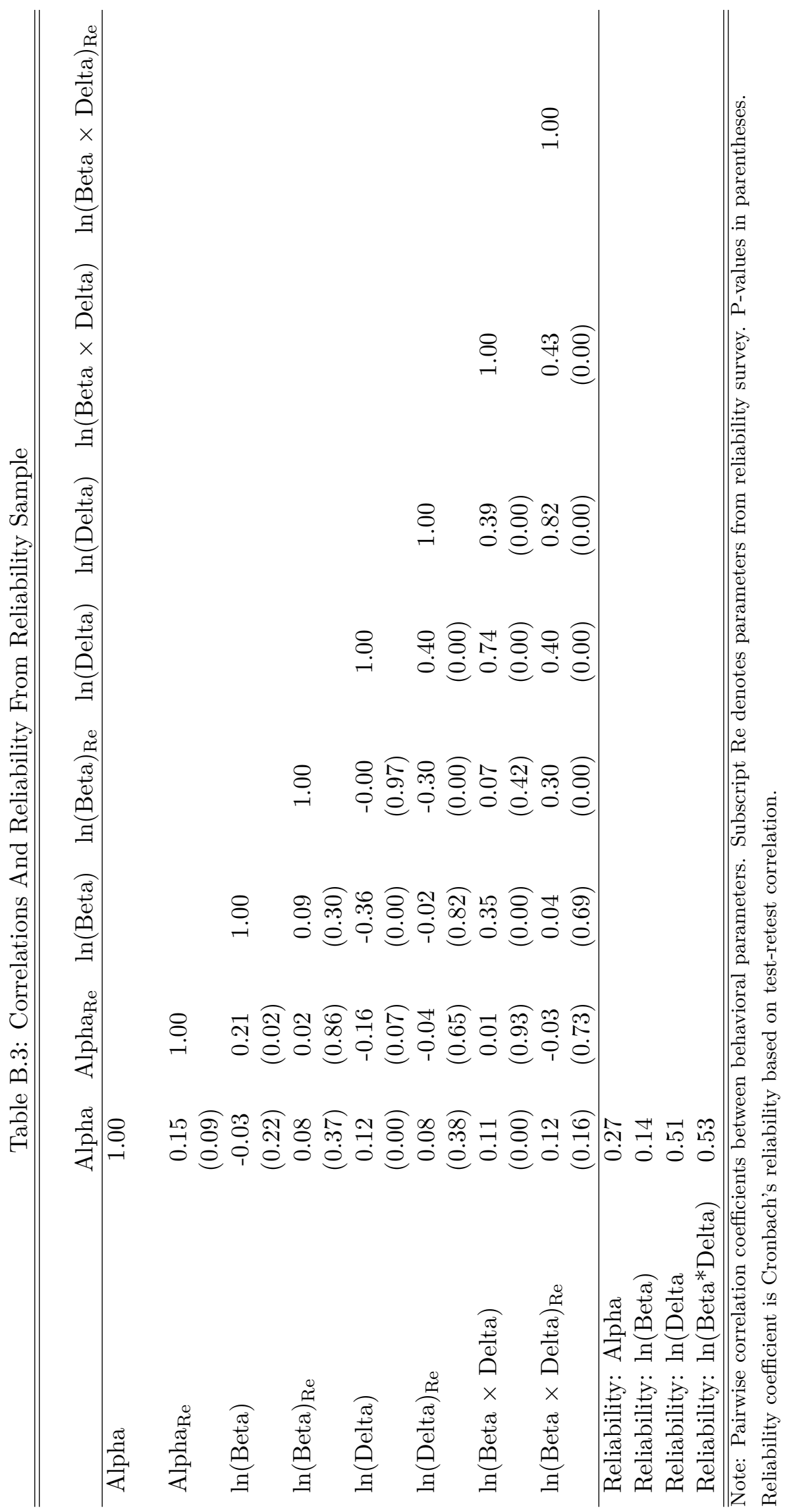


Table B.4: Summary Statistics for Instruments

\begin{tabular}{lcccc}
\hline \hline & mean & sd & $\min$ & $\max$ \\
\hline $\begin{array}{l}\text { High Stakes (Alpha) } \\
\text { Tool Use - Alpha Elicition }\end{array}$ & 0.029 & 0.168 & 0.000 & 1.000 \\
Pencil-and-Paper & & & & \\
Calculator & 0.568 & 0.495 & 0.000 & 1.000 \\
Spreadsheet & 0.382 & 0.486 & 0.000 & 1.000 \\
Other Tool & 0.056 & 0.229 & 0.000 & 1.000 \\
Received Help & 0.033 & 0.179 & 0.000 & 1.000 \\
SPQs & 0.317 & 0.465 & 0.000 & 1.000 \\
Follow Plans & & & & \\
Postpone & 3.531 & 0.925 & 1.000 & 5.000 \\
Patient & 2.572 & 1.130 & 1.000 & 5.000 \\
\hline \hline & 3.787 & 0.895 & 1.000 & 5.000 \\
Notes: SPQs scored on 5-point Likert scale (1= Strongly Disagree, $5=$ Strongly Agree). \\
Question text for SPQs is: Follow Plans, I do things when I originally planned to do \\
them; Postpone, I tend to postpone tasks even when I know it would be better to do \\
them right away; Patient, I am willing to give up something that is beneficial today \\
in order to receive a larger reward in the future.
\end{tabular}

Table B.5: Summary Statistics for Hypothetical Choice Experiment

\begin{tabular}{lcccc}
\hline \hline & Survey 1 & Control & Balance Projection & Income Projection \\
\hline Pre-Match Contribution & 3101.4 & 2850.8 & 3000.9 & 2984.9 \\
& $(3591.0)$ & $(3588.5)$ & $(3602.6)$ & $(3660.6)$ \\
Post-Match Contribution & 4244.3 & 3796.4 & 4288.7 & 4302.9 \\
& $(4800.9)$ & $(4495.2)$ & $(4866.9)$ & $(4920.1)$ \\
Paperwork This Week & 0.770 & 0.816 & 0.810 & 0.830 \\
& $(0.421)$ & $(0.388)$ & $(0.393)$ & $(0.376)$ \\
N & 2317 & 592 & 574 & 589 \\
\hline \hline
\end{tabular}

Notes: Outcomes are from hypothetical choice exercises in Surveys 1 and 2. Contributions Winsorized at $1 \%$ level. 
Table B.6: Summary Statistics for Mechanisms

\begin{tabular}{lcccc}
\hline \hline & mean & sd & $\min$ & $\max$ \\
\hline Planning & & & & \\
Thought about Planning & 3.160 & 0.514 & 1.000 & 4.000 \\
Confident about Planning & 2.926 & 0.706 & 1.000 & 5.000 \\
Employer Retirement Plan & & & & \\
Enrolled in Employer Plan & 0.766 & 0.298 & 0.000 & 1.000 \\
Annual Contribution & $4,378.555$ & $4,984.089$ & 0.000 & $1.00 \mathrm{e}+05$ \\
Asset Allocation & & & & \\
Inv Ret Savings in Equity & 0.813 & 0.325 & 0.000 & 1.000 \\
Housing \% of Assets & 0.661 & 0.228 & 0.000 & 1.000 \\
\hline \hline
\end{tabular}

Notes: Thought about Planning scored on 4-point Likert scale $(1=$ Not at all, $4=$ A great deal); Confident about Planning on 5-point scale ( $1=$ Strongly disagree, $5=$ Strongly Agree).

Figure B.1: Relationship between EGB and IQ

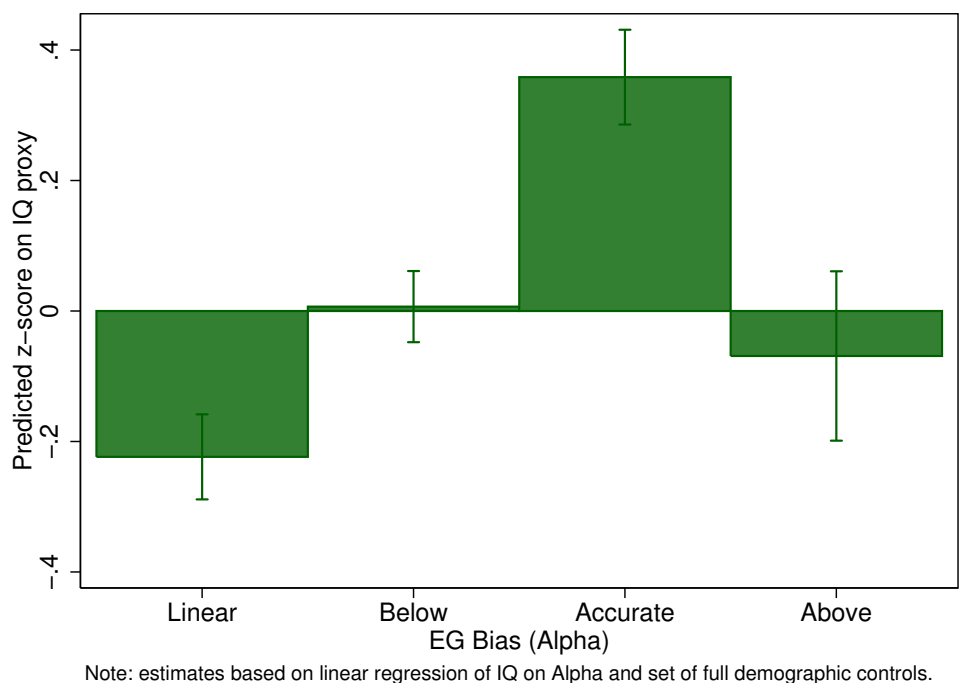


Table B.7: Summary Statistics for Additional Robustness Checks

\begin{tabular}{lccccc}
\hline \hline & mean & sd & min & max & count \\
\hline Financial Literacy / IQ & & & & & \\
First Fin Lit (3Q - Std) & 0.009 & 0.994 & -3.131 & 0.806 & 2,317 \\
First Fin Lit (5Q - Std) & -0.003 & 1.005 & -3.124 & 1.363 & 706 \\
IQ - Number & 531.922 & 23.298 & 411.600 & 568.000 & 1,287 \\
IQ - Picture & 555.995 & 23.587 & 476.000 & 602.000 & 1,287 \\
IQ - Analogy & 523.708 & 23.168 & 435.000 & 560.000 & 1,287 \\
Retirement Characteristics & & & & & \\
Empl. Offers Ret. Plan & 0.495 & 0.500 & 0.000 & 1.000 & 2,316 \\
Empl. Offers Match & 0.303 & 0.460 & 0.000 & 1.000 & 2,316 \\
Empl. Offers Non-Match Contr. & 0.174 & 0.379 & 0.000 & 1.000 & 2,316 \\
Expected Ret Age & 75.243 & 15.488 & 50.000 & 99.000 & 2,317 \\
Wealth Measures & & & & & \\
Retirement Savings (ALP FC) & $1.43 \mathrm{e}+05$ & $2.80 \mathrm{e}+05$ & 0.000 & $1.50 \mathrm{e}+06$ & 1,091 \\
Housing Equity & $1.60 \mathrm{e}+05$ & $1.01 \mathrm{e}+06$ & $-2.25 \mathrm{e}+05$ & $3.43 \mathrm{e}+07$ & 2,317 \\
FICO & & & & & \\
FICO Score & 712.355 & 107.539 & 475.000 & 825.000 & 862 \\
Don't Know Score & 0.241 & 0.428 & 0.000 & 1.000 & 1,136 \\
Subj. Health Measures & & & & & \\
RateHealthIndex & 2.497 & 0.879 & 1.000 & 5.000 & 1,388 \\
Prob(Live to 75) & 62.686 & 23.952 & 0.000 & 100.000 & 1,211 \\
Prob(Live to 85) & 45.824 & 25.034 & 0.000 & 100.000 & 1,368 \\
\hline \hline
\end{tabular}

Notes: First Fin Lit are normalized performance on first attempt on the 3-item and 5-item financial literacy batteries across any linkable survey, respectively. IQ measures are scores on Number Series, Picture Vocabulary, and Verbal Analogy modules of ALP Well Being Survey 286. Retirement characteristics are dummies for whether employer offers: any retirement plan, a matching contribution, and a non-matching contribution, as well as expected retirement age. ALP FC wealth measures are matched from ALP "Effects of the Financial Crisis" surveys, matching to a respondent's most recent answer. FICO score is midpoint of 6-bin response if known, or indicator if respondent does not know. Subjective health measures are self-rated overall health and probability of living to indicated age, matched from same FC surveys. 
Figure B.2: Relationship between EGB and Financial Literacy

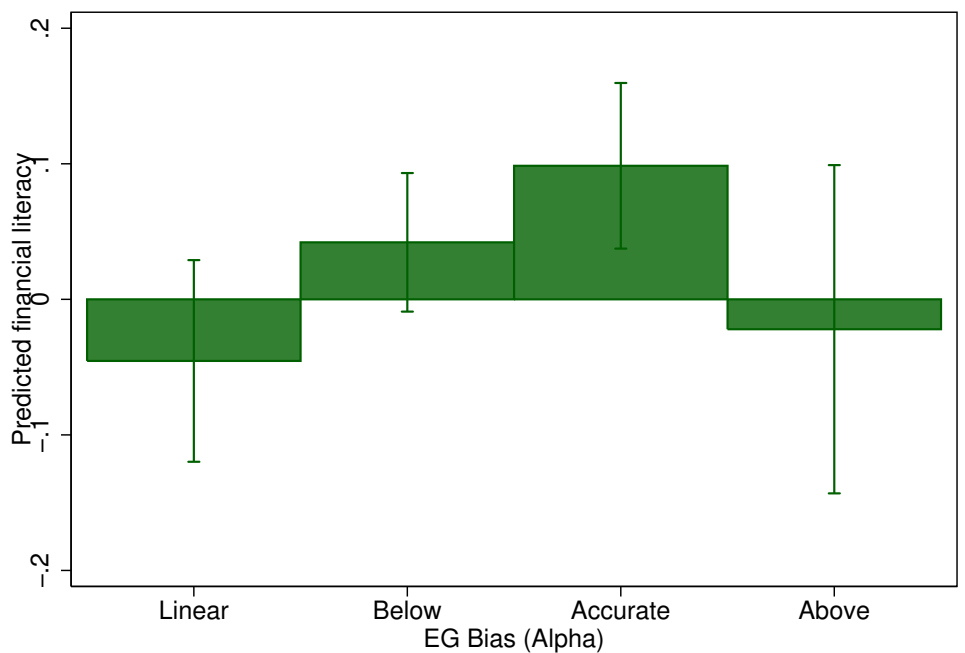

Note: estimates based on linear regression of financial literacy on Alpha and set of full demographic controls.

Figure B.3: Relationship Between Income and Alpha

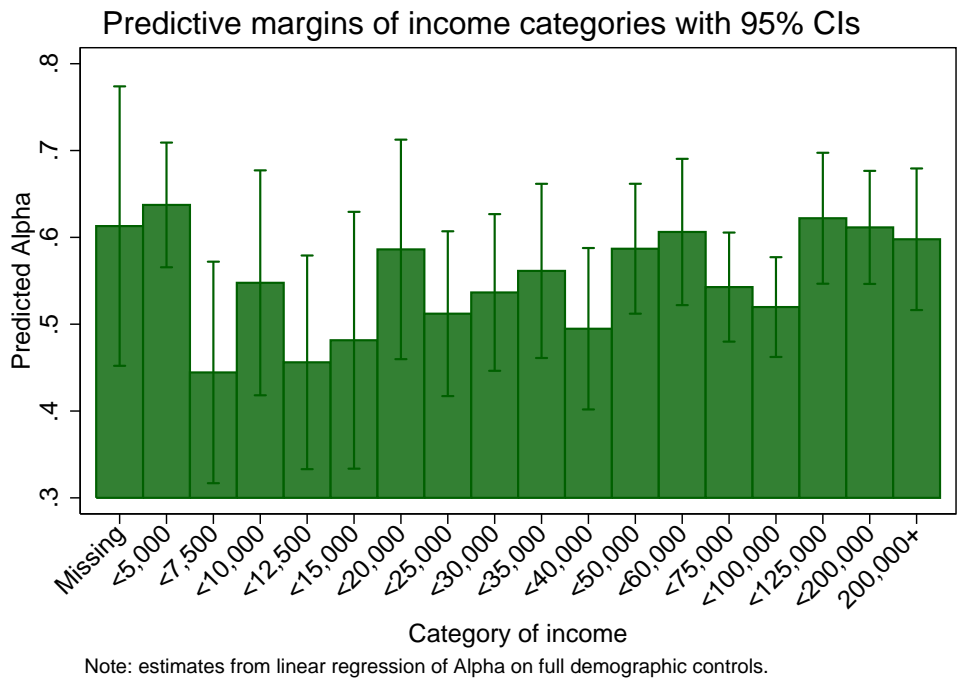


Figure B.4: Relationship Between Income and Beta

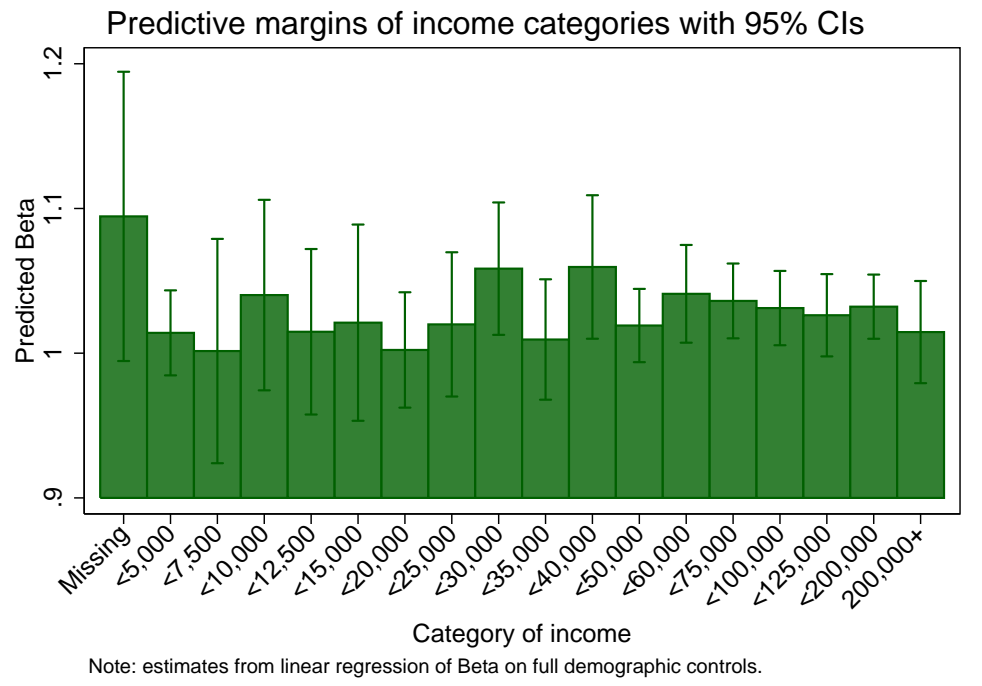

Figure B.5: Relationship Between Income and Delta

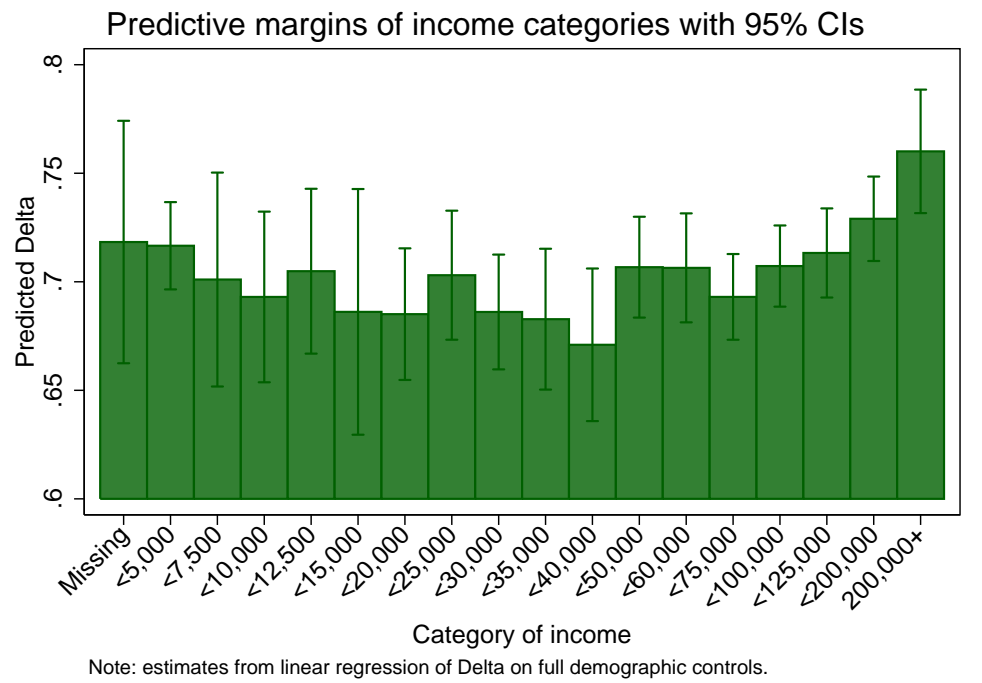


Appendix C Additional Regression Tables 


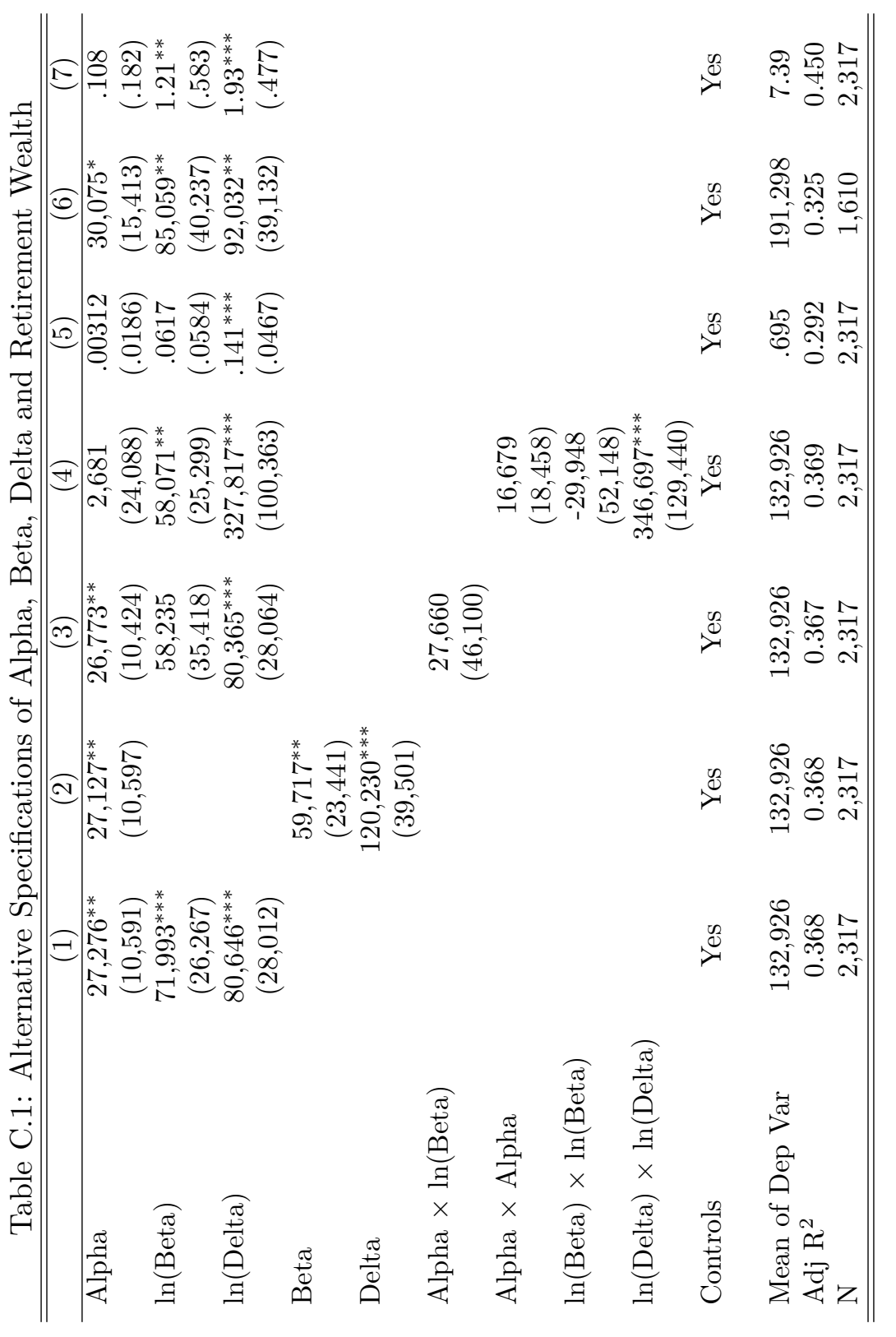

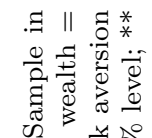

की

进.

उ

氜 풀

要

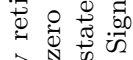

的

若苦总

究要

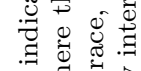

. 2 ह

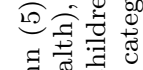

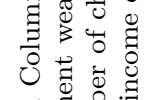

켱 요 $\times$

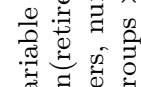

車

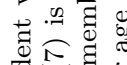

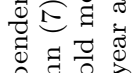

Фे

월

उ.

过

密 苞

赵苛䨔

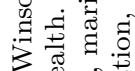

.

ङु氜

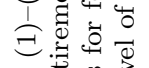

氠造

产 000

0 先

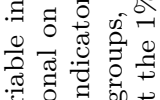

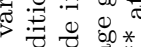

政

过

वैं

四

هิ

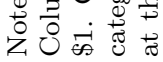




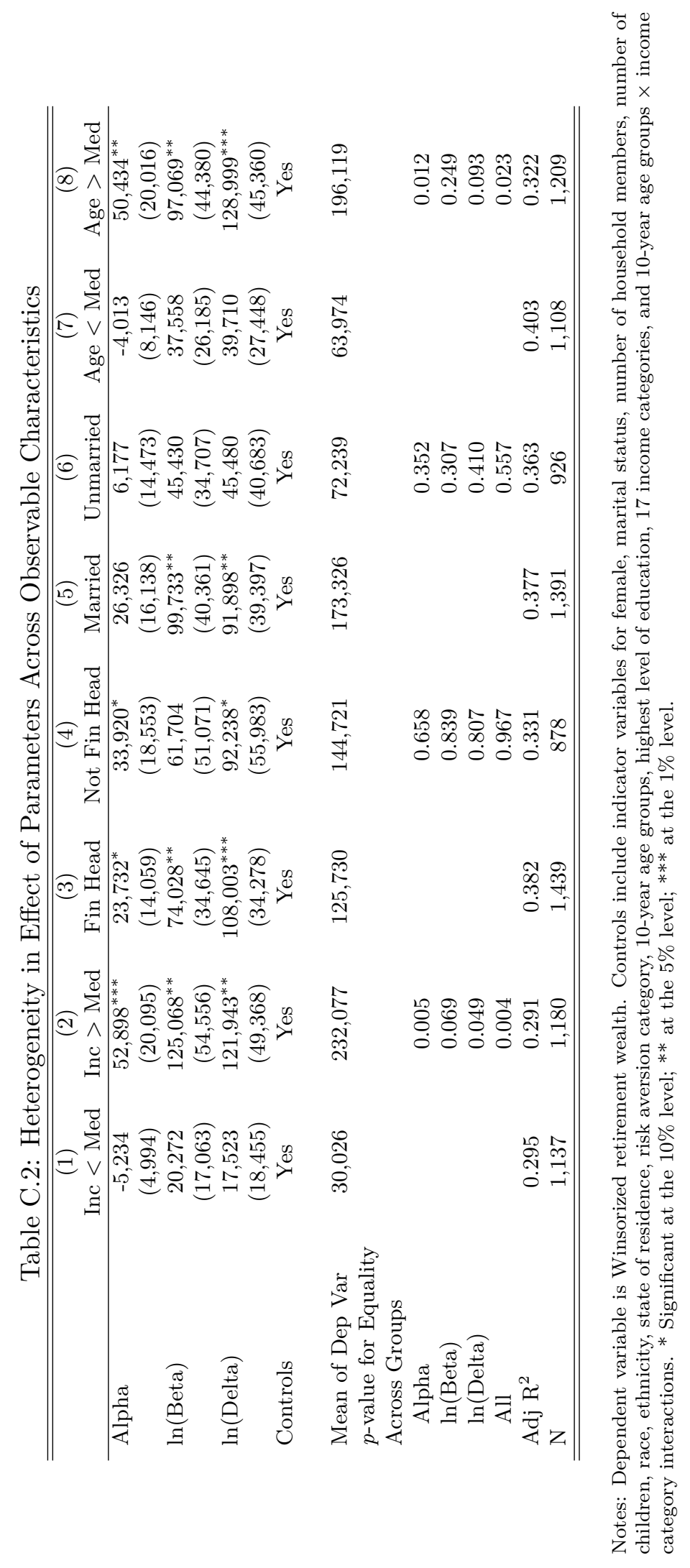




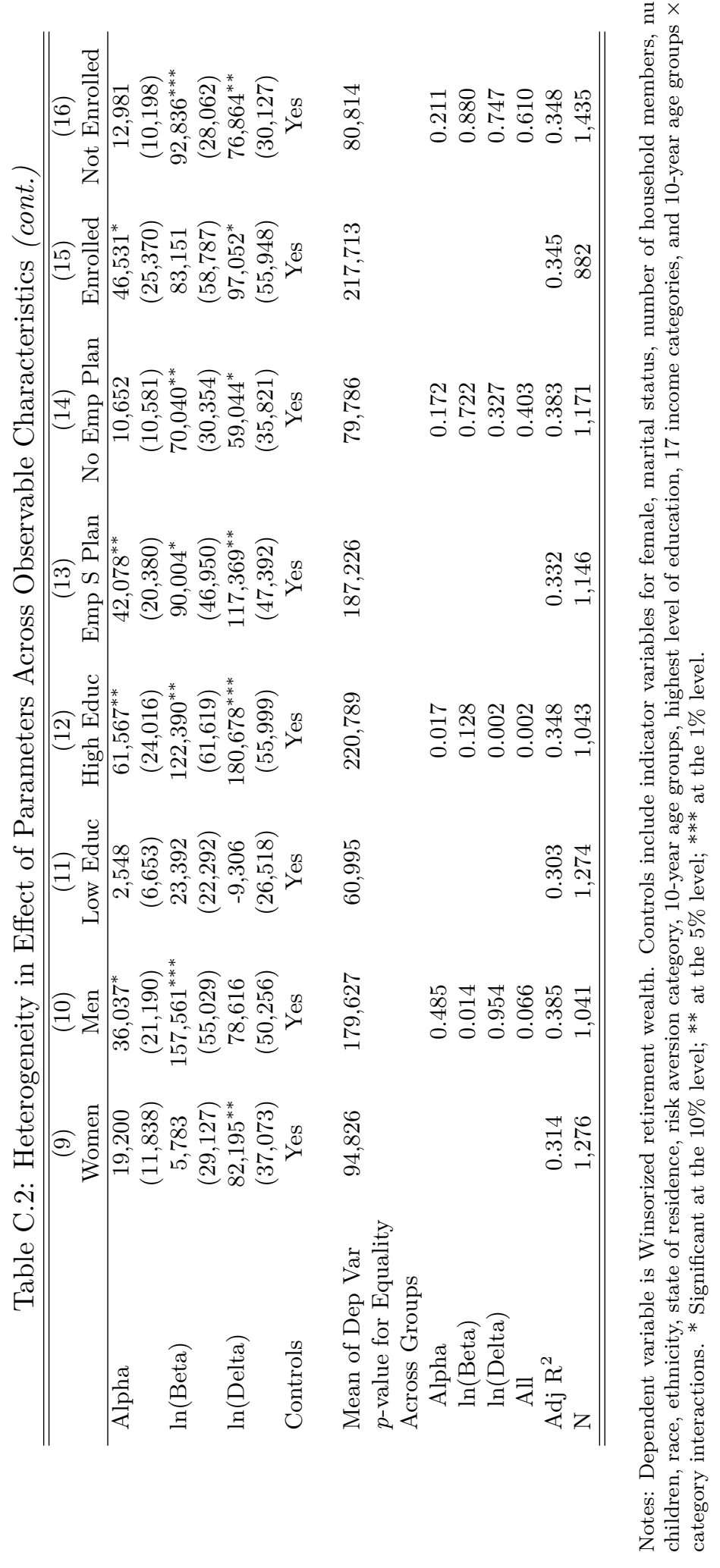




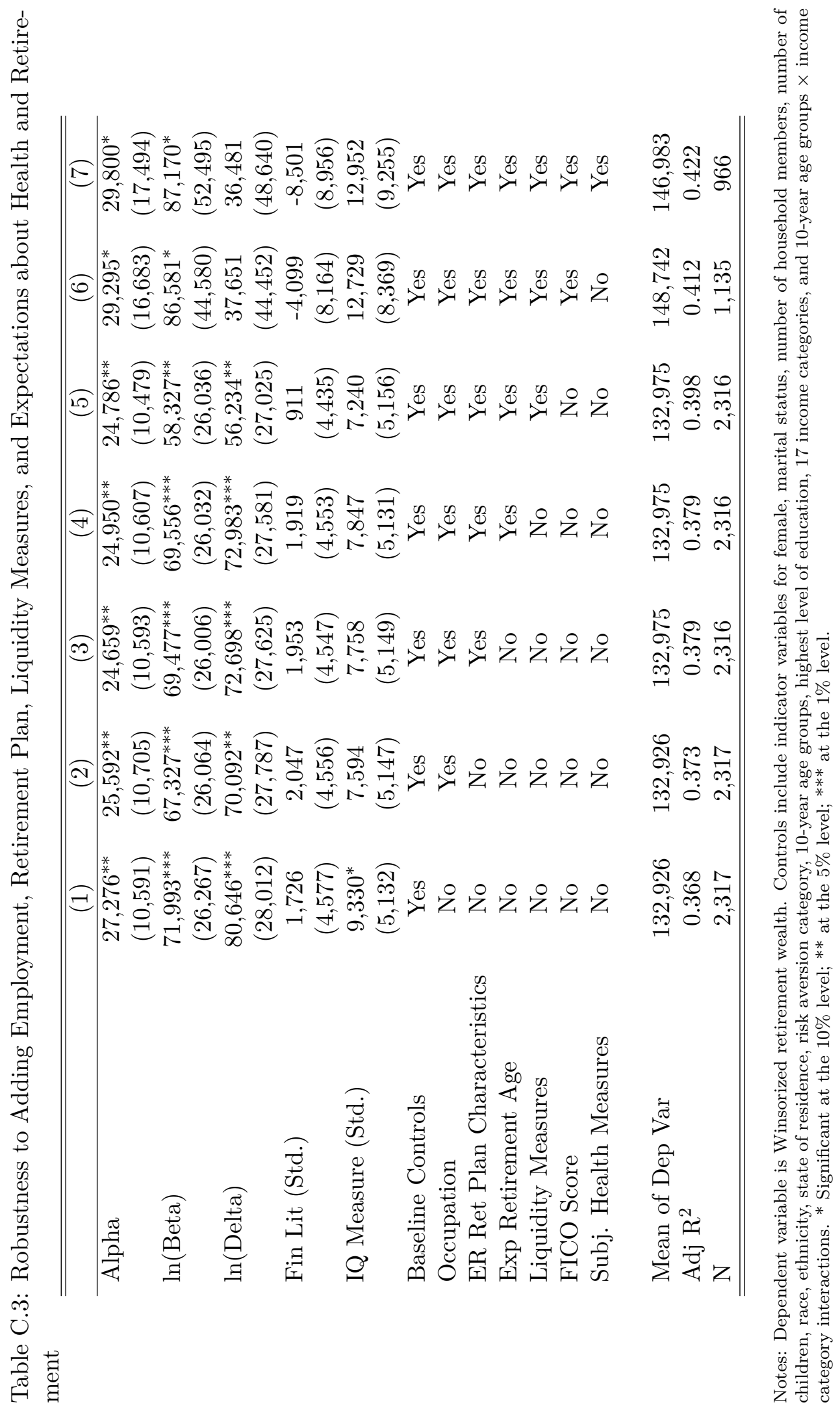


Table C.4: Robustness to Alternative Definitions of Financial Literacy and IQ

\begin{tabular}{|c|c|c|c|c|}
\hline & $(1)$ & $(2)$ & $(3)$ & (4) \\
\hline Alpha & $\begin{array}{c}27,325^{* * *} \\
(10,561)\end{array}$ & $\begin{array}{c}27,483^{* * *} \\
(10,575)\end{array}$ & $\begin{array}{c}35,447 \\
(22,763)\end{array}$ & $\begin{array}{l}34,338^{* *} \\
(15,033)\end{array}$ \\
\hline $\ln ($ Beta $)$ & $\begin{array}{c}69,908^{* * *} \\
(26,089)\end{array}$ & $\begin{array}{c}68,084^{* * *} \\
(25,909)\end{array}$ & $\begin{array}{c}142,105^{* *} \\
(61,775)\end{array}$ & $\begin{array}{c}101,542^{* * *} \\
(34,462)\end{array}$ \\
\hline $\ln ($ Delta $)$ & $\begin{array}{c}80,923^{* * *} \\
(27,981)\end{array}$ & $\begin{array}{c}79,988^{* * *} \\
(27,993)\end{array}$ & $\begin{array}{c}61,776 \\
(63,407)\end{array}$ & $\begin{array}{l}99,348^{* *} \\
(41,246)\end{array}$ \\
\hline Fin Lit (Std.) & $\begin{array}{c}1,822 \\
(4,509)\end{array}$ & & & $\begin{array}{c}-3,781 \\
(7,020)\end{array}$ \\
\hline IQ Measure (Std.) & $\begin{array}{l}8,995^{*} \\
(5,086)\end{array}$ & $\begin{array}{l}8,851^{*} \\
(5,183)\end{array}$ & $\begin{array}{c}14,582 \\
(12,097)\end{array}$ & \\
\hline First 3Q Fin Lit (Std.) & & $\begin{array}{c}2,786 \\
(4,665)\end{array}$ & & \\
\hline First 5Q Fin Lit (Std.) & & & $\begin{array}{c}13,553 \\
(10,446)\end{array}$ & \\
\hline IQ - Number & & & & $\begin{array}{c}442 \\
(367)\end{array}$ \\
\hline IQ - Picture & & & & $\begin{array}{c}346 \\
(353)\end{array}$ \\
\hline IQ - Analogy & & & & $\begin{array}{l}-316 \\
(328)\end{array}$ \\
\hline Controls & Yes & Yes & Yes & Yes \\
\hline Mean of Dep Var & 132,926 & 132,926 & 134,360 & 136,259 \\
\hline $\operatorname{Adj} R^{2}$ & 0.367 & 0.367 & 0.368 & 0.380 \\
\hline $\mathrm{N}$ & 2,317 & 2,317 & 706 & 1,287 \\
\hline
\end{tabular}

Notes: Dependent variable is Winsorized retirement wealth. Controls include indicator variables for female, marital status, number of household members, number of children, race, ethnicity, state of residence, risk aversion category, 10-year age groups, highest level of education, 17 income categories, and 10-year age groups $\times$ income category interactions. * Significant at the $10 \%$ level; ** at the $5 \%$ level; $* * *$ at the $1 \%$ level. 


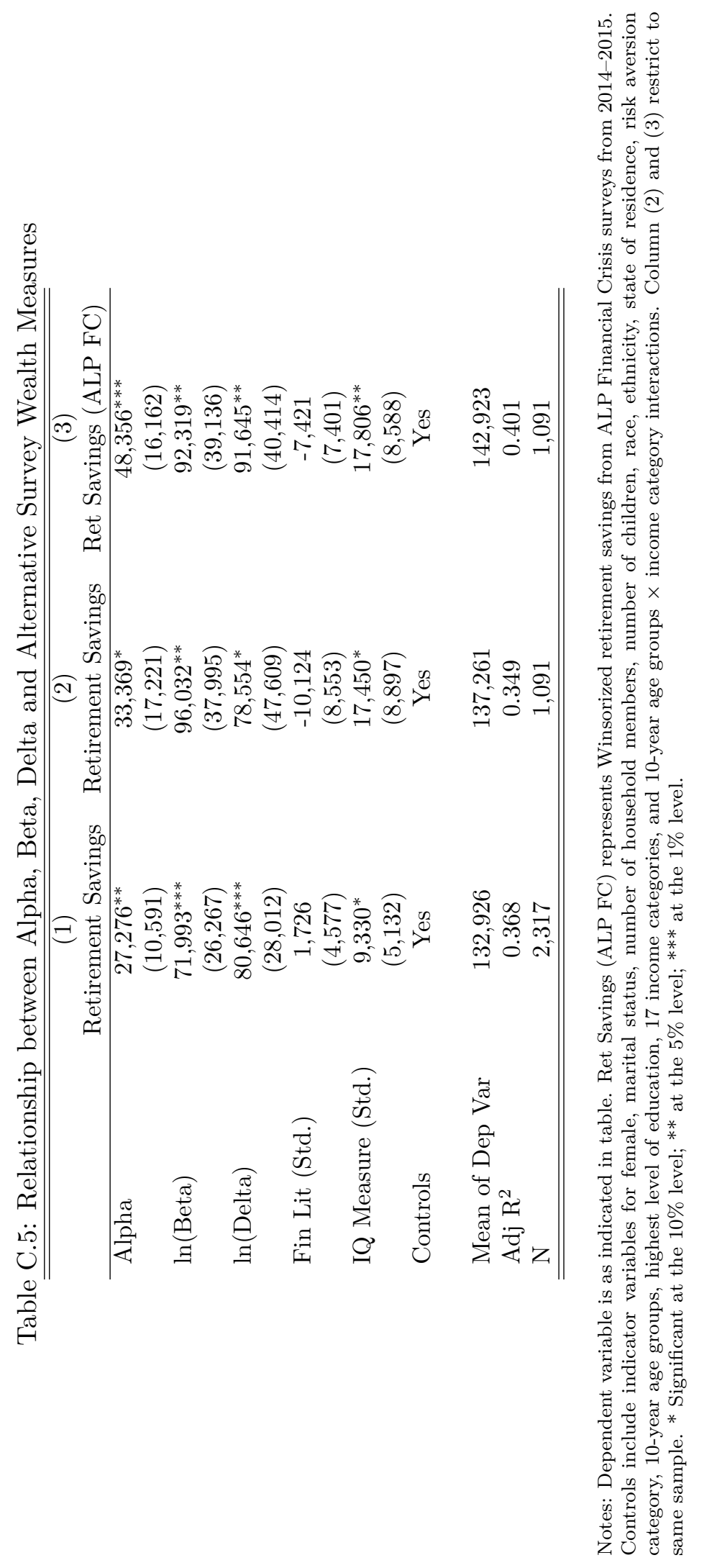


Table C.6: First Stage Results

\begin{tabular}{|c|c|c|c|c|}
\hline & $\begin{array}{c}(1) \\
\text { Alpha }\end{array}$ & $\begin{array}{c}(2) \\
\ln (\text { Beta } \times \text { Delta })\end{array}$ & $\begin{array}{c}(3) \\
\text { Alpha }\end{array}$ & $\begin{array}{c}(4) \\
\ln (\text { Beta } \times \text { Delta })\end{array}$ \\
\hline High Stakes (Alpha) & $\begin{array}{l}-.0853 \\
(.054)\end{array}$ & & $\begin{array}{l}-.0928^{*} \\
(.0537)\end{array}$ & $\begin{array}{l}.00859 \\
(.0249)\end{array}$ \\
\hline Pencil-and-Paper & $\begin{array}{l}-.0121 \\
(.0245)\end{array}$ & & $\begin{array}{l}-.015 \\
(.0245)\end{array}$ & $\begin{array}{l}-.0124 \\
(.0106)\end{array}$ \\
\hline Calculator & $\begin{array}{l}.0311 \\
(.0256)\end{array}$ & & $\begin{array}{l}.0326 \\
(.0257)\end{array}$ & $\begin{array}{r}-.00667 \\
(.0108)\end{array}$ \\
\hline Spreadsheet & $\begin{array}{l}.349^{* * *} \\
(.0434)\end{array}$ & & $\begin{array}{l}.35^{* * *} \\
(.0436)\end{array}$ & $\begin{array}{l}.00818 \\
(.019)\end{array}$ \\
\hline Other Tool & $\begin{array}{c}.0669 \\
(.0549)\end{array}$ & & $\begin{array}{c}.0712 \\
(.0553)\end{array}$ & $\begin{array}{c}.0352 \\
(.0222)\end{array}$ \\
\hline Received Help & $\begin{array}{c}.06 \\
(.0415)\end{array}$ & & $\begin{array}{l}.0555 \\
(.042)\end{array}$ & $\begin{array}{l}-.00724 \\
(.0199)\end{array}$ \\
\hline Follow Plans & & & & \\
\hline Strongly disagree & & $\begin{array}{l}.0456 \\
(.0311)\end{array}$ & $\begin{array}{l}.0443 \\
(.0772)\end{array}$ & $\begin{array}{l}.0487 \\
(.031)\end{array}$ \\
\hline Disagree & & $\begin{array}{l}-.0125 \\
(.0162)\end{array}$ & $\begin{array}{l}-.0414 \\
(.0373)\end{array}$ & $\begin{array}{l}-.0122 \\
(.0163)\end{array}$ \\
\hline Agree & & $\begin{array}{c}-.0385^{* * *} \\
(.0108)\end{array}$ & $\begin{array}{c}.0271 \\
(.0256)\end{array}$ & $\begin{array}{c}-.0369^{* * *} \\
(.0108)\end{array}$ \\
\hline Strongly Agree & & $\begin{array}{l}-.0273 \\
(.0175)\end{array}$ & $\begin{array}{c}-.03 \\
(.0383)\end{array}$ & $\begin{array}{c}-.0268 \\
(.0175)\end{array}$ \\
\hline Postpone Things & & & & \\
\hline Strongly disagree & & $\begin{array}{l}.00496 \\
(.016)\end{array}$ & $\begin{array}{r}-.00307 \\
(.0353)\end{array}$ & $\begin{array}{l}.00464 \\
(.016)\end{array}$ \\
\hline Disagree & & $\begin{array}{c}.0117 \\
(.0126)\end{array}$ & $\begin{array}{c}.02 \\
(.0295)\end{array}$ & $\begin{array}{l}.0122 \\
(.0127)\end{array}$ \\
\hline Agree & & $\begin{array}{c}-.0308^{* *} \\
(.0138)\end{array}$ & $\begin{array}{l}.0343 \\
(.0332)\end{array}$ & $\begin{array}{c}-.0296^{* *} \\
(.0139)\end{array}$ \\
\hline Strongly Agree & & $\begin{array}{c}-.0535^{* *} \\
(.0254)\end{array}$ & $\begin{array}{l}.0235 \\
(.0581)\end{array}$ & $\begin{array}{c}-.0526^{* *} \\
(.0252)\end{array}$ \\
\hline Patient & & & & \\
\hline Strongly disagree & & $\begin{array}{l}.0114 \\
(.029)\end{array}$ & $\begin{array}{l}.0947 \\
(.0737)\end{array}$ & $\begin{array}{l}.0113 \\
(.0295)\end{array}$ \\
\hline Disagree & & $\begin{array}{l}-.0173 \\
(.0216)\end{array}$ & $\begin{array}{l}.033 \\
(.0533)\end{array}$ & $\begin{array}{l}-.0178 \\
(.0216)\end{array}$ \\
\hline Agree & & $\begin{array}{l}.0593^{* * *} \\
(.0123)\end{array}$ & $\begin{array}{r}-.00146 \\
(.0287)\end{array}$ & $\begin{array}{l}.0592^{* * *} \\
(.0123)\end{array}$ \\
\hline Strongly Agree & & $\begin{array}{l}.145^{* * *} \\
(.0149)\end{array}$ & $\begin{array}{l}.0159 \\
(.0354)\end{array}$ & $\begin{array}{l}.144^{* * *} \\
(.0149)\end{array}$ \\
\hline Controls & Yes & Yes & Yes & Yes \\
\hline Mean of Dep Var & .571 & -.366 & .571 & -.366 \\
\hline Adj $R^{2}$ & 0.077 & 0.376 & 0.075 & 0.374 \\
\hline $\mathrm{N}$ & 2,317 & 2,317 & 2,317 & 2,317 \\
\hline
\end{tabular}

Notes: Dependent variable is as indicated in table. Column (1) regresses Alpha on Alpha instruments and controls. Column (2) regresses $\ln ($ Beta $\times$ Delta $)$ on Beta $\times$ Delta instruments and controls. Columns (3) and (4) regress Alpha and $\ln ($ Beta $\times$ Delta) on all instruments and controls. Controls include indicator variables for female, marital status, number of household members, number of children, race, ethnicity, state of residence, risk aversion category, 10-year age groups, highest level of education, 17 income categories, and 10-year age groups $\times$ income category interactions. ${ }^{*}$ Significant at the $10 \%$ level; ${ }^{* *}$ at the $5 \%$ level; $* * *$ at the $1 \%$ level. 


\section{Appendix D Results using nationally-representative weights}

Our main results are based on uniform weighting of observations. In this section, we reproduce many of the paper's main results after weighting observations to make the sample more representative of the U.S. adult population. Our sample is diverse but not nationally-representative due to two possible sources of selection. First, while both the ALP and UAS recruit participants through population-sampling methods designed to make each nationally representative, there may be some selection into panel participation that weights could correct. Second, among the participants in the panels whom we invite to take our surveys, not all do. Each of these could take the form of endogenous sampling - where the probability of selection into the sample varies with the dependent variable even after conditioning on observables - and each is a potential source of bias (Solon et al., 2015). The ALP and UAS each provided us with weights designed to adjust for these sources of selection and to make the response sample nationally-representative on demographics. ${ }^{45}$

For certain purposes, readers may be more interested in analyses with these weights applied than in the uniform-weighted results. For instance, to understand descriptively the marginal and joint distribution of Alpha, Beta, and Delta in the national population, then summary statistics based on weights could be more informative. Here, we present analogues of Tables 2-4 and Figure 1 here as Tables D.1-D.3 and Figure D.1.

\begin{tabular}{|c|c|c|c|c|}
\hline & mean & $\mathrm{sd}$ & $\min$ & $\max$ \\
\hline Alpha & 0.547 & 0.493 & 0.000 & 3.000 \\
\hline Beta & 1.022 & 0.214 & 0.468 & 2.135 \\
\hline Delta & 0.695 & 0.170 & 0.461 & 0.985 \\
\hline Imputed Beta & 0.160 & 0.366 & 0.000 & 1.000 \\
\hline Imputed Delta & 0.108 & 0.310 & 0.000 & 1.000 \\
\hline Fin Lit & 2.447 & 0.768 & 0.000 & 3.000 \\
\hline IQ Measure & 2.206 & 1.515 & 0.000 & 5.000 \\
\hline Missing Fin Lit & 0.001 & 0.026 & 0.000 & 1.000 \\
\hline Missing IQ Measure & 0.004 & 0.064 & 0.000 & 1.000 \\
\hline Sophisticated & 0.470 & 0.499 & 0.000 & 1.000 \\
\hline Overconfidence & 0.333 & 0.391 & -1.000 & 1.000 \\
\hline Observations & 2317 & & & \\
\hline
\end{tabular}

Notes: Fin Lit refers to number of questions correct (out of 3).

IQ Measure refers to number of questions correct (out of 5).

Applying weights changes the estimated summary statistics of Alpha, Beta, Delta, and other behavioral and survey constructs very little. The joint distribution of Alpha and Beta is also hardly affected.

Using weights, the levels of retirement savings, non-retirement savings, and net worth are estimated to be somewhat lower, as expected when giving younger people more weight. Retirement savings are estimated at mean $\$ 97,313$ and standard deviation $\$ 228,518$ using weights instead of the $\$ 132,926$ mean and $\$ 276,052$ standard deviation from Table 3. Debt statistics are barely affected.

\footnotetext{
${ }^{45}$ To pool information across two independent samples with different sets of weights from the same population, we follow Westat (2006).
} 
Figure D.1: Joint Distribution of Present Bias and EG Bias, weighted

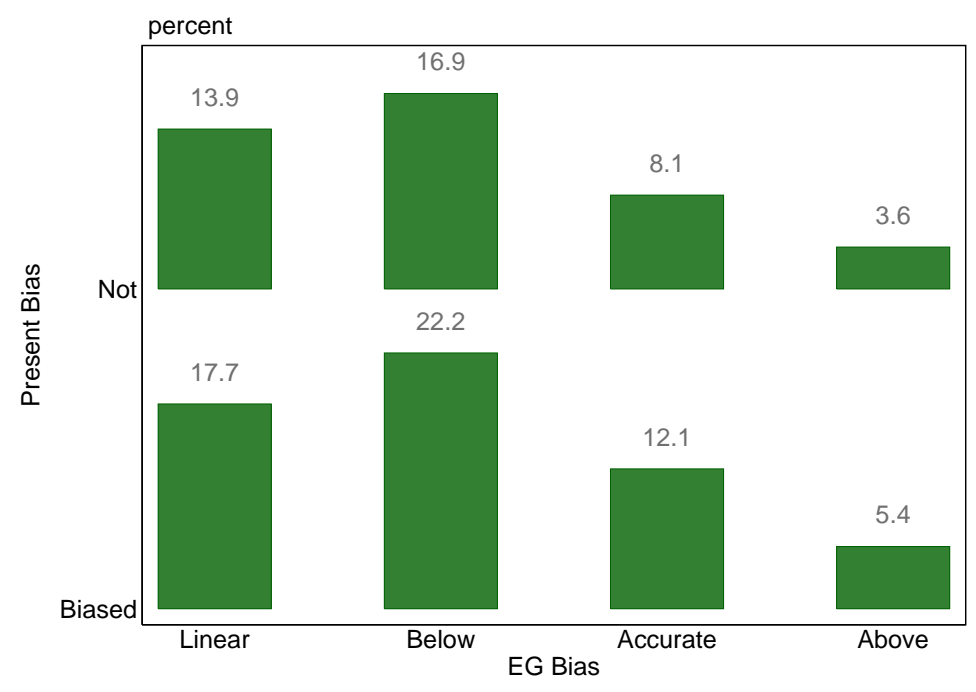

Table D.2: Retirement Savings, Non-Retirement Savings, Debt and Financial Outcomes

\begin{tabular}{lcccc}
\hline \hline & mean & sd & min & $\max$ \\
\hline Retirement Savings & 97,313 & 228,518 & 0 & 1700000 \\
Has Any Retirement Savings & .654 & .476 & 0 & 1 \\
Non-Retirement Savings & 40,371 & 134,517 & 0 & 1100000 \\
Outstanding Mortgage & 53,767 & 93,167 & 0 & 460,000 \\
Other Secured Debt & 16,383 & 36,071 & 500 & 250,000 \\
Unsecured Debt & 12,469 & 27,057 & 500 & 250,000 \\
Net Worth & 253,441 & 863,602 & $-245,500$ & 9639000 \\
Short-Term Loan (last 5 years) & .0797 & .271 & 0 & 1 \\
Declared Bankruptcy (last 5 years) & .0532 & .225 & 0 & 1 \\
\hline Observations & 2317 & & \\
\hline \hline
\end{tabular}

Notes: Retirement Savings, Non-Retirement Savings, Outstanding Mortgages Winsorized for top 1\%. Net Worth Winsorized for top 0.5\%. Other Secured Debt and Unsecured Debt represent midpoints from categorical responses. 
Using weights, the sample appears younger, lower income, and less educated. Marital status, race/ethnicity, and risk profiles barely change. By construction, sample demographics appear closer to those of the national population using weights.

Beyond calculating descriptive statistics, the study aims to measure causal relationships between retirement-savings levels and Alpha, Beta, and Delta. As summarized by Solon et al. (2015), when seeking to understand causal relationships, researchers may have three distinct motives for using weights: (1) increasing precision by correcting for heteroskedasticity, (2) achieving consistent estimates by correcting for endogenous sampling, and (3) identifying average partial effects in the presence of unmodeled heterogeneity of effects. (1) is not a large concern here. (2) and (3) might be. On the other hand, if selection into the sample is exogenous to the outcome, then weighting can reduce precision and OLS may be preferred. In the interests of transparency and to facilitate comparison, we present WLS analogues to our primary, OLS results here.

We report analogues to Tables 5-7 in Tables D.4-D.6. Using WLS rather than OLS, the relationships between our variables of interest and the control variables are quite similar. 
Table D.3: Demographic Controls

\begin{tabular}{|c|c|c|c|c|}
\hline & mean & $\mathrm{sd}$ & $\min$ & $\max$ \\
\hline Age & 46.829 & 16.803 & 18.000 & 96.000 \\
\hline Female & 0.516 & 0.500 & 0.000 & 1.000 \\
\hline Family Income & 60663.822 & 54861.945 & 0.000 & $2.00 \mathrm{e}+05$ \\
\hline \multicolumn{5}{|l|}{ Education } \\
\hline HS or Less & 0.420 & 0.494 & 0.000 & 1.000 \\
\hline Some College & 0.199 & 0.399 & 0.000 & 1.000 \\
\hline Assoc Degree & 0.089 & 0.284 & 0.000 & 1.000 \\
\hline BA/BS Degree & 0.177 & 0.382 & 0.000 & 1.000 \\
\hline Post BA/BS & 0.115 & 0.320 & 0.000 & 1.000 \\
\hline \multicolumn{5}{|l|}{ Marital Status } \\
\hline Married/Partnered & 0.624 & 0.484 & 0.000 & 1.000 \\
\hline Separated & 0.019 & 0.137 & 0.000 & 1.000 \\
\hline Divorced & 0.106 & 0.309 & 0.000 & 1.000 \\
\hline Widowed & 0.040 & 0.195 & 0.000 & 1.000 \\
\hline Never Married & 0.211 & 0.408 & 0.000 & 1.000 \\
\hline Missing & 0.000 & 0.000 & 0.000 & 0.000 \\
\hline Add'l HH Members & 1.284 & 1.155 & 0.000 & 3.000 \\
\hline Num of Children & 0.908 & 1.245 & 0.000 & 9.000 \\
\hline Hispanic/Latino & 0.173 & 0.378 & 0.000 & 1.000 \\
\hline \multicolumn{5}{|l|}{ Race } \\
\hline White/Caucasian & 0.775 & 0.418 & 0.000 & 1.000 \\
\hline Black/African American & 0.121 & 0.326 & 0.000 & 1.000 \\
\hline American Indian & 0.013 & 0.112 & 0.000 & 1.000 \\
\hline Asian & 0.027 & 0.163 & 0.000 & 1.000 \\
\hline Other & 0.065 & 0.246 & 0.000 & 1.000 \\
\hline Missing & 0.000 & 0.010 & 0.000 & 1.000 \\
\hline \multicolumn{5}{|l|}{ Risk Aversion } \\
\hline Category 1 & 0.319 & 0.466 & 0.000 & 1.000 \\
\hline Category 2 & 0.163 & 0.370 & 0.000 & 1.000 \\
\hline Category 3 & 0.181 & 0.385 & 0.000 & 1.000 \\
\hline Category 4 & 0.081 & 0.272 & 0.000 & 1.000 \\
\hline Category 5 & 0.045 & 0.206 & 0.000 & 1.000 \\
\hline Category 6 & 0.207 & 0.406 & 0.000 & 1.000 \\
\hline Missing & 0.003 & 0.059 & 0.000 & 1.000 \\
\hline Observations & 2317 & & & \\
\hline
\end{tabular}

Notes: Family Income shown Winsorized for top 5\%. Higher risk aversion categories represent decreasing risk aversion. 


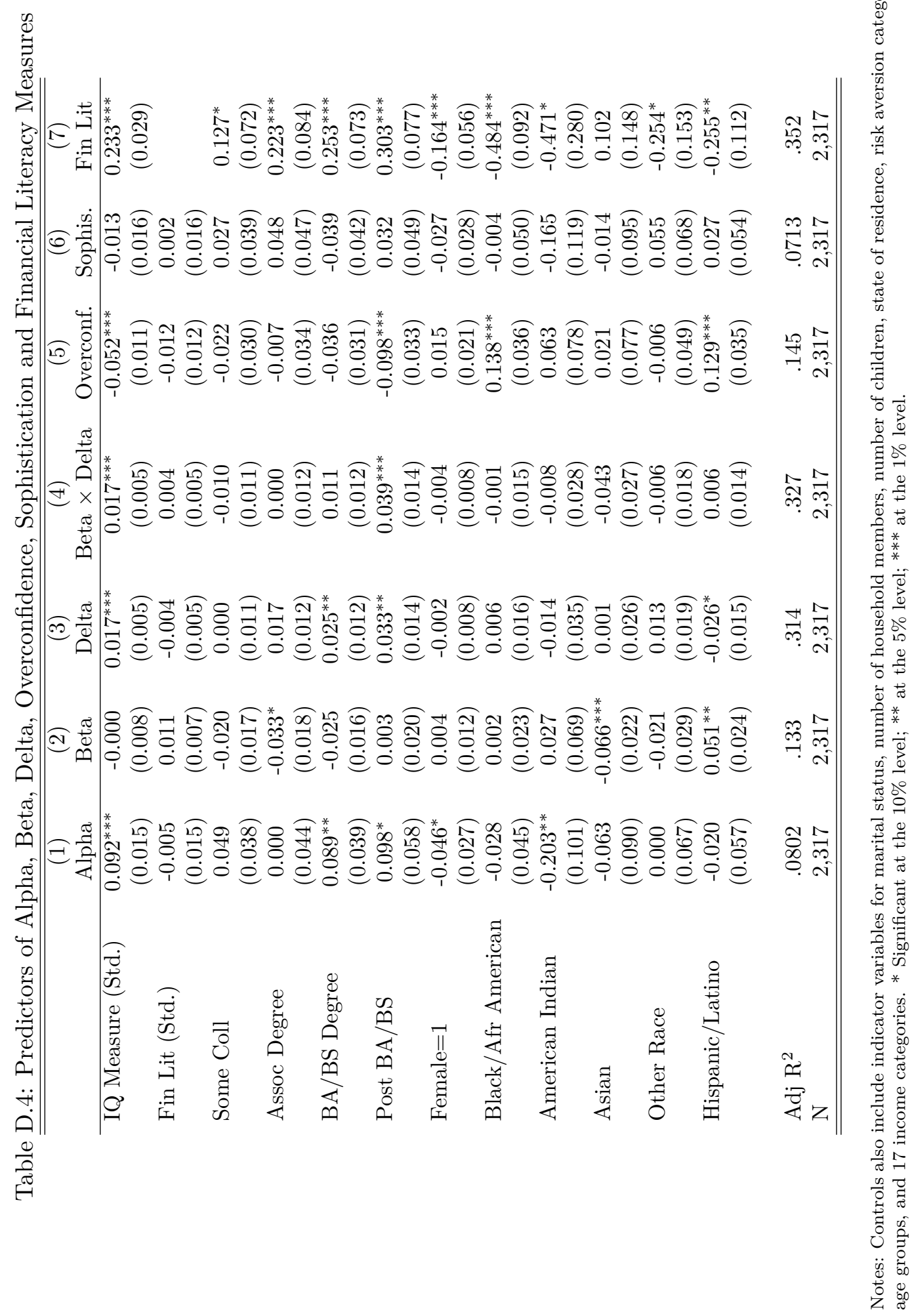


Table D.5: Relationship between Alpha, Beta, Delta and Retirement Wealth

\begin{tabular}{lcccc}
\hline \hline & $(1)$ & $(2)$ & $(3)$ & $(4)$ \\
\hline Alpha & $41,199^{* * *}$ & $19,772^{* *}$ & & $18,216^{* *}$ \\
& $(10,088)$ & $(8,648)$ & & $(8,717)$ \\
$\ln$ (Beta) & $107,228^{* * *}$ & $46,145^{*}$ & & $45,966^{*}$ \\
& $(31,385)$ & $(23,990)$ & & $(24,737)$ \\
$\ln$ (Delta) & $142,719^{* * *}$ & $51,433^{* *}$ & 38,905 & $49,408^{*}$ \\
& $(28,619)$ & $(25,936)$ & $(25,229)$ & $(26,113)$ \\
Fin Lit (Std.) & & & -303 & -822 \\
& & & $(6,185)$ & $(6,310)$ \\
IQ Measure (Std.) & & & 7,535 & 5,571 \\
& & & $(4,613)$ & $(4,690)$ \\
Demog Controls & Yes & Yes & Yes & Yes \\
Add'l Controls & No & Yes & Yes & Yes \\
& & & & \\
Mean of Dep Var & 97,313 & 97,313 & 97,313 & 97,313 \\
Adj R & & & & \\
N & 0.165 & 0.375 & 0.373 & 0.375 \\
\hline \hline
\end{tabular}

Notes: Dependent variable is Winsorized retirement wealth. Demographic controls include indicator variables for female, marital status, number of household members, number of children, race, ethnicity, state of residence, risk aversion category, and 10-year age groups. Additional controls include indicator variables for highest level of education, 17 income categories, and 10-year age groups $\times$ income category interactions. * Significant at the $10 \%$ level; ** at the $5 \%$ level; *** at the $1 \%$ level. 


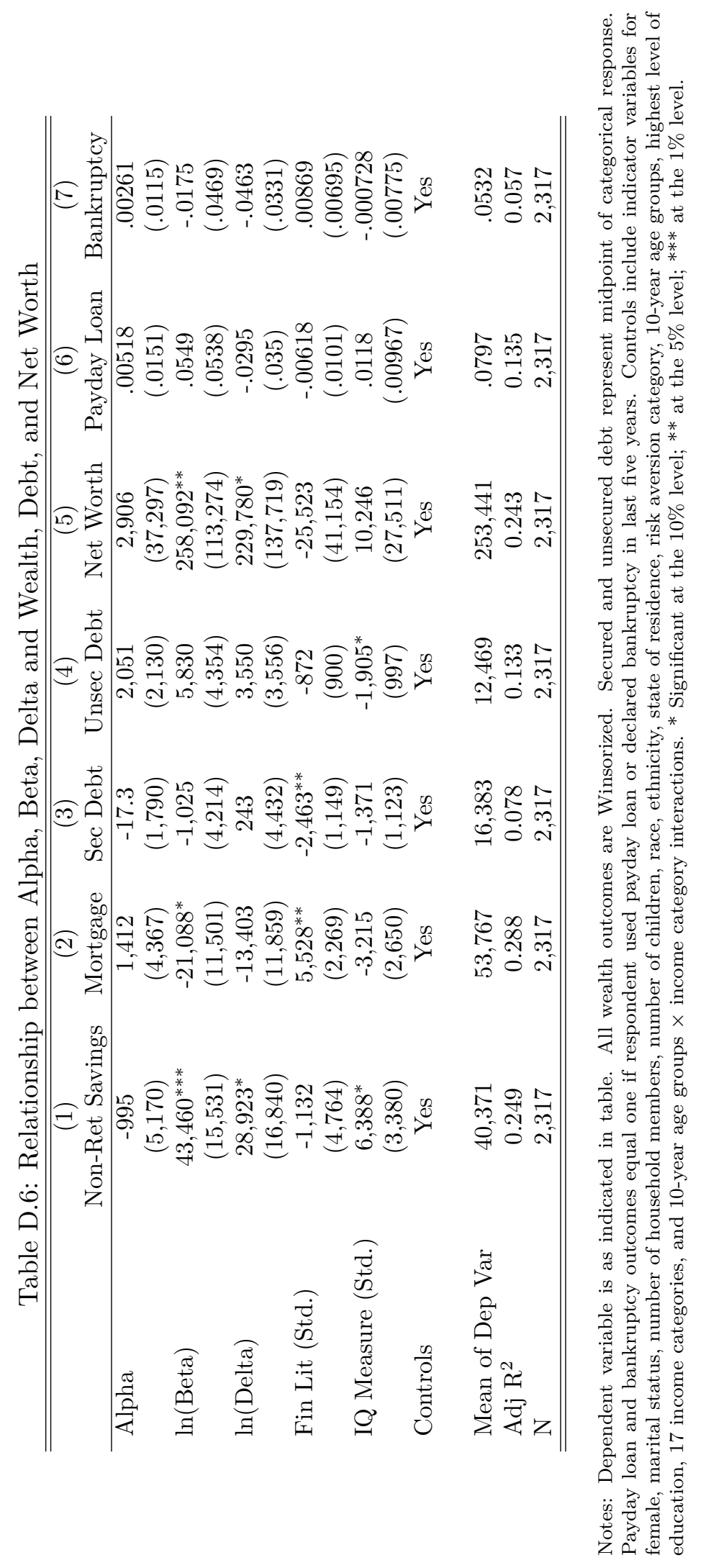




\section{Appendix E Conceptual Framework: Hypothetical Choice Task}

We modify the model presented in Section 2 to explicitly consider agents' retirement savings decision over both accumulation and decumulation. For simplicity, we assume there is no uncertainty regarding investment returns or longevity: the agent expects to retire in period $R$, to consume in retirement until period $T$, and to have exogenous income flows $\vec{y} \in \mathbb{R}^{R}$ which may be invested at rates $\vec{r} \in \mathbb{R}_{+}^{T}$. Natural extensions would include uncertainty or endogenous retirement and income.

The agent's problem is to maximize lifetime utility subject to the perceived budget constraint. To highlight the treatment effects, we break the budget constraint into two pieces: perceived balance at retirement, and perceived retirement consumption given this balance.

In the control treatment, the agent's problem is therefore to choose a perception-perfect equilibrium which maximizes:

$$
\begin{array}{r}
\max _{\vec{c}} u\left(c_{0}\right)+\beta \sum_{s=1}^{T} \delta^{s} u\left(c_{s}\right) \\
\text { s.t. } \quad A=\sum_{s=0}^{R-1} p(\vec{r}, s \mid R) \cdot\left(y_{t}-c_{t}\right) \\
\sum_{s=R}^{T} p(\vec{r}, s \mid T) c_{s} \leq p(\vec{r}, R \mid T) \cdot A
\end{array}
$$

Because of EGB, the agent is making two mistakes. In (9), the agent underestimates the impact of savings on the account balance at retirement, $A$. In (10), the agent underestimates the amount of consumption that can be financed by a given balance, since the retirement continues to earn a return during decumulation.

The balance treatment is designed to correct the mistake in (9) by giving subjects the correct expected balance at retirement for a given contribution rate. Subjects in this treatment therefore replace the mistaken constraint with the true constraint:

$$
A=\sum_{s=0}^{R-1} e(\vec{r}, s \mid R) \cdot\left(y_{t}-c_{t}\right)
$$

The income treatment is designed to correct both mistakes by calculating the feasible postretirement consumption corresponding to a given savings rate. That is, in addition to correcting (9) to $\left(9^{\prime}\right)$, it also corrects (10) to:

$$
\sum_{s=R}^{T} p(\vec{r}, s \mid T) c_{s} \leq p(\vec{r}, R \mid T) \cdot A
$$

Both treatments correct the perceived prices of consumption. If the agent's elasticity of intertemporal substitution is greater than one, so that for example, they would react to the hypothetical employer match by increasing their contributions (as most subjects did), then the decrease in the perceived price of future consumption in terms of current consumption will increase the agent's savings rate overall. The balance treatment should therefore increase savings, and the income treatment — which makes post-retirement consumption appear even less expensive — should increase savings even further. 